Florida International University

FIU Digital Commons

FIU Electronic Theses and Dissertations

University Graduate School

$11-1-2016$

\title{
Predictors of English Reading Comprehension and Performance in College-level Composition among Generation 1.5 Students
}

Ildiko Barsony

Florida International University, ibars001@fiu.edu

DOI: 10.25148 /etd.FIDC001240

Follow this and additional works at: https:// digitalcommons.fiu.edu/etd

Part of the Bilingual, Multilingual, and Multicultural Education Commons, and the Curriculum and Instruction Commons

\section{Recommended Citation}

Barsony, Ildiko, "Predictors of English Reading Comprehension and Performance in College-level Composition among Generation 1.5 Students" (2016). FIU Electronic Theses and Dissertations. 2984.

https://digitalcommons.fiu.edu/etd/2984 


\section{FLORIDA INTERNATIONAL UNIVERSITY}

Miami, Florida

\section{PREDICTORS OF ENGLISH READING COMPREHENSION AND PERFORMANCE IN COLLEGE-LEVEL COMPOSITION AMONG GENERATION 1.5 STUDENTS}

A dissertation submitted in partial fulfillment of the requirements for the degree of DOCTOR OF PHILOSOPHY

in CURRICULUM AND INSTRUCTION

by

Ildiko Barsony

2016 
To: Dean Michael R. Heithaus

College of Arts, Sciences, and Education

This dissertation, written by Ildiko Barsony, and entitled Predictors of English Reading Comprehension and Performance in College-Level Composition among Generation 1.5 Students, having been approved in respect to style and intellectual content, is referred to you for judgment.

We have read this dissertation and recommend that it be approved.

Teresa A. Lucas

Patsy A Self

Haiying Long

Eric S. Dwyer, Major Professor

Date of Defense: November 1, 2016

The dissertation of Ildiko Barsony is approved.

Dean Michael R. Heithaus

College of Arts, Sciences, and Education

Andrés G. Gil

Vice President for Research and Economic Development and Dean of the University Graduate School

Florida International University, 2016 
C Copyright 2016 by Ildiko Barsony

All rights reserved. 


\section{DEDICATION}

I dedicate this dissertation to my family. My husband, Abraham, selflessly put his own educational goals on hold to help me achieve mine. My two-year-old son, Edward Joseph, inspired me every day to make progress toward the completion of this program. Finally, my life is blessed because of the daily prayers of my dear mother, Ilona. Her two children are as different as they can be but have in common the values she instilled in them.

I wish to also dedicate this dissertation to all the teachers who made a difference in my life in Hungary and in the United States. 


\section{ACKNOWLEDGMENTS}

I wish to express my most sincere gratitude to my major professor, Dr. Eric Dwyer, who has guided me along my entire FIU journey from the first time I visited his office to inquire about the MS in TESOL program 14 years ago to the time we discussed the content of the final chapter in this dissertation. These conversations shaped my understanding of the world as much as they shaped this study.

I am also grateful for the support and advice from the members of my dissertation committee. Dr. Teresa Lucas helped me narrow the scope of the investigation. Dr. Patsy Self guided the instrument selection for college reading comprehension. Dr. Jean-Robert Cadely helped me think about the identities of generation 1.5 students living in South Florida. Dr. Haiying Long provided exceptional mentorship and support with data analysis.

Others in the College of Arts, Sciences and Education were also instrumental to the timely completion of this journey. Dr. Linda Bliss and Dr. Isadore Newman provided invaluable feedback on the early drafts of this study. I want to thank Caprila Almeida and Suzanne Barcenas, who, through phone calls and email messages, helped me stay on track and meet important deadlines.

This dissertation would not have been possible without the support from my Miami Dade College family. First, I wish to thank the campus administration, especially Dr. Jacqueline Peña, for the support and interest in this study. Estrella Iglesias, who became my supervisor in the final stages on this journey, was similarly supportive of my study. Dr. Alda Noronha-Nimmo mentored me throughout the doctoral program with the most thoughtful and authentic advice possible. Dr. Noronha-Nimmo and Ms. Karen 
Taghi Zoghi played an active role in helping me build up courage to start the doctoral program and stay focused while adding mother-to-a-newborn to my list of responsibilities.

This study could not have been possible without the professors and students who allowed me to use valuable class time for data collection. Many faculty members promptly invited me to collect data in their classes, and many others expressed their interest and support even though they were not teaching the target courses at the time. I am thankful for their generosity and genuine interest in improving outcomes for generation 1.5 students.

Finally, I wish to express my appreciation for the support and encouragement I received from FIU peers and MDC colleagues along the way. I want to thank Professor Kimberly Carter and Professor Selena Respass especially for dedicating so much of their personal time to our doctoral study support group. The hours we spent sitting in study rooms typing away on our computers and the conversations we shared made the final stages of this journey considerably more manageable. 


\section{ABSTRACT OF THE DISSERTATION \\ PREDICTORS OF ENGLISH READING COMPREHENSION AND PERFORMANCE \\ IN COLLEGE-LEVEL COMPOSITION AMONG GENERATION 1.5 STUDENTS}

by

Ildiko Barsony

Florida International University, 2016

Miami, Florida

Professor Eric S. Dwyer, Major Professor

Generation 1.5 students, foreign-born children of first-generation immigrants, complete some or most of their K-12 education in the United States. Their oral communicative competence may be advanced, but their academic language proficiency may still be underdeveloped when they enter college. In 2013, SB1720 made placement testing optional for most Florida public high school graduates, including generation 1.5 students, making them eligible to enroll directly in the college-level English Composition 1 (ENC 1101) course. In order to succeed in this course, generation 1.5 students may need additional support appropriate to their unique needs.

This study first described the literacy backgrounds of 107 generation 1.5 students at Miami Dade College. Then, guided by the interdependence hypothesis, the common underlying proficiency model of bilingual proficiency, and the compensatory model of second language reading, it examined the relationship between the predictor variables (native language literacy, English language knowledge, and pre-ENC 1101 coursework) and the criterion variables (English reading comprehension and ENC 1101 performance). 
Nearly a quarter (23.6\%) of the MDC students who completed the initial literacy survey belonged to the generation 1.5 group. English language knowledge was significantly and positively correlated to both reading comprehension $(p<.001)$ and ENC 1101 performance $(p<.05)$. The negative correlation between pre-ENC 1101 coursework and reading comprehension $(p<.001)$ was also statistically significant, but native language literacy was not significantly correlated to either English reading comprehension or ENC 1101 performance. The results of the regression analyses showed that English language knowledge accounted for nearly $50 \%$ of the variance $(p<.001)$ in generation 1.5 students' English reading comprehension; however, none of the independent variables contributed to a significant amount of variance in ENC 1101 performance in the regression model.

This study contributed to the literature that aims to provide a better understanding of the numbers, the literacy foundations, and the instructional needs of generation 1.5 college students. While the findings did not fully support the theories that framed the study, future studies should continue to focus on generation 1.5 students producing academic texts in higher education institutions. 


\section{TABLE OF CONTENTS}

CHAPTER

PAGE

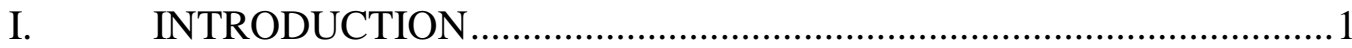

Generation 1.5 Students ..................................................................2

Potential Entry Points for Generation 1.5 Students................................ 3

Theoretical Foundations .......................................................................

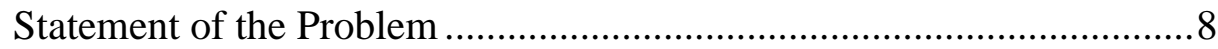

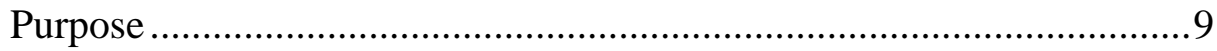

Delimitations of the Study .............................................................. 9

Assumptions of the Study ........................................................... 10

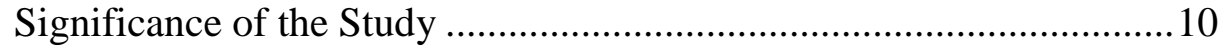

Research Questions .........................................................................11

Definitions and Operational Terms .................................................. 11

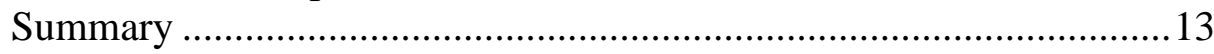

II. REVIEW OF THE LITERATURE ................................................. 14

Theoretical Foundations .................................................................... 14

Generation 1.5 Students .................................................................20

Native Language Literacy and Second Language Knowledge ............28

Remedial Coursework at the Tertiary Level .......................................33

Meeting Generation 1.5 Students' Instructional Needs ......................36

Instructional and Curricular Implications ........................................37

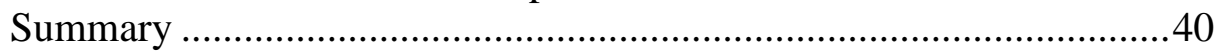

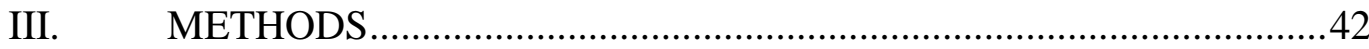

Research Hypotheses.................................................................42

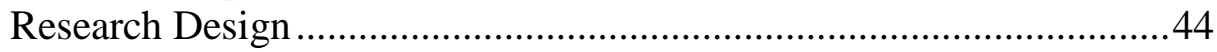

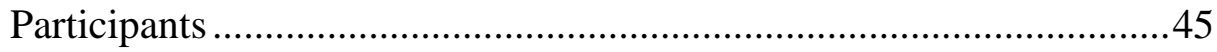

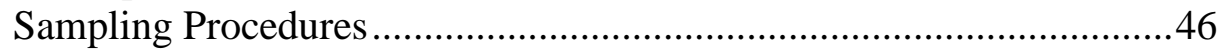

Sample Size, Power, and Precision ................................................46

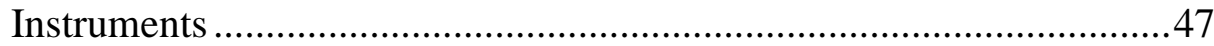

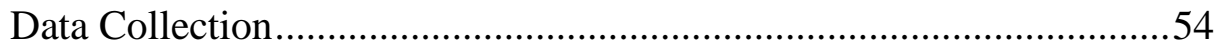

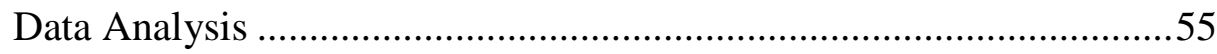

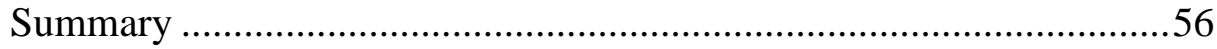

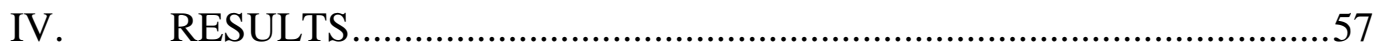

Research Question 1: Literacy Backgrounds of Generation 1.5

Students at Miami Dade College.....................................................57

Research Question 2: Predictors of Generation 1.5 Students'

English Reading Comprehension ..................................................64

Research Question 3: Predictors of Generation 1.5 Students'

College Composition Performance ............................................... 70

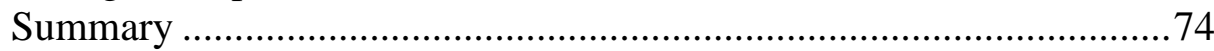




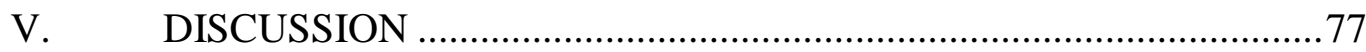

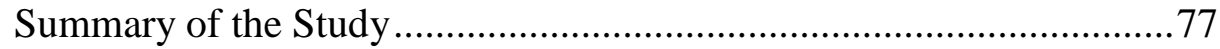

Discussion of the Findings .............................................................78

Implications for Research and Practice ..........................................86

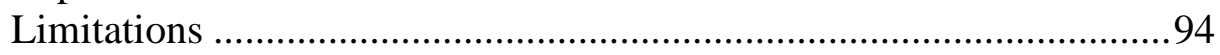

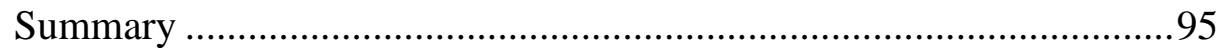

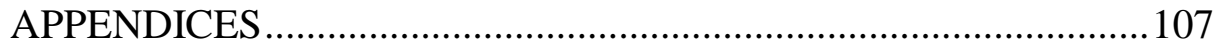

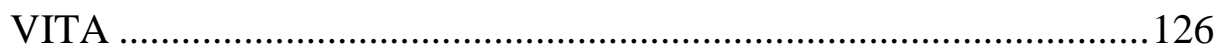




\section{LIST OF TABLES}

TABLE

PAGE

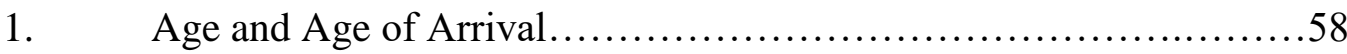

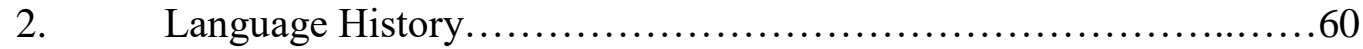

3. Language Use...........................................60

4. Language Attitudes.......................................61

5. K-12 ESOL Services by Age of Arrival...........................662

6. Self-Reported Language Proficiencies (Descending Means)............63

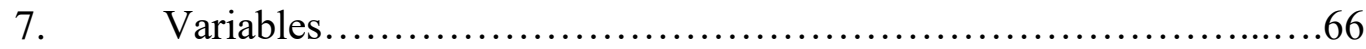

8. Correlations, Means, and Standard Deviations for Reading Comprehension Scores, English Composition 1 Grades, L1 Literacy, English Language Knowledge, and Pre-ENC 1101 Coursework.................................................67

9. Correlations, Means, and Standard Deviations for Reading Comprehension Scores, English Composition 1 Grades, Academic Understanding Proficiency, Grammar Score, Vocabulary Score, and Number of Developmental Education Course.......................68

10. Predictors of English Reading Comprehension......................70

11. Predictors of English Composition 1 Performance................... 74 


\section{ABBREVIATIONS AND ACRONYMS}

BICS: Basic Interpersonal Communication Skills

BLP: Bilingual Language Profile

BLP-M: Modified Bilingual Language Profile

CALP: Cognitive Academic Language Proficiency

CUP: Common Underlying Proficiency

EAP: English for Academic Purposes

ESL: English as a Second Language

ESOL: English for Speakers of Other Languages

FCS: Florida College System

L1: First language or native language

L2: Second language

LEAP-Q: Language Experience and Proficiency Questionnaire

MDC: Miami Dade College

P.E.R.T.: Postsecondary Education Readiness Test 


\section{CHAPTER I}

\section{INTRODUCTION}

Community colleges embody democracy in the United States (Padrón, 2014; Ronan, 2012). With their open door policies, academic support systems, remedial programs, and lower tuitions, they provide a feasible alternative to universities for students who are "more ethnically diverse, more economically distressed, more part-time and full-time employed, and more challenged in terms of transportation, housing, and language than any other population in American higher education" (Ronan, 2012, p. 33). The 28 institutions of the Florida College System (FCS) include colleges and state colleges (institutions that offer baccalaureate programs) and community colleges (institutions that do not offer baccalaureate degree programs). Although "community" is no longer part of their names, Florida colleges and state colleges remain strongly committed to the needs of the community. At the start of the 2015-2016 academic year, nearly half a million credit-seeking students were enrolled in FCS institutions, and more than $50 \%$ of these students belonged to various minority groups (Florida Department of Education, 2016).

Miami Dade College (MDC), located in Miami-Dade County, is the largest institution in the Florida College System and the fifth largest degree-granting college by enrollment in the United States (National Center for Education Statistics, 2014). In Fall 2015, MDC enrolled 13.69\% of all credit-seeking students in Florida and a much larger proportion (24.97\%) of Florida's Hispanic college students (Florida Department of Education, 2016). At Miami Dade College, more than $70 \%$ of credit-seeking students are Hispanic, and Spanish (spoken by $38 \%$ of credit-seeking students) is the most commonly 
spoken native language other than English. MDC students speak 77 different native languages (Miami Dade College, 2016a). Many of these students were born outside the United States but completed some of their pre-college education in the United States. The literature often refers to these students as generation 1.5 students.

\section{Generation 1.5 Students}

Although frequently used, the terms generation 1.5 and generation 1.5 students are rather ambiguous (Ortmeier-Hooper, 2008). The term 1.5 generation was first used in the late 1980s by Rumbaut and Ima (1988, cited in Rumbaut, 1994) to refer to individuals who were born in foreign countries and immigrated to the United States before age 12, but it has been used more liberally in the more recent literature (Blumenthal, 2002; de Kleine \& Lawton, 2015; Doolan, 2014; Goldschmidt \& Miller, 2005; Peña, 2010). Harklau, Losey, and Siegal (1999) explained that characteristics and experiences of this group resemble those of both first generation (foreign-born individuals who immigrated to the United States as adults) and second generation (U.S.-born children of firstgeneration immigrants). Generation 1.5 students graduate from U.S. high schools and enter college while still in the process of learning the English language (Harklau et al., 1999). In the present study, I use the term generation 1.5 students to describe foreignborn children of first-generation immigrants who complete some or most of their K-12 education in the United States.

In Florida, recent legislation exempts most recent public high school graduates from having to take a placement test and allows them to enroll directly in college-level composition and mathematics courses (Senate Bill 1720, 2013). If mainstreamed before their senior year in high school, generation 1.5 students who earned standard high school 
diplomas are also exempt from taking a college placement test and are entitled to begin their college careers in English Composition 1 (ENC 1101) courses. Other generation 1.5 students, however, may be required to take English for Academic Purposes or Developmental Education courses. Both of these programs are designed to prepare students for English Composition 1 (ENC 1101) courses.

\section{Potential Entry Points for Generation 1.5 Students}

The following section provides an overview of the potential college entry points for generation 1.5 students. These entry points include the college-level English Composition 1 course and two kinds of pre-ENC 1101 preparatory (remedial) programs: English for Academic Purposes and Developmental Education.

\section{English Composition 1}

English Composition 1 (ENC 1101) is a mandatory general education course for all degree-seeking students. Students enrolled in this gatekeeper course are required to compose essays and other pieces of formal writing (Miami Dade College, 2014a). English Composition 1 fulfills Florida's Gordon rule, a loosely defined college-level writing requirement to be completed in two English courses and two additional courses by all students seeking Associate in Arts degrees. Miami Dade College defined "collegelevel writing" as having (a) a clearly defined central idea or thesis, (b) adequate support for that idea, (c) clear, logical organization, (c) usage of the conventions of standard edited American English, and (d) format appropriate to the assignment. To meet the Gordon rule requirement, students enrolled in each course must produce at least three pieces of formal writing that meet these college standards and must earn a grade of $\mathrm{C}$ in the course (Miami Dade College, n.d.). In addition to essay writing, ENC 1101 course 
competencies call for responding to literature and conducting research, tasks that assume high levels of underlying reading fluency and comprehension.

\section{English for Academic Purposes}

Many Florida public high school graduates are exempt from the placement testing requirement. However, students who receive ESOL services during their senior year in high school are required to take the COMPASS-ESL placement test upon entering MDC. On the basis of the results, they may either proceed as regular college students (with a score of 98 out of 99 on the grammar, reading, and listening portions of the placement test as well as a score of 10 out of 12 on the writing portion; MDC 2016b) or be placed at one of six levels of English for Academic Purposes (EAP), remediation specifically designed for non-native speakers.

The traditional EAP program at MDC consists of four three-credit courses: reading, speech/listening, writing, and grammar at each of its six levels. In addition, EAP students are required to take two one-credit labs, a speech lab and a writing lab, along with the courses. Thus, if a student starts at level 1, that student needs 2 years to complete the program provided the student takes a full load of 14 credits each term, including the summer. To determine placement, students take the COMPASS-ESL test, and while in the EAP program, they are also required to take the Postsecondary Education Readiness Test (P.E.R.T.).

COMPASS-ESL. Miami Dade College, for the purposes of course placement, considers non-native speakers those students who graduate from a non-English-speaking high school, take ESOL during their 12th grade at an American high school, or earn a GED in Spanish. To be eligible for college-level studies, these students must demonstrate 
proficiency in the English language on the Test of English and a Foreign Language (TOEFL) or on COMPASS-ESL, a placement test measuring their English language skills. Students who are not proficient in English are placed in the EAP program. The COMPASS-ESL measures language competence in English listening, reading, and grammar (MDC, 2016b).

Postsecondary Education Readiness Test. Once in the EAP program, students must take the Postsecondary Education Readiness Test (P.E.R.T.) at level 4 or above if they intend to continue their studies at MDC. In the next semester, these students either take ENC 1101 or advanced (5 and 6) levels of EAP. Thus, passing the P.E.R.T. early enables students to bypass 28 mandatory credits in at least 2 semesters. If EAP students are placed at level 5 or 6, they must take the P.E.R.T. prior to registering for EAP courses. If their scores do not satisfy the college-ready requirement, they must complete the EAP program. However, they are able to enroll directly in ENC 1101 upon successful completion of level 6. Before 2013, EAP students were required to complete the EAP sequence, take the regular college placement test, and enroll in remedial courses if they did not succeed. Historically, many EAP students struggled with academic reading in English, and close to $50 \%$ of those who took the reading portion of the placement test scored below the college-ready benchmark (Rodriguez, 2010, 2011).

\section{Developmental Education}

The Postsecondary Education Readiness Test (P.E.R.T.) or other college readiness measures (ACT or SAT) are required for all non-exempt students seeking admission to Miami Dade College. If these students' scores are below the benchmark scores (P.E.R.T.: 106 in reading and 103 in writing; ACT: 19 in reading and 17 in 
writing; SAT: 440 on Critical Reading Subtest; MDC 2016b), they are required to enroll in Developmental Education courses.

The Developmental Education program is designed to provide remediation in reading, writing, and mathematics to students whose college placement test scores in these subjects are below college-ready level. The reading and writing programs consist of two levels and include lab in the four credit hours students pay for each class. In reading, the competencies of the upper-level Developmental Education Reading II (REA 0017) course expand on the competencies of Developmental Education Reading I (REA 0007). Text difficulty in the lower-level reading course is equivalent to texts in Grades 6-8, while in the upper level reading course text difficulty is equivalent to texts in Grades 9-12. Both levels of writing courses address grammar, but students in the lowerlevel writing course (Developmental Education Writing I, ENC 0015) produce paragraphs while those in the upper-level course (Developmental Education Writing II, ENC 0025) compose essays (Miami Dade College, 2014a).

\section{Placement Dilemmas}

The literature (Blumenthal, 2002; Harklau et al., 1999; Holten, 2009; Roberge, 2009) suggests that generation 1.5 students are overlooked in all of these programs. Those who are determined to be college-ready may still need academic language support to succeed in college-level composition courses. Developmental courses are designed for

academically underprepared native English speakers, while EAP courses are designed for non-native speakers who are assumed to have significant life experience and background knowledge but may lack knowledge of U.S. culture. 


\section{Theoretical Foundations}

This section provides a brief overview of the study's theoretical underpinnings, the interdependence hypothesis, common underlying proficiency, and the compensatory model of second language reading.

\section{The Interdependence Hypothesis and Common Underlying Proficiency}

College students who are non-native speakers of English possess a wide range of prior literacy experiences. In the EAP program, for instance, some students struggle to make passing grades as they progress from the lower levels through level 6 . These students are likely to have limited prior literacy experiences not only in English but also in their native languages. Generation 1.5 students may be especially at risk of not having sufficient native language (L1) foundations because academic exposure to the L1 likely ceased upon arrival in the United States. The interdependence hypothesis (Cummins, 1979), sometimes referred to as linguistic interdependence hypothesis or developmental interdependence hypothesis, underscores the important role L1 literacy plays in bilingual learners' second language (L2) development and explains that if a student possesses strong literacy foundations in L1, those literacy skills transfer to that student's L2 performance. Language transfer occurs because, despite the differences in superficial language features that differentiate the learner's L1 from L2, underneath those features there is a common underlying proficiency (CUP), defined as "the cognitive/academic knowledge and abilities that underlie academic performance in both languages" (Cummins, 2005, p. 4.). In addition to conceptualizing the relationship between L1 and L2 in general terms, the interdependence hypothesis explains the significant correlations research had found between L1 and L2 reading abilities. 


\section{Compensatory Model of Second Language Reading}

The compensatory model of second language reading (Bernhardt, 2011)

demonstrates the important role L1 literacy plays in L2 reading comprehension and explains why college-level reading represents a challenge for students whose

L1 foundations might be limited. The model captures numerous variables that have been found to influence L2 reading comprehension. Two variables, L2 language knowledge and L1 literacy (which have most predictive power), may cover as much as $50 \%$ of the variance in L2 reading scores, according to the model. Knowledge of L2 consists of the reader's knowledge about the vocabulary and syntax of L2 as well as the distance between the two languages. Bernhardt's model posits that this variable can account for up to $30 \%$ of the variance. Literacy in L1, accounting for up to $20 \%$ of the variance in L2 comprehension scores, “includes how a reader's first language realizes L1 phonemics, how texts are structured, purposes for reading, beliefs about reading, knowledge of how words and sentences are structured, and so forth" (Bernhardt, 2011, p. 35). While the model describes the $50 \%$ of the variance not explained by L1 literacy and L2 knowledge as unexplained variance, it is still comprehensive and provides a suitable framework to address the research questions posed in this study.

\section{Statement of the Problem}

Achieving academic literacy skills in the second language is a difficult endeavor, especially if one lacks appropriate L1 literacy foundations. Generation 1.5 students might especially be affected as their L1 literacy instruction experienced a hiatus, if it did not completely cease, upon the students' arrival in the United States. The literature suggests that existing college remedial programs do not meet the needs of generation 1.5 students. 
Presently, however, few institutions collect data about their generation 1.5 population; therefore, little is known about the literacy foundations or performance in remedial courses and beyond among members of this group. At the same time, the need to identify and assist generation 1.5 students at Miami Dade College has never been more urgent as many might be placing themselves in academic risks due to recent developments in course placement procedures or EAP - ENC 1101 course progression.

\section{Purpose}

The purpose of this study was to address gaps in our understanding of generation 1.5 students' academic performance by first describing generation 1.5 college students' prior literacy experiences and then by investigating native language literacy, English language knowledge, and pre-ENC 1101 (Developmental Education or EAP) coursework as predictors of English reading comprehension and performance in college-level composition courses.

\section{Delimitations of the Study}

The present study was delimited to generation 1.5 students who were enrolled in English Composition 1 or the last levels of Developmental Education courses at one of MDC's six campuses. English Composition 1 was targeted because this is the first college-level English course all degree-seeking students are required to take and a prerequisite to a number of courses in students' academic plans.

The study was further delimited to only the two major cognitive variables from Bernhardt's compensatory model of second language reading (L1 literacy and L2 language knowledge) and an institutional variable, pre-ENC 1101 coursework, defined as coursework completed in the English for Academic Purposes or Developmental 
Education program, to determine their contribution to the variance in English reading comprehension scores and ENC 1101 course grades.

\section{Assumptions of the Study}

The following assumptions guided this study. First, the self-reported data from the participants were assumed to be error-free, and participants were assumed to understand the difference between the examples of the literacy tasks provided to them on the literacy survey and to be able to critically judge their abilities accordingly.

\section{Significance of the Study}

In spite of all the research evidence, Genesee, Lindholm-Leary, Saunders, and Christian (2006) concluded that the evidence has not been able to consistently relate L1 literacy to measures of L2 literacy. The present study tested the interdependence hypothesis and the compensatory model of second-language reading among generation 1.5 college students in order to contribute to this body of research. It also contributes to the under-researched area of linguistically diverse students at the college level (de Kleine \& Lawton, 2015).

In doing so, the findings of the present study may help to improve these students' academic prospects. As Miami Dade College is working to decrease time in developmental education and EAP programs and increase key course enrollment and success (MDC, 2014c), the institution may consider the findings of this study in the initial screening and advising generation 1.5 students. The findings of this study also offer some insights into these students' literacy backgrounds and identifications with native and adopted cultures and languages, which may serve as a springboard for the development of additional academic programming for these students. Generation 1.5 
students who tested out of ESOL before their senior year in high school are affected by the newly introduced Florida placement policy that deems college-ready all Florida public high school students with a standard high school diploma. The findings of the present study may also inform research concerning the effectiveness of this policy.

\section{Research Questions}

This study was guided by the following research questions:

1. What literacy backgrounds do generation 1.5 students at Miami Dade College have?

2. What relationship exists between generation 1.5 students' native language literacy, English language knowledge, pre-ENC 1101 (Developmental Education or EAP) coursework and English reading comprehension?

3. What relationship exists between generation 1.5 students' native language literacy, English language knowledge, pre-ENC 1101 (Developmental Education or EAP) coursework and their performance in English Composition 1 (ENC 1101)?

\section{Definitions and Operational Terms}

\section{Reading Comprehension}

For the purpose of this study, reading comprehension is defined as understanding written text. English reading comprehension was measured by the Gates-MacGinitie reading test. Level AR of this test was designed for use by tertiary institutions that need to assess the general reading achievement of their students, and it was normed at community colleges across the United States. Participants were enrolled in credit English courses or were in the last remedial English class. Test form T, used in this study, has 
Kuder-Richardson Formula 20 reliability coefficient .93 (Maria \& Hughes, 2008). The instrument is often administered to non-native speakers of English (Kamhi-Stein, 1998; Roessingh, Kover, \& Watt, 2005).

\section{Performance in English Composition 1}

Performance in English Composition 1 was measured by end-of-term grades earned in the English Composition 1 (ENC 1101) course.

\section{First Language (L1) Literacy}

First language (L1) or native language literacy refers to students' ability to read, write, and understand their native language. The data were self- reported on the Bilingual Language Profile (BLP; Birdsong, Gertken, \& Amengual, 2012), modified by the researcher for the purposes of this study.

\section{English Language Knowledge}

According to Bernhardt's (2011) reading model, L2 knowledge, accounting for $30 \%$ of the variance in reading comprehension scores, consists of "grammatical form, vocabulary knowledge, the impact of cognates, the distance between first language and second language, the value system attached to literacy, and so forth" (p. 35). Knowledge of two major components of this definition, grammatical form and vocabulary, was measured. Knowledge of grammatical form, also referred to as English proficiency, was measured by a retired copy of the Structure and Written Expression components of the paper-based TOEFL, modified by the researcher for the purposes of the study.

Knowledge of English vocabulary was measured by the vocabulary section of the GatesMacGinitie reading test, level AR. 


\section{Pre-ENC 1101 Coursework}

The term pre-ENC 1101 coursework is used to refer to Developmental Education reading and writing courses as well as English for Academic Purposes courses in this study.

\section{Summary}

The purpose of this study was to address gaps in our understanding of the literacy backgrounds of generation 1.5 students at Miami Dade College. In addition to establishing a baseline about this particular population of students, this study focused on two variables, L1 literacy and L2 proficiency, that could account for up to $50 \%$ of the variance in reading comprehension according to Bernhardt's (2011) compensatory model of second-language reading and asked whether these variables, in addition to preENC1101 coursework, could predict generation 1.5 students' L2 reading comprehension scores and their performance in college-level composition courses. 


\section{CHAPTER II}

\section{REVIEW OF THE LITERATURE}

This chapter begins with a review of the theoretical framework: the interdependence hypothesis (Cummins, 1979), the common underlying proficiency model of bilingual proficiency (Cummins, 2005), and the compensatory model of second language reading (Bernhard, 2011). The review of the theoretical foundations is followed by a description of generation 1.5 student characteristics. After a review of previous research focusing on native language literacy, English language knowledge, and college remediation, I close the chapter with preliminary instructional and curricular implications based on the literature.

\section{Theoretical Foundations}

The theoretical framework of this study consists of the interdependence hypothesis (Cummins, 1979), the common underlying proficiency model of bilingual proficiency (Cummins, 2005), and the compensatory model of second language reading (Bernhard, 2011).

\section{The Interdependence Hypothesis and Common Underlying Proficiency}

The theoretical basis of the discussion of the role of L1 literacy in L2 learning is the interdependence hypothesis (Cummins, 1979) and the common underlying proficiency (CUP) model of bilingual proficiency, a logical extension of the interdependence hypothesis (Cummins, 2005).

The interdependence hypothesis. The hypothesis, also referred to as the developmental interdependence hypothesis or the linguistic interdependence hypothesis in the literature, posits that "the level of L2 competence which a bilingual child attains is 
partially a function of the type of competence the child has developed in L1 at the time when intensive exposure to L2 begins" (Cummins, 1979, p. 33). That is, strong L1 literacy skills make it possible to transfer existing knowledge to a second language. Cummins (2005) described five types of transfer: transfer of conceptual elements, transfer of metacognitive/metalinguistic elements, transfer of pragmatic aspects of language use, transfer of specific linguistic elements, and transfer of phonological awareness. Linguistic distance between L1 and L2 is a strong determinant of the type of transfer that will occur. The interdependence hypothesis is often utilized to explain significant correlations between L1 and L2 reading comprehension.

The interdependence and threshold hypotheses. The interdependence hypothesis was put forward along with another, much debated hypothesis. The threshold hypothesis (Cummins, 1979), states that "those aspects of bilingualism which might positively influence cognitive growth are unlikely to come into effect until the child has attained a certain minimum or threshold level of competence in a second language" (p. 229). Taken out of context, this hypothesis was likened to Clarke's (1980) short-circuit hypothesis, according to which limited L2 knowledge "short-circuits" a good reader's understanding when reading in an L2, and as a consequence the reader returns to poor reader strategies. After reviewing both the threshold and the short-circuit hypotheses, Alderson (1984) posed the question whether L2 reading difficulties were a reading problem or a language problem. He concluded that "foreign language readers will not be able to read as well in the foreign language as in their first language until they have reached a threshold level of competence in that foreign language" (p. 19). Using this reduced form of the threshold hypothesis of bilingual cognitive competence to a theoretical threshold of L2 proficiency 
needed to successful transfer of L1 skills to L2 reading, many researchers have attempted to answer Alderson’s question (e.g. Bernhardt \& Kamil, 1995; Brisbois, 1995; Jiang, 2011; Lee \& Schallert, 1997, Park, 2013). The intention of the threshold hypothesis, however, was not to send researchers to look for the minimal level of L2 knowledge necessary to understand L2 texts. Rather, it focused on the (a) minimum linguistic competence in both languages necessary for cognitive growth and (b) proficiency in both languages needed to enjoy the cognitive benefits of bilingualism. Cummins (2000) himself believed that the threshold hypothesis was "speculative" and not as relevant to education as the interdependence hypothesis. Although the findings of studies that obsessed over the L2 reading threshold may be conflicting, they are also valuable because they confirmed the importance of both L1 literacy and L2 knowledge in L2 reading.

The interdependence hypothesis and generation 1.5 students. The contribution of the interdependence hypothesis to education is that it asserts that students with higher levels of L1 literacies are at better odds when they begin L2 acquisition and provides a rationale for bilingual education. In the context of this study, the interdependence hypothesis provides a theoretical foundation to investigate the L1 literacies of this study's target population because little is known about what type of L1 literacy backgrounds generation 1.5 students at Miami Dade College may have. Furthermore, if both English language knowledge and L1 literacy are important contributors to generation 1.5 students' English reading comprehension and ENC 1101 performance, then assistance should be provided to them to develop skills and knowledge not only in the English language but also in their native languages. 
The common underlying proficiency model of bilingual proficiency. Transfer

between L1 and L2 occurs because, despite the differences in superficial language

features that differentiate the learner's L1 from L2, underneath the superficial language

features there is a common underlying proficiency (CUP), defined as "the

cognitive/academic knowledge and abilities that underlie academic performance in both

languages" (Cummins, 2005, p. 4.). Because the CUP model is built on the

interdependence hypothesis, it allows for knowledge acquired in one language to also

increase knowledge in the other language. In contrast, the separate underlying proficiency

model implies that language abilities in the two languages are separate. Cummins (2005)

provided a visual representation of the difference between the SUP and CUP models

(Figure 1).

The SEParate

Underlying Proficiency

(SUP) MODEL OF

Bilingual Proficiency

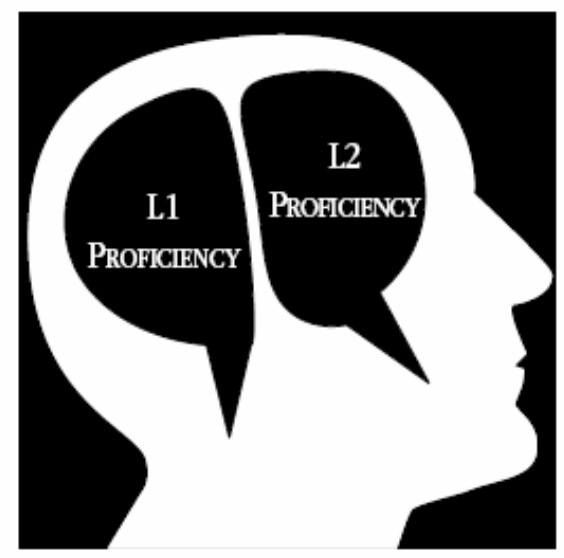

The Common

Underlying Proficiency

(CUP) MODEL OF

Bilingual Proficiency

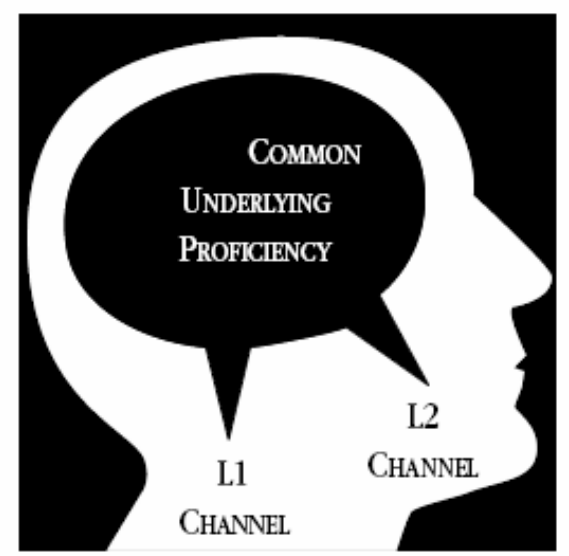

Figure 1. The difference between the SUP (left) and the CUP (right) models of bilingual proficiency (Cummins, 2005) 
In the SUP model, acquiring knowledge in one language would not result in growth in the other language, resulting in approaches such as target-language only instruction with zero tolerance to L1 use in the classroom. On the other hand, the utilization of CUP model empowers instructors to allow for the constructive use of the L1 in an L2 classroom.

\section{Compensatory Model of Second Language Reading}

In addition to describing linguistic transfer, the interdependence hypothesis was essential in explaining the significant correlations found between L1 and L2 reading ability. But L1 literacy is only one of many variables that have been found a significant predictor in one's ability to read L2 texts. Elizabeth Bernhardt's compensatory model of second language reading (2011) is presently the only L2 reading model to provide a comprehensive view of L2 reading. The model is a result of a critical review of peerreviewed research on adolescent or adult L2 reading published since the early 1990s. In order to be included in the review, studies had to (a) use more than one text to collect data, (b) specify the participants' L1 backgrounds, and (c) establish L1 literacy and L2 grammatical knowledge levels (Bernhardt, 2011).

The compensatory model of L2 reading is depicted in Figure 2. The variables that have been shown to predict L2 reading comprehension are categorized as L1 literacy, L2 language knowledge, and unexplained variance. Any variable in any of the categories has the capability to assist the reader in the reading process when needed thus compensating for the breakdown in the reading process. L1 literacy, accounting for up to $20 \%$ of the variance in comprehension scores, "includes how a reader's first language realizes L1 phonemics, how texts are structured, purposes for reading, beliefs about reading, knowledge of how words and sentences are structured, and so forth" (Bernhardt, 
2011, p. 35). Next, L2 knowledge, accounting for 30\% of the variance in reading comprehension scores, consists of "grammatical form, vocabulary knowledge, the impact of cognates, the distance between first language and second language, the value system attached to literacy, and so forth" (Bernhardt, 2011, p. 35). Finally, unexplained variance, accounting for $50 \%$ of the variance in L2 reading comprehension scores "implicates an interaction of individual reader variables with the universe of texts and topics" (Bernhardt, 2011, p. 35). The model indicates that some of these reader variables may be "comprehension strategies, engagements, content and domain knowledge, interest, motivation, etc." (Bernhardt, 2011, p. 35); that is, all variables that cannot be categorized as L1 literacy or L2 language knowledge.

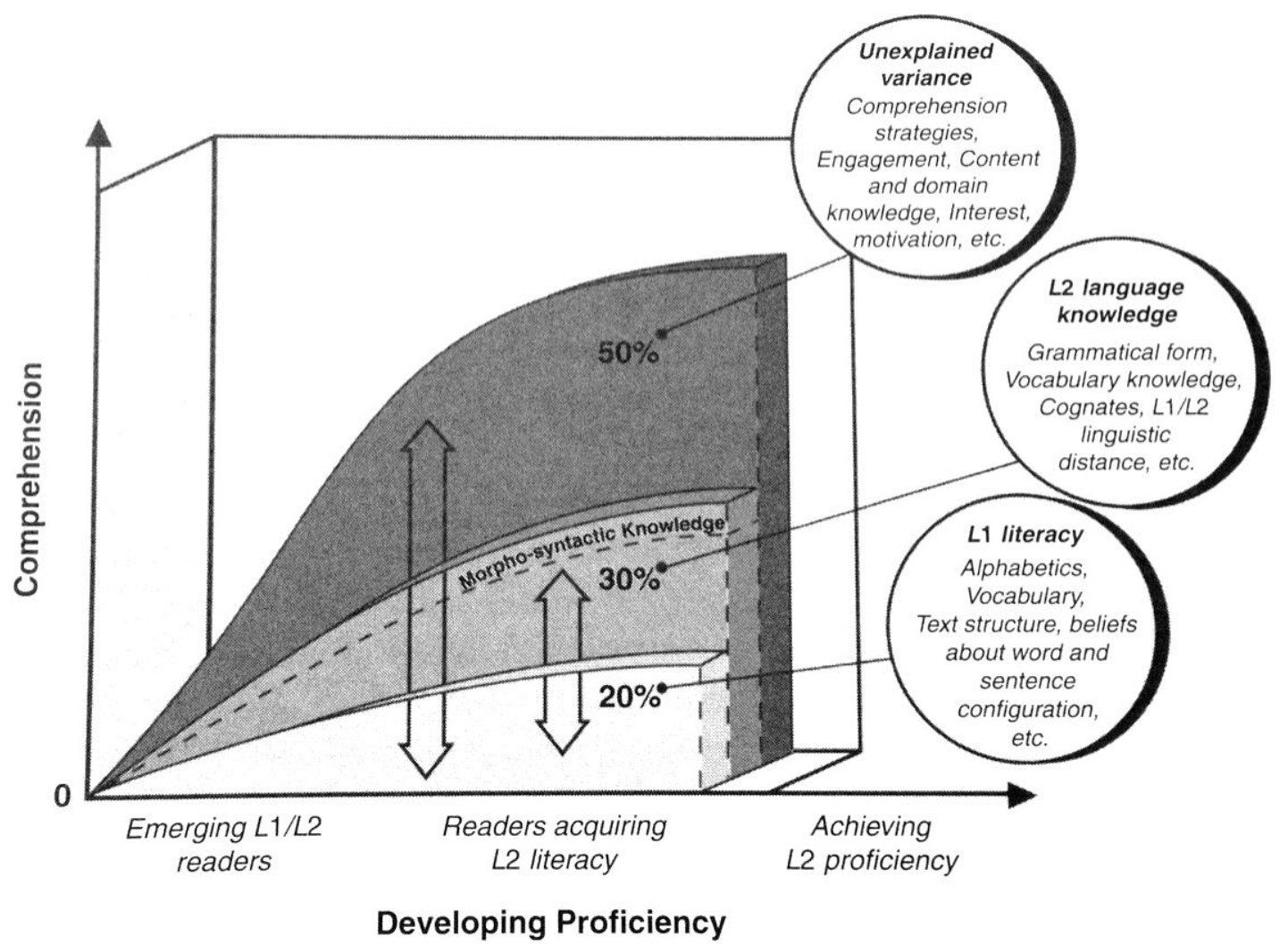

Figure 2. The compensatory model of second language reading (Bernhardt, 2011) 
One weakness of the Bernhardt model is that the variables filed under the miscellaneous category "unexplained variance" have in fact been extensively researched (e.g. Dörnyei's work on motivation and Horwitz's work on language anxiety). However, because of its focus on L1 literacy and L2 knowledge, the model is well suited to serve as the theoretical foundation to investigating English reading comprehension in this study.

\section{Generation 1.5 Students}

In this section, I first summarize the literature regarding the general characteristics of generation 1.5 students. Then, I discuss major concepts associated bilingualism and matriculation in U.S. universities. Because the majority of non-native speakers at Miami Dade College are from Hispanic and Haitian backgrounds, the section closes with a focused discussion on the specific characteristics of Hispanic and Haitian generation 1.5 students.

\section{General Characteristics of Generation 1.5 Students}

The term one-and-a-half generation was first used by Rumbaut and Ima (1988, cited in Rumbaut, 1994) to refer to foreign-born youths who immigrated to the United States before age 12; however, recently the term has been used less strictly to refer to immigrant youth of high-school age and younger (Goldschmidt \& Miller, 2005) who graduate from U.S. high-schools (Peña, 2010). Blumenthal (2002) defines generation 1.5 students as immigrants who "arrive in the United States in their preteen or early teen years and acquire at least some education in U.S. high schools and possibly middle schools" (p. 49). Doolan's (2014) criteria for generation 1.5 are (a) having been in the U.S. education system for more than four years, (b) speaking a language other than English at home, and (c) being younger than 22 years of age. Because there are many 
developmental stages encompassed in the term, a generation 1.5 immigrant who arrives in the United States at a very young age could have more in common culturally and linguistically with peers who are U.S.-born than with peers who are late-arrival generation 1.5. In general, generation 1.5 students share characteristics of both the first generation (foreign-born individuals who immigrated to the United States as adults) and the second generation (US-born children of first-generation immigrants). Culturally, their worlds are split between the native culture at home and English at school (Goldschmidt \& Miller, 2005). I will use the term generation 1.5 students to describe foreign-born and U.S. educated children of first-generation immigrants, who completed some or most of their K-12 education in the United States.

\section{The Bilingualism of Generation 1.5 Students}

The linguistic characteristics of generation 1.5 students may be best described as showing features of both native (L1) and second (L2) languages. According to Blumenthal (2002), their reading and writing reveal the L2 learner although orally they may display native-like fluency. Peña (2010), on the other hand, found that many of the Hispanic generation 1.5 participants in her study preferred to use Spanish during their interviews. At the time of arrival in the United States, generation 1.5 students possess differing levels of English language proficiency: some might have advanced levels of English coursework behind them, while others may have not learned English in their home countries at all. In her review of the research regarding the length of time it takes to master a second language for academic purposes, Collier (1989) found that before puberty it does not matter when the initial exposure in the second language begins. Overall, long-term academic achievement will not suffer as long as L1 cognitive 
development continues at least until age 12. Additionally, adolescent students (ages 8-12) with solid L1 literacy backgrounds may be faster in acquiring basic communicative competence as well as school language than children. These students, with at least 2 years of schooling in their L1, take approximately 5-7 years to reach the academic performance of native speakers in reading and social and natural sciences. (They may need just 2 years to perform at grade level in mathematics and language arts). However, without schooling in their L1, they may take "as long as 7 to 10 years in reading, social studies, and science, or indeed, never" (p. 527). Collier presented a similarly grim outlook for adolescent arrivals who have had not L2 exposure and are not able to continue their studies in their L1. Quite simply, they "do not have enough time left in high school to make up the lost years of academic instruction" (p. 527).

In addition to various levels of L2 literacy, generation 1.5 students' L1 literacy may also be limited, especially if L1 literacy instruction ceased at the time of arrival in the U.S. Collier (1989) recommended that L1 instruction continue after arrival. As long as L1 cognitive development is continued, academic achievement does not suffer, especially before the age of 12 , by which age $\mathrm{L} 1$ acquisition is assumed to be completed. Dual language programs are therefore most beneficial for these students (Thomas \& Collier, 2002). Conversely, if children's L1 development is discontinued before this age, they may experience negative cognitive effects in L2 development (Collier, 1989). While Cummins (2001) did not determine a specific age, he also explained that cognitive academic language proficiency (CALP) in the L1 develops until around mid-adolescence. But some content-area instruction would be desirable even when students arrive after 
their mid-adolescent years with well-equipped with L1 literacy skills so that they can have access to grade-level academic material while they are learning English.

Thompson (2015) suggested age 5 as another critical age in language development. In her longitudinal study, Thompson found that differences in academic proficiency in both L1 and English at kindergarten were associated with differences in the likelihood of reclassification from English language learner to English proficient by the end of middle school.

Generation 1.5 students arrive in the U.S. with differing levels of literacy as well as general background knowledge. Those who arrive with rich educational backgrounds generally adjust faster than those with limited or interrupted education (Harklau, Siegal, \& Losey, 1999; Thompson, 2015). As a result, some generation 1.5 students may be quite prepared for college-level studies upon graduating from high school, while others might need additional time to catch up and get ready for college.

\section{Generation 1.5 Students at Tertiary Institutions}

Data regarding the numbers of generation 1.5 students in higher education are scarce. Institutions generally do not collect the kind of information that would allow researchers to gauge the numbers of generation 1.5 students enrolled in college and university courses. In prior studies, the percentage of generation 1.5 students in the student body was 17 - 18\% (Harklau \& Siegal, 2009; Jiang, 2016; Patthey, ThomasSpiege, \& Dillon, 2009).

While some researchers report that generation 1.5 students are more likely to enroll and persist in college than their US - born peers, college can also become rather challenging for generation 1.5 students (Harklau \& Siegal, 2009). Academically, 
generation 1.5 students may be considered underprepared due to insufficient academic language proficiency and, in many cases, lacking general prior knowledge. Depending on the age of arrival in the United States, they may not have had enough time to develop L2 CALP and close the achievement gap (Collier, 1989; Cummins, 2001).

College writing performance. Researchers generally agree that second-language characteristics are common in generation 1.5 students' writing, but there is still considerable ambiguity surrounding these characteristics. Studies comparing generation 1.5 writing to L1 and L2 writing have come to contradictory conclusions (diGennaro, 2013; Doolan \& Miller, 2012; Doolan, 2014; de Kleine \& Lawton, 2015; de Kleine, Lawton, \& Woo, 2016). Researchers seem to agree, however, that generation 1.5 students' writing patterns are distinct from both L1 and L2 writers.

Placement issues. When generation 1.5 students enter college, they may be placed into credit-bearing courses. Schwartz (2004) proposed the term cross-over students for generation 1.5 students who tested out of ESOL, were mainstreamed in highschool, and continue in credit-bearing courses in college. Other generation 1.5 students are likely to place into Developmental Education (DE), English as a Second Language (ESL), or English for Academic Purposes (EAP) courses, neither of which may be suitable for them. Developmental Education courses are designed for academically underprepared native speakers. These courses might provide some remediation of general background knowledge, but they are not typically designed to address second-language issues. At the same time, academic ESL or EAP courses are designed for first generation immigrants and also represent a misfit for generation 1.5 students. Credit-bearing ESL or EAP course designs assume that students earned their K-12 or higher education abroad 
and arrived in the ESL classroom with significant life experience and background knowledge (Blumenthal, 2002; Harklau, Siegal, \& Losey, 1999; Holten, 2009). Roberge (2009) pointed out the underlying philosophical dichotomy in these programs. Programs such as ESL and EAP are designed for the "foreign" student to help them learn the English language and U.S. culture in addition to their existing knowledge of the home language and culture. On the other hand, DE programs are designed for English monolinguals "who are somehow 'deficient' and must be 'fixed' or 'remediated' so they can go on to 'regular' English classes" (p. 5). Clearly, neither "learned non-native speaker" nor "deficient native speaker" describes generation 1.5 students appropriately. Generation 1.5 students may be especially offended by placement in ESL as they may have already placed out of ESOL in high school (Blanton, 1999; Blumenthal, 2002; Goldschmidt \& Miller, 2005; Holten, 2009; Peña, 2010).

Emotional issues. For generation 1.5 students, feelings of resentment and confusion stemming from the shock of the inability to cope with college-level coursework (or the inability to even access college level course work until remedial coursework is completed) are often combined with identity issues. Rumbaut (1994) explained that "contextual dissonance" increases an awareness of ethnicity and ethnic group boundaries, and young people try to deal with the pressures arising from this dissonance by trying to assimilate or, just the opposite, by reaffirming their identification with their ethnic groups. Rumbaut calls this a segmented identificational perspective, and it is dependent on contextual factors as well as on the degree of identification with parents and their sense of ethnic identity. Contextual factors include racial discrimination (its presents or absence), location (in or away from inner-city areas), and a strong 
receiving community (its presence or absence). Rumbaut hypothesized that contexts with the positive features of these factors lead to a resilient sense of ethnic identity, while contexts combining the negative features lead to assimilation with native racial minorities. Generation 1.5 students may lack understanding of who they are and where they belong. Behind weak ethnic identity is often weak self-esteem (Goldschmidt \& Miller, 2005), further disrupting their academic success.

Furthermore, generation 1.5 students may perceive faculty as unaware of their bicultural identities (Goldschmidt \& Miller, 2005; Ortmeier-Hooper, 2008). Peña (2010) found that on their own initiative Hispanic generation 1.5 students did not seek engagement opportunities with faculty, staff, or peers outside the classroom. OrtmeierHooper (2008) called attention to the possibility that generation 1.5 students may also be at odds with the culture of the university; that is, in their homelands they may have attended schools and heard stories of higher education institutions committed to more of a scholar-academic and less student-centered tradition.

\section{Generation 1.5 College Students from Hispanic Backgrounds}

The Hispanic community is extremely diverse in terms of countries of origin, immigration patterns, and social-economic status in the native countries and in the United States. Like other generation 1.5 students, Hispanic generation 1.5 college students are likely to have various levels of L2 proficiency and L1 literacy skills upon entering college. Although presently there is no information regarding the numbers and ethnic backgrounds of generation 1.5 students enrolled at MDC, $38 \%$ of the general student population enrolled in credit-bearing courses report Spanish as native language and Hispanic students constitute 73\% of the credit student population (MDC, 2016a). 
Generation 1.5 students' preference toward the English language could be the reason why the percentage of native Spanish speakers are much lower than the percentage of those who identify themselves as Hispanics, which would be consistent with research findings among Haitian generation 1.5 students (Kepley, 2011).

\section{Generation 1.5 College Students from Haiti}

Like other generation 1.5 students, Haitian generation 1.5 college students are likely to have various levels of L2 proficiency upon entering college. Unique to their L1 background is their home country's system of education that discriminates against Creole in favor of French, the language of prestige and opportunity. Although in 1987 the Haitian Constitution declared Creole the second official language of the country (Cadely, 2012), reports are still concerned about the pervasive social prejudice against Creole, the native language of most Haitians (Berrouet-Oriol, 2011; Degraff, 2010; Hebblethwaite, 2011). Children from privileged families get plenty of assistance from their parents and private school teachers to learn in French; thus, it becomes their de facto first language. Working class Haitians do not have the money to pay the tuition high-end private schools charge. In the schools these parents can afford, teachers are sometimes not quite proficient French speakers themselves (Berrouet-Oriol, 2011; Hebblethwaite, 2011).

Upon arrival in the United States, Haitian immigrants may face the threat of language loss. Haitian Americans report low levels of L1 literacy (Portes \& Schauffler, 1994), and Haitian youth may prefer to speak English to hide their ethnic identities (Stepick, 1998; Vanderkooy, 2007). In South Florida, however, the Haitian community is known to embrace Creole and to have a sense of pride in the maintenance of language and culture (Stepick, 1998). A great example of this pride is MDC in the Haitian 
Community, a Creole language show featured on the college-based MDC-TV. Since December 2013, the program showcases interviews with successful professionals of Haitian backgrounds (Rodriguez, 2014). Similarly, Buxton and colleagues (2008) found that teachers and parents, regardless of their level of education felt strongly about the importance of not only maintaining but also improving fluency and literacy in Creole. However, Haitian youth do not necessarily consider knowledge of Haitian Creole a prerequisite of association with the Haitian culture (Kepley, 2011; Vanderkooy, 2007). Kepley (2011) found that the majority of the Haitian college student participants in her study considered Creole their native language, but only $37.1 \%$ indicated that their preferred language was Creole. Similarly, they trusted their English language abilities more than their Creole abilities.

\section{Native Language Literacy and Second Language Knowledge}

The first part of this section reviews studies that investigated the role of either L1 literacy or L2 knowledge separately in L2 reading will be reviewed. The second part focuses on research that included both variables as predictors.

\section{Native Language Literacy}

Numerous studies confirmed the link between L1 and L2 proficiency (Chuang, Joshi, \& Dixon, 2011; Gottardo, Yan, Siegel, \& Wade-Woolley, 2001; Nguyen, Shin, \& Krashen, 2001; Reese, Garnier, Gallimore, \& Goldenberg, 2000; Sparks, Patton, Ganschow et al., 2006; Upton \& Lee-Thompson, 2001; van Gelderen, Schoonen, Stoel et al., 2007). Nguyen, Shin, \& Krashen (2001), for instance, surveyed Vietnamese children in Southern California regarding their language preferences and attitudes toward the native language. Their findings indicated that the students' preference in using 
Vietnamese was not detrimental to literacy development in English. Upton and LeeThompson's (2001) research inquired into the process transfer between languages occurs. Using think-aloud protocols and interviews, Upton and Lee-Thompson investigated the strategies Chinese and Japanese college students with high levels of L1 literacy used to utilize their L1 skills in comprehending L2 texts and found five different learner approaches to using the L1 to facilitate the comprehension of L2 texts. In addition, they found that the intermediate ESL students used their L1 $61 \%$ of the time, the advanced ESL students $43 \%$ of the time, and the post-ESL students used their L1 only $15 \%$ of the time. Literacy skills in L1 are considered foundational in L2 reading (Atwill, Blanchard, Gorin, et al., 2007), writing (Schoonen, Van Gelderen, de Glopper et al., 2003; Wang, 2003; Woodall, 2002), and overall achievement (Jiang \& Kuehn, 2001; Lasagabaster, 2001; Sparks, Patton, Ganschow et al., 2006).

\section{Second Language Knowledge}

Bernhardt (2011) defines L2 knowledge as "grammatical form, vocabulary knowledge, the impact of cognates, the distance between first language and second language, the value system attached to literacy, and so forth" (p. 35). Measures of L2 grammar and vocabulary are generally included as indicators of L2 knowledge in the research literature (Brisbois, 1995; Park, 2013; Yamashita \& Shiotsu, 2015). Although the intention of Cummins's (1979) threshold hypothesis has often been misinterpreted, and some researchers have even discussed it as an alternative to the interdependence hypothesis (Lee \& Schallert, 1997; Jiang, 2011), research has confirmed that familiarity with grammar and vocabulary in a L2 greatly enhances understanding of L2 texts; in fact, findings have generally confirmed that at higher levels of L2 knowledge L2 readers are 
more successful in transferring L1 reading ability (Burt, Peyton, \& Adams, 2003; Yamashita, 2002) although the reliance of L1 reading skills might decrease as L2 proficiency increases (Park, 2013; Upton \& Lee-Thompson, 2001).

Of the two measures of L2 knowledge, L2 vocabulary and grammar, vocabulary seems to the stronger predictor of L2 reading performance (Brisbois, 1995; Proctor, August, Carlo, \& Snow, 2006; Zhang, 2012). Zhang (2012), for example, examined the contribution of vocabulary and grammatical knowledge to the English reading comprehension of Chinese students. Two measures of vocabulary knowledge (breadth and depth), two measures of grammatical knowledge (implicit and explicit) and three measures of reading comprehension (coreference, textual inference, and main idea) were utilized. A confirmatory factor analysis procedure revealed that both the two measures of vocabulary and the two measures of grammar loaded significantly into their respective latent factors. Vocabulary knowledge and grammatical knowledge correlated moderately but significantly $(r=.352, p=.016)$ and together accounted for $81.1 \%$ of the variance in reading comprehension, but after accounting for the contribution of vocabulary knowledge, grammatical knowledge did not show any significant unique contribution to the variance in reading scores $(\beta=.660, p=.078)$. When vocabulary size was used as covariate and entered first in a hierarchical regression equation, implicit knowledge of grammar (as measured by a timed grammaticality judgment task) showed a stronger relationship to reading comprehension than explicit knowledge of grammar (as measured by a grammatical error correction task), over and above the effect of vocabulary size. 


\section{The Predictive Power of L1 Literacy and L2 Knowledge}

Regression analysis is often utilized to determine the variance in $\mathrm{L} 2$ reading comprehension scores that is attributable to L1 literacy and L2 language knowledge among other predictors (Bernhardt \& Kamil, 1995; Brisbois, 1995; Carson, Carrell, Silberstein, Kroll, \& Kuehn, 1990; Carrell, 1991; Chuang, Joshi, \& Dixon, 2011; Jiang, 2011; Lee \& Schallert, 1997; Park, 2013; Pichette, Segalowitz, \& Connors, 2003; Yamashita \& Shiotsu, 2015). These studies, as Yamashita (2002) pointed out, focused on the product rather than the process of reading comprehension.

Research conducted in the 1990s found conflicting results regarding the contributions of L2 knowledge and L1 literacy to the variance in L2 scores. Bernhardt and Kamil (1995) and Carrell (1991) found that both L1 reading and L2 knowledge were important predictors with L2 knowledge covering a larger area of the variance, but in Carrell's study this was only the case for the native English speakers learning Spanish. In the case of the Spanish speakers learning English (whose L2 knowledge was higher than that of the native English speakers), L1 reading contributed more strongly to the variance in L2 reading scores. In both of these studies, L2 knowledge was measured by the participants' instructional level, that is, by the level of the courses they were enrolled in. When Brisbois (1995) introduced grammar and vocabulary tests to measure the participants' L2 knowledge, she found that together these measures explain only a small percentage of the variance. An additional finding was that L2 vocabulary knowledge predicted reading scores better than grammar knowledge.

From the studies reviewed above, it is evident that L1 literacy and L2 knowledge emerge consistently as crucial indicators of L2 performance. Using these measures, Jiang 
(2011) and Park (2013) found L2 knowledge to be a better predictor of L2 reading than L1 literacy, thus confirming the results of previous research as well as Bernhardt's (2011) model. However, unlike previous studies that found a positive relationship between L2 knowledge and the variance accounted for by L1 literacy, Park (2013) found that the predictive power of L1 literacy decreased as L2 knowledge increased.

The interdependence hypothesis has generally been confirmed in studies using multiple regression analysis to predict L2 reading. Most researchers concluded that transfer of L1 reading skills occurs at higher levels of L2 knowledge. At higher levels of L2 proficiency, L1 reading covers a larger amount of the variance in L2 reading scores than at lower levels of L2 proficiency. Pichette, Segalowitz, and Connors (2003), for example, found that L1 reading and L2 knowledge accounted for $44 \%$ of the variance in the French reading comprehension of their Serbo-Croatian participants, and the predictive power of the two variables combines was similarly high (45\%) a year later. However, Pichette and colleagues did not find a significant correlation between L1 reading and L2 reading at the first administration, but they did when L2 knowledge was higher a year later. An additional interesting finding in this study was that the participants who maintained L1 reading habits had more L2 reading gains over time.

More recently, L2 listening has been introduced to the analysis as a predictor variable. Yamashita and Shiotsu (2015) found that L2 listening was the strongest predictor of L2 reading among the 325 Japanese university student participants, and 94\% of L2 reading variance was explained by the predictors. However, L1 reading did not contribute significantly to the variance in the whole sample. Among participants with higher L2 proficiency, 93\% of the variance was explained by the 3 predictors, and the 
contribution of L1 reading was moderate but significant. The strongest predictor was L2 knowledge.

Two noticeable gaps can be identified in the research. First of all, there is no consistency in the operational definition of L1 literacy. Most studies include a measure of L1 reading comprehension in the regression model. Reading skill is certainly an important but not unique factor in literacy. In the interdependence hypothesis, Cummins (1979) discusses the transfer of L1 competency, and Bernhardt's (2011) reading model indicates that L1 literacy as a predictor of L2 reading is a composite of several variables. "First-language literacy is a complex of variables that includes how a reader's first language realizes phonemics, how texts are structured, the purposes for reading, beliefs about reading, knowledge of how words and sentences are configured, and so forth" (p. 35). Thus, L1 reading skills should not be the only variable representing L1 literacy in the regression equation. Second, none of the studies reviewed were conducted among generation 1.5 students or specified whether they had generation 1.5 participants. I attempted to fill these two important gaps in the literature with this study.

\section{Remedial Coursework at the Tertiary Level}

This section discusses the issues surrounding the placement and performance of generation 1.5 students at the tertiary level.

\section{Placement Dilemmas}

Course placement at tertiary institutions often represents a misfit for generation 1.5 students. Those who are determined to be college-ready may still struggle in first-year composition courses because placement tests are not always accurate measures of writing ability. Current Florida college-readiness policies may exacerbate the situation as more 
generation 1.5 students who were mainstreamed before Grade 12 might be enrolling directly into ENC 1101 due to being exempt from the placement testing requirement.

Generation 1.5 students who take DE or EAP courses may also be dissatisfied with their courses as neither curriculum may be suitable for them. Developmental courses are designed for academically underprepared native speakers. These courses might provide some remediation of general background knowledge, but they are not typically designed to address second-language issues. Blanton (1999) summed up the instructional practices often used in developmental writing courses that are inappropriate for generation 1.5 writers in seven points: (a) modeling preparatory writing courses after single-genreoriented freshmen English writing courses, (b) positioning language as a subject rather than as a medium, (c) ignoring students' lived experience, (d) denying students the opportunity to construct meaning from reading, (e) treating writing as a solitary act, (f) not allowing students to come up with their own purposes for writing, and (g) treating texts as models of styles and strategies.

English for Academic Purposes courses, on the other hand, are designed for nonnative speakers who are assumed to have significant life experience and background knowledge (Blumenthal, 2002; Harklau et al., 1999; Holten, 2009; Roberge, 2009). Generation 1.5 students may be offended by placement in ESL as they may have already placed out of ESOL in high school (Blanton, 1999; Blumenthal, 2002; Goldschmidt \& Miller, 2005; Holten, 2009; Peña, 2010). 


\section{Performance and Persistence}

Research suggests that generation 1.5 students who earn their high-school diplomas in the United States and have fewer years of formal education in their own language are generally not as well prepared for academic studies as educated traditional first generation immigrants or international students (Bosher and Rowekamp, 1998; Muchisky and Tagren, 1999). Jiang and Kuehn (2001) illustrated the differences between the academic preparedness of generation 1.5 students and first generation students with higher L1 literacy levels who were enrolled in a college ESL course. Generation 1.5 participants were between 18 to 34 years of age with a mean age of 22.2. The researchers compared pre-and post-test scores of the early immigrant (generation 1.5) and the late immigrant groups using an Analysis of Covariance, controlling for years of English instruction and years in the U.S. The results showed that, although both groups made significant gains as a result of instruction, the late immigrant group made better progress than the early immigrant group. Furthermore, significant correlations between L1 and L2 writing scores $(r=.382)$ indicated transfer of writing skills. Moderate positive correlation of total years of education to L1 and L2 writing scores were also found. Finally, interviews with students suggested that the students with more L1 education used more cognitive strategies and made conscious connections between the two languages to solve language problems in both languages than generation 1.5 students. Overall, Jiang and Kuehn's findings showed that generation 1.5 students with fewer years of L1 education were not as prepared academically as adult immigrants with at least 10 years of L1 education. However, more generation 1.5 students than late arrival students believed that knowledge of their L1 helped them in learning English. 
Patthey, Thomas-Spiegel, and Dillon (2009) also found evidence of persistence among generation 1.5 students. Patthey and colleagues examined a large data set from the Intersegmental Project to Assure Student Success (IPASS), a data-sharing collaboration between 14 community colleges and two state universities in California from 1990 to 2000. Over 200,000 student records were disaggregated and "likely generation 1.5" students identified by using the following criteria: age (under 22), primary language other than English, and completion of US high school. The majority of these students started college at the pre-collegiate English level either in ESL or Basic Skills English. Only $16 \%$ of them (compared to $27 \%$ of the total population studied) started in college-level English 101. The findings revealed that likely generation 1.5 students performed somewhat better than the general population and fewer generation 1.5 students failed English 101 than the general population. However, in English 101, generation 1.5 students earned a lower average grade, indicating that college-level writing was a challenge for generation 1.5 students but they were more persistent than the general population. It was also evident from the data that advanced ESL students were the second-most successful group in terms of GPA in English 101 and overall GPA. Like Jiang and Kuehn (2001), Patthey et al. (2009) concluded that those who arrive in the U.S. with academic literacy in their L1 outperform underprepared English native peers.

\section{Meeting Generation 1.5 Students' Instructional Needs}

The generation 1.5 literature has called attention to the curriculum in Developmental Education and English for Academic Purposes programs that may be unsuitable for these students (Blanton, 1999; Blumenthal, 2002; Harklau, Siegal, \& Losey, 1999; Roberge, 2009). Others call attention to the need for professional 
development and training for instructors of the growing numbers of linguistically diverse students on college campuses (deKleine \& Lawton, 2015). Currently, the Southern Association of Colleges and Schools Commission on Colleges, Miami Dade College's the accreditation agency, does not require college-level and Developmental Education faculty to complete ESL coursework courses (Miami Dade College, 2014d). Research regarding the college professors' preparedness to deal with ESL student issues is scarce (Chang, 2013; Schwartz, 2004).

In the K-12 setting, there is some controversy surrounding the subject of teacher training. Grant and Wong (2003) discussed several barriers that exist within the literacy education profession that slow down or even prevent ELLs from becoming fully literate in both English and in their native languages. These barriers include "(a) xenophobic English-only movements (Donahue, 1995); (b) limited resources personnel within ESL (August \& Hakuta, 1997; (c) controversy about bilingual education (Faltis \& Hudelson, 1998; Krashen, 1996); (d) differences about the duration and type of language services children should receive (Collier, 1987); and (e) cultural and linguistic deficit models (Luke, 1986)" (p. 387). Grant and Wong worried about the inadequate preparation of reading professionals. English language learners may not be provided adequate support in classrooms taught by teachers who were taught TESOL strategies by non-TESOL university faculty (Dwyer \& Barsony, 2014).

\section{Instructional and Curricular Implications}

Two major issues emerge from the literature review: taking native language literacy in consideration when placement and instructional decisions are made and meeting the remedial needs of generation 1.5 students. 


\section{Taking Native Language Literacy into Consideration}

Burt, Peyton, and Adams (2003) warned that L1 literacy should not be considered dichotomous (as L1-literate or not L1-literate) as L1 literacies vary a great deal according to the cultural and socio-economic backgrounds of their speakers as well as the linguistic characteristics of the L1 itself and its distance from English. Native language literacy plays a crucial role in L2 learning according to the interdependence hypothesis and the numerous studies confirming it. Furthermore, Bernhardt's (2011) L2 reading model assigned a relative importance of $20 \%$ to L1 literacy in L2 reading comprehension. In spite of the mounting evidence, however, L1 literacy is rarely considered for program placement or instructional decisions (Burt, Peyton, \& Adams, 2003), and English-only continues to be the norm in college ESL classrooms. Curriculum design should plan for existing (or non-exisiting) L1 literacies and treat language as a resource (Ruíz, 1984).

In the K-12 setting, there is ample evidence to illustrate the superiority of wellplanned bilingual programs. For example, Slavin and Cheung's (2005) review of 17 experimental studies on reading instruction for ELLs showed that the best reading programs were those that combined reading in the L1 and in English at different times each day. Similarly, the National Literacy Panel on Language Minority Children and Youth, which reviewed research "to identify, assess, and synthesize research on the education of language-minority children and youth with regard to literacy attainment" (August and Shanahan, 2006, p. 2), found conclusive evidence to favor the inclusion of L1 in English language instruction. There is no reason to believe that these findings would not stand at the college level as well. 
Good bilingual readers use reading strategies that are unique to their bilingual status. Specifically, strategies such as relying on knowledge of cognates, transferring information learned in one language to the other language, and mentally translating from one language to the other (Jiménez, García, \& Pearson, 1996) can be taught directly. Kern (1994) found mental translation beneficial as it helped the readers to think through the text and figure out the meaning, clarify syntactic clues, and retain information. Students' L1 can also be used very effectively in teaching L2 vocabulary (Augustyn, 2013; Bell \& Le Blanc, 2000; Celik, 2003; Grace, 1998; Grace, 2000: Sagarra \& Alba, 2006). There is also some evidence to support the use of $\mathrm{L} 1$ in $\mathrm{L} 2$ reading assessment. Godev, Martinez-Gibson, and Toris (2002) provided evidence that beginning and intermediate readers' reading comprehension may be more accurately measured when open-ended questions are phrased in the L1.

In writing, conscious use of the L1 provides scaffolding for the developing L2 CALP at various stages of the writing process (Anton \& DiCamilla, 1998; Belz, 2002; Qi, 1998; Storch \& Wigglesworth, 2003). Using the L1 under timed writing conditions, however, might not benefit all students (Pappamihiel, Nishimata, \& Mihai, 2008). In addition to the native language, students might bring the native styles of writing that characterize the cultures they come from. Schwartz (2010) challenged composition teachers to be open to a blended rhetoric and celebrate the mixture of styles what reflects the identities of generation 1.5 students. 


\section{Meeting the Remedial Needs of Generation 1.5 Students}

The growing numbers of generation 1.5 students in higher education institutions and the growing interest in finding ways to assist them have resulted in curricular and procedural changes at several institutions of higher education. Goldschmidt and Miller (2003), for instance, described Penn State University's American Studies Course Cluster (ASCC), whose goals were to address not only the academic but also the emotional needs of generation 1.5 students, specifically their reluctance to engage with faculty, an issue Peña (2010) also found. Similarly, an interdisciplinary collaboration between ESL and college composition faculty resulted in the design of a course that targeted generation 1.5 students at the University of California in Los Angeles (Holten, 2009). San Francisco State University introduced an array of reforms in placement procedures and instructional practices as a result of the increased attention on its generation 1.5 population (Roberge, 2009). The writing center literature has also recognized the specific needs of generation 1.5 students in traditional composition courses. Thonus (2003) provided the following recommendations to writing center tutors who assist generation 1.5 students: (a) teach the metalanguage and sociopragmatic conventions of writing, (b) affirm the student's cultural and linguistic heritage, (c) balance grammar corrections with rhetorical concerns, (d) offer explicit direction, and (e) avoid appealing to native speaker intuitions.

\section{Summary}

The literature reviewed in this chapter indicates that generation 1.5 students enter college with varied literacy experiences, levels of academic preparation, and instructional needs that existing types of college remedial programs may not be able to meet (Blumenthal, 2002; Goldschmidt \& Miller, 2005; Harklau, et al., 1999; Peña, 2010). 
The theoretical framework of this study, the interdependence hypothesis (Cummins, 1979), the common underlying proficiency model of bilingual proficiency (Cummins, 2005), and the compensatory model of second language reading (Bernhard, 2011), calls for an examination of native language literacy and second language knowledge in discussions of reading comprehension and academic performance in a second language. Following a review of previous research focusing on native language literacy, English language knowledge, and college remediation, this chapter closed with preliminary instructional and curricular implications based on the literature. 


\section{CHAPTER III}

\section{METHODS}

The overarching goals of this study were to describe the literacy backgrounds of generation 1.5 students at Miami Dade College and to examine the predictors of success in their English reading comprehension and English Composition 1 (ENC 1101) courses. The research questions were the following:

1. What literacy backgrounds do generation 1.5 students at Miami Dade College have?

2. What relationship exists between generation 1.5 students' native language literacy, English language knowledge, pre-ENC 1101 (Developmental Education or EAP) coursework and English reading comprehension?

3. What relationship exists between generation 1.5 students' native language literacy, English language knowledge, pre-ENC 1101 (Developmental Education or EAP) coursework and their performance in English Composition 1 (ENC 1101)?

\section{Research Hypotheses}

Self-reported descriptive data and institutional data were used to describe the literacy backgrounds of generation 1.5 enrolled in English Composition 1 (ENC 1101), Developmental Education Reading 2 (REA 0017), or Developmental Education Writing 2 (ENC 0025) at Miami Dade College during Fall 2015 to answer research question 1. To answer research questions 2 and 3, the following two hypotheses were developed: 


\section{General Research Hypotheses}

Hypothesis \#1: Generation 1.5 students' native language literacy, English language knowledge, and pre-ENC1101 (Developmental Education or EAP) coursework are significant predictors of English reading comprehension. Hypothesis \#2: Generation 1.5 students' native language literacy, English language knowledge, and pre-ENC1101 coursework are significant predictors of their performance in English Composition 1 (ENC 1101).

\section{Specific Research Hypotheses}

Hypothesis \#1: Generation 1.5 students' native language literacy, English language knowledge, and pre-ENC 1101 coursework are significant predictors of English reading comprehension.

a. There is a significant positive correlation between generation 1.5 students' native language literacy and English reading comprehension.

b. There is a significant positive correlation between generation 1.5 students' English language knowledge and English reading comprehension.

c. There is a significant correlation between generation 1.5 students' preENC1101 coursework and English reading comprehension.

d. Each independent variable (native language literacy, English language knowledge, pre-ENC1101 coursework) accounts for a significant unique variance independent of each other in generation 1.5 students' English reading comprehension. 
e. Together, the three independent variables (native language literacy, English language knowledge, pre-ENC1101 coursework) account for a significant unique variance in generation 1.5 students' English reading comprehension.

Hypothesis \#2: Generation 1.5 students' native language literacy, English language knowledge, and pre-ENC1101 coursework are significant predictors of their performance in English Composition 1 (ENC 1101).

a. There is a significant positive correlation between generation 1.5 students' native language literacy and their performance in ENC 1101.

b. There is a significant positive correlation between generation 1.5 students' English language knowledge and their performance in ENC 1101.

c. There is a significant correlation between generation 1.5 students' preENC1101 coursework and their performance in ENC 1101.

d. Each independent variable (native language literacy, English language knowledge, pre-ENC1101 coursework) accounts for a significant unique variance independent of each other in generation 1.5 students' performance in ENC 1101.

e. Together, the three independent variables (native language literacy, English language knowledge, pre-ENC1101 coursework) account for a significant unique variance in generation 1.5 students' performance in ENC 1101.

\section{Research Design}

The research design is ex post facto. Newman, Newman, Brown, and McNeely (2006) defined ex post facto as "research which is initiated after the independent variable (the variable of interest) has already occurred or the independent variable is a type that 
cannot be manipulated such as age, race, gender, economic status, etc.” (p. 99). Newman and colleagues explained that ex-post facto design may be powerful in terms of internal validity in the presence of research hypotheses and tests for alternative hypotheses. Furthermore, ex-post facto design may have strong external validity defined as "the ability to generalize the results from the testing situation to the general population that was not tested (p. 101)." In experimental design, with the increase of experimental controls specific to the testing situation, the difficulty of generalizability to the general population may also increase. Thus, ex post facto research may be weaker than true experimental research in terms of internal validity, but it may be stronger than true experimental research in terms of external validity. This study employed both descriptive and inferential multivariate analysis to test the research hypotheses (McNeil, Newman, and Fraas, 2012).

\section{Participants}

The participants in this study were generation 1.5 students who were enrolled in English Composition 1 (ENC 1101), Developmental Education Reading 2 (REA 0017), or Developmental Education Writing 2 (ENC 0025) at Miami Dade College. Generation 1.5 for the purpose of this study was defined as foreign-born children of first-generation immigrants who completed some or most of their K-12 education in the United States. To be included in this study, in addition to being enrolled in one of the above courses, participants had to (a) be foreign-born, (b) be 18 years of age, (c) have arrived in the U.S. as children, and (d) have completed at least some pre-college education in the U.S. 


\section{Sampling Procedures}

Participants for this study were selected by convenience sampling. While the study was under institutional review, the researcher solicited the approval of the Academic Dean at one of Miami Dade College's six campuses. The Chairperson of the English and Communications department then forwarded the researcher's email message to full-time and part-time English composition and Developmental Education faculty. Data were collected in the 28 sections taught by the 12 faculty members who responded to the researcher's email.

\section{Sample Size, Power, and Precision}

Following the recommendations of Peng, Long, and Abaci (2012), the statistical software G*Power 3.1.9.2 (Faul, Erdfelder, Buchner, \& Lang, 2009) was used to estimate a desirable sample size as a function of significance level $\alpha$, power, and the desired effect size $f^{2}$. Peng and colleagues called attention to the neglect in the published research literature of prospective (a priori) power analysis despite a report written in 1999 by the American Psychological Association's (APA) Task Force on Statistical Inference. In this report and in the publication manuals published since then, the APA strongly recommended a-priori power analyses to determine desired sample sizes. In this study, the level of significance was set at .05 , an $\alpha$ level commonly used in social science research. Based on recommendations by Hinkle, Wiersma, and Jurs (2003), the ratio of $\beta$ to $\alpha$ in this study was set to $4: 1$; hence, the a-priori power $(1-\beta) .80$ was selected. Finally, the effect size $f^{2}=.15$ was selected. Similar studies, with the exception of Strebel Halpern (2009), did not indicate either the power or the effect size. In examining the predictors of English language learners' standardized reading test scores, Strebel Halpern (2009) chose 
an effect size of .15 based on Cohen's (1992) recommendation with the rationale that this represented an effect that the careful observer could see. Given that the hypotheses include three predictor variables, the total desirable sample size was determined to be 77 .

\section{Instruments}

The variables in this study were self-reported (literacy experiences, L1 literacy), assessed using objective measures (English reading comprehension, English language knowledge), or retrieved from college records (ENC 1101 performance, pre-ENC1101 coursework). Answers to research question 1 originated from college records and a literacy background survey.

\section{Literacy Backgrounds}

The following variables were used to describe the literacy experiences of Miami Dade College students to answer research question 1.

1. Age of arrival in the U.S.

2. Native languages

3. Literacy Experiences

a. Language history

i. Age at which literacy experiences began

ii. Age when participants became comfortable with each language

iii. Years of formal education in each language

iv. Years spent in a country, family, and work environment where each language is spoken

b. Language Use

i. Average percentage of time each language is used with friends, family, school/work

ii. Frequency of thinking and counting in each language

c. Language Attitudes

i. Identification with each language and culture

ii. Native speaker identity in each language

iii. Pre-college academic coursework

4. Language Proficiency: Reading, writing, speech, and comprehension ability in each language 
Bilingual Language Profile (BLP). Information about the literacy backgrounds was collected using college records and a modified paper version of the Bilingual Language Profile (BLP; Birdsong, Gertken, \& Amengual, 2012). The BLP is a 19question survey that has been developed to address the shortcomings of previous literacy background surveys, such as the Language Experience and Proficiency Questionnaire (LEAP-Q; Marian, Blumenfeld, \& Kaushanskaya, 2007). While the LEAP-Q or its modified versions have been widely utilized in research in linguistics (Keating, VanPatten, \& Jegersky, 2011), cognitive psychology (Kirk, Fiala, Scott-Brown, \& Kempe, 2014; Schroeder and Marian, 2012), brain research (Krizman et al., 2012), and information processing research (Libben and Titone, 2009; Shi, 2010), a pilot study conducted at Miami Dade College showed that it was not a fitting tool for non-native speaker participants who completed the survey (Barsony, 2015). First, the LEAP-Q was designed for adults who are already bilingual or multilingual. This was problematic because respondents who were not yet fully bilingual were confused by questions regarding the age at which they became proficient in reading and speaking English. Similarly, students not proficient in their L1 may also have had trouble answering the same question about their L1. Additionally, some of the questions on the LEAP-Q were confusing and the survey itself was time consuming. The BLP, on the other hand, does not assume fully bilingual status. Respondents have the option of answering "not yet" if they are not fully comfortable using either language. It contains only 19 questions and all scalar responses, and the time needed for completion is estimated to be 10 minutes. 
Modified Bilingual Language Profile (BLP-M). For the purposes of this study, the following key modifications to the BLP were needed. First, three questions relevant especially to the generation 1.5 experience were added: age at the time of arrival in the U.S., number of years spent in a K-12 ESOL program, and age when (if ever) participants tested out of ESOL before college. Second, native languages are specifically named on the BLP, and a separate form is needed for each English- native language pair, such as English- Spanish, English-Arabic, English-French, English-Catalan, English-Gallego, etc. For the purposes of this study, a new form was created. The new form allowed students to fill in their native languages and another language if they spoke more than two languages. At the same time, it was general enough to collect linguistic information from the monolingual English speaker participant as well. These adjustments were necessary because the researcher had no way (a) to anticipate what language pairs might be needed in each college classroom and (b) separate monolingual English speakers from non-native speakers of English for the purposes of data collection. Further modifications and the BLP-M can be found in Appendices A and B.

Validity and Reliability. The BLP was validated with 68 English-French bilinguals in the United States and in France (Gertken, Amengual, and Birdsong, 2014). Factor analysis showed that the underlying factors explained the majority of the variance in the data. Cronbach's alphas showed moderate or high reliability, and the self-report items showed a strong positive correlation to an objective measure of French proficiency. Specific reliability and validity estimates, however, have not yet been published.

Validity of the BLP-M. A consensus of the dissertation committee members that the modified Bilingual Language Profile (BLP-M) would be an appropriate measure of 
literacy background helped to establish the content validity of the instrument.

To distinguish between academic and functional literacy, the committee recommended the inclusion of items that provide participants with an opportunity to reflect on their language proficiencies in both academic and non-academic scenarios. The aggregate of the academic L1 reading, writing, listening, and speaking proficiencies was included in the analysis as a predictor of English reading comprehension and performance in collegelevel composition. An MDC faculty member provided feedback on the final draft of the BLP-M. The instrument was then sent to the dissertation committee for final review and approval.

The language proficiency questions of the BLP-M were key to the subsequent analyses to determine the predictive power of L1 literacy of the variance in English reading comprehension and college composition performance. Therefore, to determine the underlying constructs measured by these items, principal components analysis (PCA) was conducted (Meyers et al., 2013). The analysis (Kaiser-Meyer-Olkin Measure of Sampling Adequacy $=.83$ ) returned 2 components with eigenvalues higher than 1 accounting for $70.69 \%$ of the variance in the survey data. The first component consisted of all L1 proficiency items, including both functional and academic proficiencies. The second component consisted of all English proficiency items, including both functional and academic proficiencies.

Reliability of the BLP-M. Cronbach's alphas showed high reliability for language proficiency items $(\alpha=.89)$ and language attitudes $(\alpha=.72)$, but they were moderate-tolow for language history $(\alpha=.68)$ and language use $(\alpha=.12)$. 


\section{English Reading Comprehension}

The dependent variable in research question 2 was English reading comprehension, measured by the reading comprehension component of Level AR of the Gates-MacGinitie Reading Test (GMRT). Level AR of this test was designed for use by tertiary institutions that need to assess the general reading achievement of their students, and it was normed at community colleges across the United States. Participants were

enrolled in credit English courses or were in the last Developmental Education class. Test form T, used in this study, has Kuder-Richardson Formula 20 reliability coefficient .93 (Maria \& Hughes, 2008). The instrument is often administered to non-native speakers of English (Kamhi-Stein, 1998; Roessingh, Kover, \& Watt, 2005). Level AR features a variety of content catered toward the interest of adult readers, but the readability of the text is approximately at Level 7/9 of the GMRT, the level for students in Grades 7 to 9.

\section{Performance in College-Level Composition}

The dependent variable in research question 3 was performance in college-level composition, measured by course grades earned in ENC 1101, English Composition 1.

\section{Native Language Literacy}

Native language literacy was one of three independent variables in research questions 2 and 3. It was self-reported using the BLP-M. In Section II, Language Proficiency, students were asked to rate their functional and academic reading, writing, speech, and listening comprehension abilities. For each language skill, two scenarios (one functional and one academic) were posed, and participants rated their ability to cope with each scenario on a 6-point Likert scale ranging from 0 (not very well at all) to 6 (very well). The reading, writing, and oral language ability scales were combined to one 
literacy score for the analysis. Gertken and colleagues (2014) argued that research evidence had established sufficiently that bilinguals are able to assess their language abilities in a way that their assessment corresponds with the results of standardized measures of language performance.

\section{English Language Knowledge}

English language knowledge (L2 language knowledge) was the second of three independent variables in research questions 2 and 3. It was conceptualized by Bernhardt (2011) as a variable that consists of grammatical form, vocabulary knowledge, the distance between L1 and L2, the impact of cognates, etc. Clarke (1980) and Brisbois (1995) understood L2 knowledge as knowledge of L2 grammar and vocabulary. To measure L2 knowledge, a retired copy of the paper-based TOEFL exam is frequently used (Yamashita, 2002; Yamashita \& Shiotzu, 2015).

In this study, English language knowledge was defined as the knowledge of English vocabulary and grammar. To measure knowledge of vocabulary, the vocabulary section of Level AR of the Gates-MacGinitie reading test was used. To measure knowledge of English structure, a modified version of the Structure of and Written Expression component of the TOEFL ITP test was used. The Educational Testing Service offers the paper-based TOEFL ITP test for colleges and universities to evaluate nonnative speaker students' English language proficiency (Educational Testing Service, 2016). ETS reported a high (.90) reliability for Section 2 (Structure and Written Expression) of Level 1 of the TOEFL ITP. The instrument used in this study was a modified version of the full practice test available in ETS's Official Guide to the TOEFL ITP Test (Educational Testing Service, 2014). The modified Structure and Written 
Expression test included eight multiple choice structure questions, aimed at testing participants' ability to construct complete and grammatically correct sentences, and 12 multiple choice written expression questions, aimed at measuring participants' ability to detect errors in academic writing. The following areas of English grammar were addressed by the questions:

1. Auxiliary verbs (do or be)

2. Relative pronouns

3. Dependent phrases/modifiers

4. Past-tense infinitives

5. Placement of adjectives

6. Sentence components: subjects and verbs

7. Infinitives

8. Placement of adverbs

9. Avoiding redundancy of subjects

10. Comparative form of adverbs

11. Agreement of tenses

12. Word form (adj. vs. noun)

13. Word form (adj vs. adv)

14. Subject-verb agreement

15. Articles

16. Passive voice collocations

17. Singular/plural agreement (nouns)

18. Pronoun-antecedent agreement

19. Conjunctions

20. Count/non-count nouns

These items were chosen to provide a sampling of language issues, cutting across the language evenly to ensure that no grammatical issue is overemphasized and a variety of issues are addressed within the constraints of data collection (Dwyer, personal communication, August 17, 2015). 


\section{Pre-ENC1101 Coursework}

Pre-ENC 1101 coursework was the third independent variables in research questions 2 and 3. Information about participants' pre-ENC 1101 coursework was retrieved from college records. Developmental Education consists of two levels of two courses (reading and writing); thus, there were two variables. For each variable, a value of 0 meant that no coursework had been taken. A value of 1 indicated completion of one developmental education course. All graded attempts were counted regardless of grade. The English for Academic Purposes program consists of 6 levels of 4 courses (reading, writing, grammar, and speech/listening); thus, there were four variables. For each variable, a value of 0 meant that no coursework had been taken. A value of 1 indicated completion of one EAP course. All graded attempts were counted regardless of grade.

\section{Data Collection}

After I secured permissions from the Institutional Review Board at Florida International University, the College Academic and Student Support Council Research and Testing Committee at Miami Dade College, and the Campus Dean of Academic Affairs, the English and Communications Department Chairperson forwarded my email request for participation to full-time and part-time faculty. Twelve faculty members responded and invited me to collect data in their classes. During Fall 2015, I visited 28 classes taught by the 12 instructors. Data collection took one or two class sessions, depending on the length of class; evening classes that met once a week for a longer period of time were visited only once, while morning classes were visited twice. On the first day of administration, I explained the details of the study and privacy of information to participants as a group. The participants then received and signed the consent forms. 
Morning groups completed the modified BLP and modified TOEFL on the first day and the Gates-MacGinite booklet on the second day. Evening groups completed all instruments on the same day. Participants received no compensation, but complementary snacks were available. Most students needed about 100 minutes to complete the survey and tests. Because data collection took place during class time, students who opted out of the study were given a practice TOEFL test, which took approximately the same time to complete as the data collection instruments. Students were aware that the results of the tests were shared with the faculty members but the scores would not be used in grade calculations.

Participants' privacy was protected by using student ID numbers as identifiers instead of names. The use of student ID numbers was necessary to get participants' final ENC 1101 course grades and information regarding re-ENC 1101 coursework. However, no student ID numbers were published and the data were kept on an external hard drive locked securely when not used.

\section{Data Analysis}

Data analysis was conducted utilizing IBM's Statistical Package for Social Sciences (SPSS) 23. First, descriptive analysis was conducted to examine the characteristics of the sample in terms of age, sex, native language, cultural identification, age of arrival in the U.S., age at which literacy experiences began, literacy levels in each language, current exposure to English and the native language, pre-college ESOL services received. Pearson correlation analyses were conducted to describe the relationship between self-reported native language literacy, English language knowledge, pre-ENC 1101 coursework, English reading comprehension scores, and ENC 1101 
grades. After checking assumptions, I conducted standard multiple regression analyses to determine the predictive work of each of the predictor variables over and above the other predictor variables and to identify the variance explained by the independent variables altogether (Meyers, Gamst, \& Guarino, 2013).

\section{Summary}

This study (a) described the literacy backgrounds of generation 1.5 students at Miami Dade College and (b) examined the predictors of success in their English reading comprehension and English Composition 1 courses using Pearson correlation and standard multiple regression analysis. 


\section{CHAPTER IV}

RESULTS

This chapter describes the results of the data analysis conducted to answer the following research questions:

1. What literacy backgrounds do generation 1.5 students at Miami Dade College have?

2. What relationship exists between generation 1.5 students' native language literacy, English language knowledge, pre-ENC 1101 (Developmental Education or EAP) coursework and English reading comprehension?

3. What relationship exists between generation 1.5 students' native language literacy, English language knowledge, pre-ENC 1101 (Developmental Education or EAP) coursework and their performance in English Composition 1 (ENC 1101)?

\section{Research Question 1:}

\section{Literacy Backgrounds of Generation 1.5 Students at Miami Dade College}

During the fall semester of 2015, 454 students enrolled in 28 sections of English Composition 1 (ENC1101), Developmental Education Reading II (REA 0017), or Developmental Education Writing II (ENC 0025) participated in this study. The sample consisted of 107 generation 1.5 students (23.6\% of the total number of participants), 60 women $(56.1 \%)$ and 47 men (43.9\%). The majority (87 participants, $81.3 \%$ ) of the generation 1.5 participants were enrolled in ENC 1101, with most attending morning (71 participants, $66.4 \%$ ) or evening (19 participants, $17.8 \%$ ) sessions. They were less likely to take afternoon ( 9 participants, $8.4 \%$ ) or weekend college (8 participants, $7.5 \%$ ) 
classes. Descriptive data analysis was conducted using IBM's Statistical Package for Social Sciences (SPSS) 23. The sample was analyzed in terms of age of arrival in the United States, native languages (L1), literacy experiences, and levels of proficiency in reading, writing, and oral language in each language.

\section{Age of Arrival in the US}

Data regarding participants' age and age of arrival are displayed in Table 1. The mean age was 20.45 years. The mean age at which the participants arrived in the United States was 8.65 years and varied from 3 weeks of age to 18 years of age. Seventy-seven participants ( $72 \%$ of generation 1.5ers and $17 \%$ of the total sample) arrived in the United States at or after age 5, and 39 participants (36.4\% of generation $1.5 \mathrm{ers}$ and $8.6 \%$ of the total sample) arrived at or after age 12 .

Table 1

Age and Age of Arrival

\begin{tabular}{lccccc}
\hline \multicolumn{1}{r}{ Characteristics } & $\mathrm{n}$ & Min. & Max. & Mean & SD \\
\hline Age & 107 & 18 & 43 & 20.45 & 4.21 \\
Age of Arrival in U.S. & 107 & 0.05 & 18 & 8.65 & 4.97
\end{tabular}

\section{Native Languages}

Most generation 1.5 students in the sample considered Spanish (70 participants, 65.4\%) to be their L1. Haitian Creole (21 participants,19.6\%) was the second most common L1, followed by English ( 9 participants, $8.5 \%$ ), and other languages such as Chinese, French, Norwegian, Jamaican Patois (Patwa), and Portuguese (7 participants, $6.5 \%)$. The majority of the participants reported bilingual (78 participants, $72.9 \%$ ) or trilingual (22 participants, 20.6\%) competence. Data from the nine participants whose L1 
was English were used to answer research question 1; however, these data were excluded from the analysis to answer research questions 2 and 3.

\section{Literacy Experiences}

College records and self-reported data from the modified Bilingual Language Profile (BLP-M) reveal a wide array of literacy experiences in terms of language history, language use, attitudes toward language, and pre-college academic coursework.

Language history. Data regarding participants' linguistic background were selfreported on the BLP-M. Participants were encouraged to answer all questions on the survey but were allowed to skip questions with which they did not feel comfortable. Furthermore, participants who considered English their native language were directed to skip questions regarding the native language and answer only the questions relevant to English.

For most generation 1.5 students, the age at which they began learning English was consistent with the age of arrival in the United States. Seventy-two percent arrived in the United States at or after 5 years of age, and 69.8\% began learning English at or after age 5. In all cases, L1 acquisition had begun by age 5. A summary of participants' responses to four linguistic background questions is displayed in Table 2.

On average, participants received more formal education in English $(\bar{x}=10.95$ years, $n=103)$ than in L1 $(\bar{x}=7.08$ years, $n=99)$ although the time they spent in countries where English and L1 were spoken $\left(\bar{x}_{\text {English }}=11.79\right.$ years, $n=105 ; \bar{x}_{L 1}=10.39$ years, $n=99$ ) was nearly equal. They spent more time in families where L1 was spoken $\left(\bar{x}_{\text {English }}=8.59\right.$ years, $n=105 ; \bar{x}_{L 1}=18.44$ years, $\left.n=99\right)$. 
Table 2

Language History

\begin{tabular}{lcccc}
\hline \multirow{2}{*}{ Language History Event } & \multicolumn{4}{c}{ Age } \\
\cline { 2 - 5 } Started learning English & $0-4$ & $5-11$ & $12+$ & Not Yet \\
\hline \multirow{2}{*}{ Started learning L1 } & $(30.2 \%)$ & $(38.7 \%)$ & $(31.1 \%)$ & \\
Became comfortable with English & 97 & 1 & 0 & \\
& $(99 \%)$ & $(1 \%)$ & & \\
Became comfortable with L1 & 18 & 40 & 46 & 2 \\
& $(87.7 \%)$ & $(37.7 \%)$ & $(43.4 \%)$ & $(1.9 \%)$ \\
& $(6.1 \%)$ & $(3.1 \%)$ & $(3.1 \%)$ \\
\hline
\end{tabular}

Note: Missing responses were due to participants' ability to skip questions. Those who considered English to be their L1 were directed to answer the questions about English and skip questions about L1.

Language use. Data regarding language use were also self-reported on the BLP-M, and participants were allowed to skip questions. Generation 1.5 students reported English as the preferred language of communication with friends, but L1 was generally used to communicate with their families. Sixty-five percent of those who had a job spoke mainly English at their place of employment. Participants preferred English as a medium for thinking and counting. Data regarding generation 1.5 students' language use are displayed in Table 3.

Table 3

Language Use

\begin{tabular}{|c|c|c|c|c|c|c|c|}
\hline Questions & $\begin{array}{c}n \\
\text { Eng. }\end{array}$ & $\begin{array}{c}\% \\
\text { Eng. }\end{array}$ & $\begin{array}{c}n \\
\text { L1 }\end{array}$ & $\begin{array}{c}\% \\
\text { L1 }\end{array}$ & $\begin{array}{c}n \\
\text { Both }\end{array}$ & $\begin{array}{c}\% \\
\text { Both }\end{array}$ & $\begin{array}{c}n \\
\text { Total }\end{array}$ \\
\hline \multicolumn{8}{|l|}{ In an average week, which } \\
\hline $\begin{array}{l}\text { language do you use most often } \\
\text { with friends? }\end{array}$ & 81 & 75.7 & 21 & 19.6 & 5 & 4.7 & 107 \\
\hline $\begin{array}{r}\text { with family? } \\
\text { at work? }\end{array}$ & $\begin{array}{l}15 \\
70\end{array}$ & $\begin{array}{l}14.0 \\
65.4\end{array}$ & $\begin{array}{c}86 \\
4\end{array}$ & $\begin{array}{c}80.4 \\
3.7\end{array}$ & $\begin{array}{l}6 \\
7\end{array}$ & $\begin{array}{l}5.6 \\
6.5\end{array}$ & $\begin{array}{c}107 \\
81\end{array}$ \\
\hline \multicolumn{8}{|l|}{ In which language do you } \\
\hline think most often? & 72 & 67.3 & 29 & 27.1 & 6 & 5.6 & 107 \\
\hline count most often? ${ }^{\mathrm{a}}$ & 71 & 66.4 & 30 & 28.0 & 4 & 3.7 & 105 \\
\hline
\end{tabular}

${ }^{\mathrm{a}}$ Two participants reported counting in three languages. 
Language attitudes. Generation 1.5 students reported generally positive attitudes toward both English and their native languages. On a six-point Likert scale, most participants marked 5 or 6 for identification with both English (75 participants, 76.5\%) and L1 (81 participants, 82\%). They identified with both the American culture and their native culture: 56 participants (57\%) rated their identification with the American culture 5 or 6 on a 6-point scale, and 67 participants (69\%) rated their identification with the native culture 5 or 6 on a 6-point scale. Language attitudes reported on the BLP-M are displayed in Table 4.

Table 4

Language Attitudes

\begin{tabular}{|c|c|c|c|c|}
\hline \multirow[b]{2}{*}{ Statements } & \multicolumn{3}{|c|}{ Scale Scores } & \multirow[b]{2}{*}{$\begin{array}{c}n \\
\text { Total } \\
\end{array}$} \\
\hline & $\begin{array}{c}\text { Low } \\
0-2\end{array}$ & $\begin{array}{c}\text { Medium } \\
3-4\end{array}$ & $\begin{array}{c}\text { High } \\
5-6\end{array}$ & \\
\hline \multicolumn{5}{|l|}{ I feel like myself when I speak... } \\
\hline English. & 6 & 17 & 75 & 98 \\
\hline my native language. & 2 & 16 & 81 & 99 \\
\hline \multicolumn{5}{|l|}{ I identify with... } \\
\hline the American culture. & 13 & 29 & 56 & 98 \\
\hline my native culture. & 10 & 20 & 67 & 97 \\
\hline \multicolumn{5}{|l|}{ It is important to me to use (or eventually use)... } \\
\hline English like a native speaker. & 3 & 15 & 81 & 99 \\
\hline my native language like a native speaker. & 9 & 13 & 75 & 97 \\
\hline \multicolumn{5}{|l|}{ I want others to think I am a native speaker of... } \\
\hline English. & 29 & 27 & 42 & 98 \\
\hline my native language. & 16 & 21 & 61 & 98 \\
\hline
\end{tabular}

Pre-college academic English coursework. Participants' self-reported high school literacy experiences revealed that 35 participants (32.7\%) did not participate in K-12 ESOL. Generation 1.5 students who received ESOL services (65.4\%) were generally mainstreamed by Grade 12, with the exception of the 12 students who arrived 
in the U.S. at or after age 12 . Two students $(1.9 \%)$ did not provide data regarding K-12 ESOL coursework. Table 5 displays students' self-reported K-12 ESOL histories.

Table 5

K-12 ESOL Services by Age of Arrival

\begin{tabular}{cccc}
\hline Age of Arrival in & $n$ & $n$ & $n$ \\
U.S. (Years) & Total & K-12 ESOL & ESOL in Grade 12 \\
3 weeks -4.5 & 30 & 11 & 0 \\
$5-11$ & 38 & 27 & 0 \\
12 & 6 & 6 & 1 \\
13 & 10 & 10 & 3 \\
14 & 8 & 8 & 2 \\
15 & 6 & 2 & 2 \\
16 & 6 & 5 & 2 \\
17 & 2 & 0 & 1 \\
18 & 1 & 1 & 1 \\
\hline Total & 107 & 70 & 12 \\
\hline
\end{tabular}

Note: Two participants did not provide this information. Thirty-five participants did not receive ESOL services.

In college, few students took coursework to prepare them for college-level composition. Two students completed EAP coursework before enrolling in English Composition 1 (ENC1101). Although over $90 \%$ of the sample did not consider themselves native English speakers, only those 12 students who had received ESOL services in Grade 12 were tested with the COMPASS-ESL. Generation 1.5 students were more likely to enroll in Developmental Education courses than in EAP courses before ENC1101. Twenty-nine percent of the participants completed at least one developmental reading course, and $26.2 \%$ completed at least one developmental writing course.

Enrollment in developmental courses was required for non-exempt students, but exempt students could opt to take these courses first instead of enrolling directly in ENC1101. 


\section{Self-Reported Language Proficiency}

Participants were asked to rate their own functional and academic reading, writing, speaking, and listening comprehension abilities in each language in two scenarios (one functional and one academic) on a 6-point Likert scale ranging from 0 (not very well at all) to 6 (very well). Participants were most confident about their functional listening comprehension abilities in both languages and least confident about their academic reading, writing, and speaking abilities in their L1. Self-reported language proficiency data are displayed in Table 6.

Table 6

Self-Reported Language Proficiencies (Descending Means)

\begin{tabular}{lccccc}
\hline \multicolumn{1}{c}{ Proficiencies } & $n$ & Min. & Max. & $M$ & $S D$ \\
\hline Funct. Understanding Proficiency in English & 107 & 4 & 6 & 5.78 & .520 \\
Funct. Understanding Proficiency in L1 & 99 & 2 & 6 & 5.66 & .894 \\
Acad. Understanding Proficiency in English & 107 & 3 & 6 & 5.64 & .635 \\
Funct. Reading Proficiency in English & 107 & 3 & 6 & 5.62 & .760 \\
Funct. Writing Proficiency in English & 107 & 1 & 6 & 5.60 & .878 \\
Acad. Understanding Proficiency in L1 & 98 & 1 & 6 & 5.40 & 1.023 \\
Acad. Reading Proficiency in English & 107 & 3 & 6 & 5.38 & .797 \\
Funct. Speaking Proficiency in English & 106 & 2 & 6 & 5.30 & 1.044 \\
Funct. Reading Proficiency in L1 & 99 & 0 & 6 & 5.21 & 1.423 \\
Funct. Speaking Proficiency in L1 & 99 & 0 & 6 & 5.19 & 1.353 \\
Acad. Writing Proficiency in English & 107 & 2 & 6 & 5.13 & 1.029 \\
Funct. Writing Proficiency in L1 & 99 & 0 & 6 & 5.07 & 1.553 \\
Acad. Speaking Proficiency in English & 107 & 1 & 6 & 5.05 & 1.161 \\
Acad. Speaking Proficiency in L1 & 98 & 0 & 6 & 4.86 & 1.492 \\
Acad. Reading Proficiency in L1 & 98 & 0 & 6 & 4.79 & 1.528 \\
Acad. Writing Proficiency in L1 & 99 & 0 & 6 & 4.57 & 1.630 \\
\hline
\end{tabular}

Note: $n=107$; participants were allowed to skip questions. 


\section{Research Question 2:}

\section{Predictors of Generation 1.5 Students' English Reading Comprehension}

In this section, a summary of the study's first research hypothesis is followed by description of the variables and the results of the statistical analyses to investigate the relationship between generation 1.5 students' native language literacy, English language knowledge, pre-ENC 1101 coursework, and English reading comprehension.

\section{Hypothesis 1}

The study was guided by the hypothesis that generation 1.5 students' native language literacy, English language knowledge, and pre-ENC 1101 coursework are significant predictors of English reading comprehension. The following specific research hypotheses were stated:

a. There is a significant positive correlation between generation 1.5 students' native language literacy and English reading comprehension.

b. There is a significant positive correlation between generation 1.5 students' English language knowledge and English reading comprehension.

c. There is a significant correlation between generation 1.5 students' preENC1101 coursework and English reading comprehension.

d. Each independent variable (native language literacy, English language knowledge, pre-ENC1101 coursework) accounts for a significant unique variance independent of each other in generation 1.5 students' English reading comprehension. 
e. Together, the three independent variables (native language literacy, English language knowledge, pre-ENC1101 coursework) account for a significant unique variance in generation 1.5 students' English reading comprehension.

\section{Variables}

This section describes the dependent variable English reading comprehension and the independent variables native language literacy, English language knowledge, and preENC 1101 coursework. The characteristics of the variables used in the analyses are displayed in Table 7.

English reading comprehension. English reading comprehension, the dependent variable in research question 2, was measured by the reading comprehension component of Level AR of the Gates-MacGinitie reading test. Level AR of this test was designed for use by tertiary institutions that need to assess the general reading achievement of their students, and it was normed at community colleges across the United States. There were 48 multiple-choice questions on the test. Ninety-five participants completed the reading comprehension test. The mean score was 29.12 , and the standard deviation was 7.96.

Native language literacy. The independent variable native language literacy was averaged from participants' self-reported academic speaking, understanding, reading, and writing proficiency scores on the BLP-M for all participants whose L1 was other than English. The new variable, L1 literacy, ranged from 0.5 to 6, with a mean of 4.89 and standard deviation of 1.31 .

English language knowledge. The independent variable English language knowledge was computed as the aggregate score of the modified version of the TOEFL Structure and Written Expression Test (grammar) and the Vocabulary Subtest of Level 
AR of the Gates-McGinitie Reading Test. The new variable, English language knowledge ranged from 17 to 62 , with a mean of 41.79 and standard deviation of 9.29. This variable was used in further analyses.

Pre-ENC 1101 coursework. The independent variable, pre-ENC1101 coursework was computed as the aggregate of the number of Developmental Education and English for Academic Purposes courses. This variable was used in further analyses.

Table 7

Variables

\begin{tabular}{lcccccc}
\hline \multicolumn{1}{c}{ Variables } & $n$ & Min. & Max. & Mean & $S D$ & $V$ \\
\hline English Reading Comprehension & 95 & 12 & 47 & 29.12 & 7.96 & 63.4 \\
English Composition 1 Performance & 87 & 1 & 5 & 3.94 & 1.3 & 1.7 \\
L1 Literacy (Self-Reported) & 97 & 0.5 & 6 & 4.89 & 1.31 & 1.71 \\
English Language Knowledge & 94 & 17 & 62 & 41.79 & 9.29 & 86.4 \\
Pre- ENC 1101 Coursework & 107 & 0 & 16 & .91 & 1.92 & 3.69 \\
\hline
\end{tabular}

\section{Results of Pearson Correlations}

Pearson correlation analyses were conducted to describe the relationship between self-reported native language literacy, English language knowledge, pre-ENC 1101 coursework, and English reading comprehension scores.

As can be seen from Table 8, the correlation between generation 1.5 students' native language literacy and English reading comprehension was not statistically significant $(r=-.015, p=.89)$; therefore, hypothesis 1a was not supported.

However, the correlation between generation 1.5 students' English language knowledge and English reading comprehension was statistically significant $(r=.67$, $p<.001$ ), which supported hypothesis $1 \mathrm{~b}$. The association between English language knowledge and English reading comprehension was positive and fairly large. 
Similarly, the correlation between generation 1.5 students' pre-ENC 1101 coursework and English reading comprehension was statistically significant $(r=-.46$, $p<.001$ ), supporting hypothesis $1 \mathrm{c}$. However, the medium-strength association between pre-ENC1101 coursework and English reading comprehension was negative.

Table 8

Correlations, Means, and Standard Deviations for Reading Comprehension Scores, English Composition 1 Grades, L1 Literacy, English Language Knowledge, and Pre-ENC 1101Coursework

\begin{tabular}{lcccccc}
\hline \multicolumn{1}{c}{ Variables } & $M$ & $S D$ & 1 & 2 & 3 & 4 \\
\hline 1. Reading scores & 29.12 & 7.962 & & & & \\
2. ENC 1101 grades & 3.94 & 1.306 & $.33^{* *}$ & & & \\
3. L1 Literacy & 4.89 & 1.31 & -.02 & .12 & & \\
4. English Language Knowledge & 41.79 & 9.29 & $.67 * * *$ & $.26^{*}$ & -.02 & \\
5. Pre-ENC1101 Coursework & 0.91 & 1.92 & $-.46^{* * *}$ & -.12 & .02 & $-.49 * * *$ \\
${ }^{*} p<.05,{ }^{* * *}<<.001,{ }^{* * *} p<.001$ & & & & & &
\end{tabular}

Each separate component of English language knowledge had a significant positive correlation to English reading comprehension scores (English grammar knowledge $r=.48, p<.001$ and English vocabulary knowledge $r=.66, p<.001$ ).

A close examination of the components of the pre-ENC 1101 coursework variable revealed that the correlation between the number of Developmental Education courses taken and reading comprehension scores was significant and negative for both reading and writing courses (number of Dev. Ed. Reading courses $r=-.44, p<.001$ and number of Dev. Ed. Writing courses $r=-.37, p<.001)$. Similarly, the number of Developmental Education reading and writing courses and English language knowledge had significant negative correlations (number of Dev. Ed. Reading courses $r=-.46, p<.001$ and number of Dev. Ed. Writing courses $r=-.44, p<.001)$. The relationships between the number of EAP courses and reading comprehension scores was not statistically 
significant $(r=-.12, p=.25)$, nor was the relationship statistically significant between the number of EAP courses and English language knowledge $(r=-.04, p=.68)$. These correlations are displayed in Table 9.

Table 9

Correlations, Means, and Standard Deviations for Reading Comprehension Scores, English Composition 1 Grades, Academic Understanding Proficiency, Grammar Score, Vocabulary Score, and Number of Developmental Education Course

\begin{tabular}{llllllllll}
\hline Variables & $M$ & $S D$ & 1 & 2 & 3 & 4 & 5 & 6 \\
\hline
\end{tabular}

1. Reading score

2. ENC 1101 grades

3. Acad. Underst. Prof.

(L1 Literacy)

4. Grammar score (English lg. knowledge)

5. Vocabulary score (English lg. knowledge)

6. Number of Dev. Ed. Reading courses (Pre-ENC 1101)

7. Number of Dev. Ed.

$$
\text { Writing courses }
$$

29.127 .962

$3.94 \quad 1.306 \quad .33^{* *}$

$5.40 \quad 1.023$

.03

$.23^{*}$

14.593 .705

$.48 * * *$

$.27 * \quad .17$

$27.28 \quad 6.779$

$.66^{* * *}$

$\begin{array}{lll}.23 * & -.08 & .58 * * *\end{array}$

$$
.565
$$

$-.44 * * *$

$-.21$

$-.08$

$-.33^{* *}$

$-.43 * * *$

(Pre-ENC 1101)

Note: Components of the composite variables L1 literacy, English language knowledge, and pre-ENC 1101 coursework are shown only if their relationships to other variables were statistically significant.

$* p<.05, * * p<.001, * * * p<.001$

\section{Results of the Multiple Regression Analysis}

It was hypothesized that generation 1.5 students' native language literacy, English language knowledge, and pre-ENC 1101 coursework are significant predictors of their English reading comprehension. A close examination of the relationships between the 
predictor variables revealed that English language knowledge and the number of preENC 1101 courses correlated significantly $(r=-.49, p<.001)$. Meyers, Gamst, and Guarino (2013) recommended that predictors correlating at the middle .7 level or higher should not be used in the regression analysis together to prevent collinearity or multicollinearity. Because the correlation between English language knowledge and preENC 1101 coursework was not strong enough to cause a collinearity issue in this study, both predictors were used in the analysis. No correlation between the variables was high enough $(r>.7)$ to assume that they might be interchangeable (Meyers et al., 2013).

To determine the predictive work of L1 literacy, English language knowledge, and pre-ENC1101 coursework in English reading comprehension scores, and to identify the variance in reading scores explained by the independent variables altogether, standard multiple regression analysis was conducted (Meyers, Gamst, \& Guarino, 2013). As can be seen from Table 10, the prediction model was statistically significant, $F(3,79)=$ $26.09, p<.001$, and accounted for approximately $50 \%$ of the variance of English reading comprehension scores $\left(R^{2}=.498\right.$, Adjusted $\left.R^{2}=.479\right)$. English reading comprehension scores were primarily predicted by English language knowledge. L1 literacy and preENC1101 coursework were not statistically significant predictors. Therefore, hypothesis 1d was partially supported as only English language knowledge accounted for a significant unique variance in generation 1.5 students' English reading comprehension. Hypothesis 1e was also partially supported because although the regression model explained a significant unique variance in English reading comprehension scores, English language knowledge was the only significant contributor. 
Table 10

Predictors of English Reading Comprehension

\begin{tabular}{lccc}
\multicolumn{1}{c}{ Variables } & \multicolumn{3}{c}{ Model } \\
\hline Constant & 7.807 & 4.642 & $\beta$ \\
L1 Academic Literacy & -.152 & .466 & -.026 \\
English Language Knowledge & $.543^{*}$ & .085 & $.605^{*}$ \\
Pre-ENC 1101 Coursework & -.975 & .579 & -.161 \\
$R^{2}$ & .498 & & \\
$F$ & $26.093^{*}$ & & \\
\hline
\end{tabular}

Note: $n=83$

$* p<.001$

\section{Research Question 3: Predictors of Generation 1.5 Students' College Composition \\ Performance}

In this section, a summary of the study's second research hypothesis is followed

by description of the variables and the results of the statistical analyses to investigate the relationship between generation 1.5 students' native language literacy, English language knowledge, pre-ENC 1101 coursework, and ENC 1101 performance.

\section{Hypothesis 2}

The study was guided by the hypothesis that generation 1.5 students' native language literacy, English language knowledge, and pre-ENC1101 coursework are significant predictors of their performance in English Composition 1 (ENC 1101).

a. There is a significant positive correlation between generation 1.5 students' native language literacy and their performance in ENC 1101.

b. There is a significant positive correlation between generation 1.5 students' English language knowledge and their performance in ENC 1101.

c. There is a significant correlation between generation 1.5 students' preENC1101 coursework and their performance in ENC 1101. 
d. Each independent variable (native language literacy, English language knowledge, pre-ENC1101 coursework) accounts for a significant unique variance independent of each other in generation 1.5 students' performance in ENC 1101.

e. Together, the three independent variables (native language literacy, English language knowledge, pre-ENC1101 coursework) account for a significant unique variance in generation 1.5 students' performance in ENC 1101.

\section{Variables}

This section describes the dependent variable performance in college composition and the independent variables native language literacy, English language knowledge, and pre-ENC 1101 coursework. The characteristics of the variables used in the analyses are displayed in Table 7 above.

College composition performance. The dependent variable performance in college composition was measured by English Composition 1 (ENC 1101) grades, which were retrieved from college records after the conclusion of the term. Letter grades were coded on a 5-point scale. The number 1 was assigned to the grade of $\mathrm{F}$ as well as the grades of W and IW (withdrawn and withdrawn by instructor, respectively). The letter grades D, C, B, and A were assigned the numbers 2, 3, 4, and 5. Nearly fifteen percent (14.9\%) of the generation 1.5 participants failed ENC 1101. Another 14.9\% earned grades of C, while $21.8 \%$ earned B's and $48.3 \%$ earned A's.

Native language literacy. The independent variable native language literacy was averaged from participants' self-reported academic speaking, understanding, reading, and writing proficiency scores on the BLP-M for all participants whose L1 was other than 
English. The new variable, L1 literacy, ranged from 0.5 to 6 , with a mean of 4.89 and standard deviation of 1.31 .

English language knowledge. The independent variable English language knowledge was computed as the aggregate score of the modified version of the TOEFL Structure and Written Expression Test (grammar) and the Vocabulary Subtest of Level AR of the Gates-McGinitie Reading Test. The new variable, English language knowledge ranged from 17 to 62 , with a mean of 41.79 and standard deviation of 9.29 . This variable was used in further analyses.

Pre-ENC 1101 coursework. The independent variable pre-ENC1101 coursework was computed as the aggregate of the number of Developmental Education and English for Academic Purposes courses. This variable was used in further analyses.

\section{Results of Pearson Correlations}

Pearson correlation analyses were conducted to describe the relationship between self-reported native language literacy, English language knowledge, pre-ENC 1101 coursework, and ENC 1101 grades.

As the results displayed in Table 8 demonstrate, the correlation between generation 1.5 students' native language literacy and English Composition 1 performance was not significant $(r=.12, p=.29)$; therefore, hypothesis 2 a was not supported.

However, there was a small positive correlation between generation 1.5 students' English language knowledge and English Composition 1 performance, statistically significant at the $\alpha=.05$ level $(r=.26, p=.03)$. Thus, hypothesis $2 \mathrm{~b}$ was supported by the data. 
Hypothesis 2c was not supported as pre-ENC1101 coursework had no significant correlation to ENC 1101 performance $(r=-.12, p=.27)$.

The correlation between ENC 1101 grades and one component of L1 literacy, academic understanding proficiency was statistically significant $(r=.23, p=.04)$. Each component of English language knowledge had a significant positive correlation to ENC 1101 performance (English grammar knowledge $r=.27, p=.01$ and English vocabulary knowledge $r=.23, p=.04$ ). One component of pre-ENC 1101 coursework, the number of Developmental Education writing courses taken, was negatively correlated to ENC 1101 performance $(r=-.23 ; p=.03)$. These results are displayed in Table 9 above.

\section{Results of the Multiple Regression Analysis}

It was hypothesized that generation 1.5 students' native language literacy, English language knowledge, and pre-ENC 1101 coursework are significant predictors of their English Composition 1 (ENC 1101) performance. A close examination of the relationships between the predictor variables revealed that English language knowledge and the number of pre-ENC 1101 remedial courses taken in college correlated significantly $(r=-.49, p<.001)$. Meyers and colleagues (2013) recommended that predictors correlating at the middle .7 level or higher should not be used in the regression analysis together to prevent collinearity or multicollinearity. Because the correlation between English language knowledge and pre-ENC 1101 coursework was not strong enough to cause a collinearity issue in this study, both predictors were used in the analysis. No correlation between the variables was high enough $(r>.7)$ to assume that they might be interchangeable (Meyers et al., 2013). 
To determine the predictive work of L1 literacy, English language knowledge, and pre-ENC1101 coursework in ENC 1101 performance and to identify the variance in ENC 1101 grades explained by the independent variables altogether, standard multiple regression analysis was conducted (Meyers et al., 2013). As can be seen from Table 11, the prediction model was not statistically significant, $F(3,65)=2.17, p=1$. The three independent variables accounted for only $9 \%$ of the variance of English Composition 1 performance $\left(R^{2}=.09\right.$, Adjusted $\left.R^{2}=.05\right)$, and none of the independent variables entered were significant predictors. There was virtually no variance in the model that was uniquely explained by either one of the independent variables. Therefore, hypotheses $2 \mathrm{~d}$ and $2 \mathrm{e}$ were not supported as the independent variables did not account for a significant unique variance in ENC 1101 performance.

Table 11

Predictors of English Composition 1 Performance

\begin{tabular}{lccc} 
& \multicolumn{3}{c}{ Model } \\
\hline \multicolumn{1}{c}{ Variables } & $B$ & SE B & $\beta$ \\
\hline Constant & 1.919 & 1.106 & \\
L1 Academic Literacy & .116 & .123 & .112 \\
English Language Knowledge & .034 & .021 & .219 \\
Pre-ENC 1101 Coursework & -.097 & .155 &.-084 \\
$R^{2}$ & .09 & & \\
$F$ & 2.17 & & \\
Note: $n=69$ & & & \\
$*_{p}<.001$ & & &
\end{tabular}

\section{Summary}

The purpose of this chapter was to describe the literacy backgrounds of the generation 1.5 participants in this study and to examine the variables that may predict performance in English reading and writing. More than $20 \%$ of the total number of 
participants who completed the modified Bilingual Language Profile (BLP-M) belonged to the generation 1.5 group.

The generation 1.5 sample was analyzed in terms of age of arrival in the United States, native languages, literacy experiences, and levels of proficiency in reading, writing, and oral language in each language. The mean age at which the participants arrived in the United States was 8.65 years. While $65.4 \%$ of the 107 generation $1.5 \mathrm{ers}$ in the sample received ESOL services at some point in their K-12 careers, only 12 participants were still receiving ESOL services in their senior year. In college, 29\% of the participants completed at least one Developmental Education reading course, 26.2\% completed at least one Developmental Education writing course, and only two students completed English for Academic Purposes coursework before enrolling in the collegelevel English Composition 1.

Most generation 1.5 students in the sample considered Spanish (70 participants, 65.4\%) or Haitian Creole (21 participants, 19.6\%) to be their native language. College records as well as self-reported data from the BLP-M revealed a wide array of prior literacy experiences in terms of language history, language use, attitudes toward language, and pre-college academic coursework. On average, participants received more formal education in English than in the native language. Generation 1.5 participants used their native languages less frequently than they used English. On the other hand, they identified with both languages equally and they were more likely to identify with their native cultures than with the American culture.

The study's first hypothesis, that generation 1.5 students' native language literacy, English language knowledge, and pre-ENC 1101 coursework are significant predictors of 
English reading comprehension was partially supported by the data. The correlation between native language literacy and English reading comprehension was not statistically significant $(r=-.02, p=.89)$, but the correlations between English language knowledge and reading comprehension $(r=.67, p<.001)$ and pre-ENC 1101 coursework and reading comprehension $(r=-.46, p<.001)$ were statistically significant. The results of the regression analysis showed that only English language knowledge accounted for a significant unique variance in generation 1.5 students' English reading comprehension.

The study's second research hypothesis that generation 1.5 students' native language literacy, English language knowledge, and pre-ENC 1101 coursework are significant predictors of performance in English Composition 1 (ENC 1101) as measured by course grades was not supported by the data. The correlations between generation 1.5 students' native language literacy and English Composition 1 performance $(r=.12$, $p=.29)$ and pre-ENC 1101 coursework and ENC 1101 performance $(r=-.12$, $p=.27$ ) were not significant. There was only a small positive correlation between English language knowledge and English Composition 1 performance, statistically significant at the $\alpha=.05$ level $(r=.26, p=.03)$. None of the independent variables contributed to a significant amount of variance in ENC 1101 performance in the regression model. Chapter 5 discusses these results and their implications to research and practice. 


\section{CHAPTER V}

\section{DISCUSSION}

This chapter begins with a brief summary of the study followed by a discussion of the findings, their implications to research and practice, and recommendations for further research.

\section{Summary of the Study}

The purpose of this study was to address gaps in our understanding of the literacy backgrounds of generation 1.5 students at Miami Dade College. Although 45\% of the institution's students are nonnative speakers of English, there are no currently available data that describe the generation 1.5 student population (Miami Dade College, 2016c). Thus, this study was carried out to establish baseline data about this particular population of students and to investigate native language literacy, English language knowledge, and pre-ENC 1101 (Developmental Education or English for Academic Purposes) coursework as predictors of English reading comprehension and performance in collegelevel composition courses among generation 1.5 students.

Cummins's interdependence hypothesis (1979), common underlying proficiency theory (2005) and Bernhardt's (2011) compensatory model of second language reading provided the theoretical framework for this study. I was also interested in the impact of Developmental Education and English for Academic Purposes coursework for a number of reasons. First, it has been well documented in the literature that these preparatory programs may not be suitable to meet the specific literacy needs of generation 1.5 students (Blumenthal, 2002; Harklau, Siegal, \& Losey, 1999; Roberge, 2009). Second, recent legislative action in Florida made it possible for many recent public high school 
graduates, including generation 1.5 students, to enroll directly in College Composition 1 (ENC 1101) without taking any remedial coursework at all. The research questions asked whether native language (L1) literacy, English language knowledge, and pre-ENC 1101 coursework could predict English reading comprehension scores and performance in college-level composition courses among generation 1.5 students.

Two general research hypotheses guided this study. First, it was hypothesized that generation 1.5 students' L1 literacy, English language knowledge, and pre-ENC1101 (Developmental Education or EAP) coursework were significant predictors of English reading comprehension. The second hypothesis was that generation 1.5 students' L1 literacy, English language knowledge, and pre-ENC1101 coursework were significant predictors of their performance in ENC 1101.

\section{Discussion of the Findings}

In this section, some literacy background data will be highlighted followed by a discussion of the predictors of English reading comprehension and composition performance among generation 1.5 students.

\section{Research Question 1: Literacy Backgrounds of Generation 1.5 Students}

The results of the study indicated that $23.6 \%$ of the student body at Miami Dade College could potentially belong to the generation 1.5 group. While data regarding the exact numbers of generation 1.5 students are still limited, this finding suggests that the generation 1.5 student population at Miami Dade College may be at least comparable in size to the generation 1.5 student population at other diverse institutions nationwide (Jiang, 2016; Patthey et al., 2009). Considering that the percentage of non-native speakers 
in the sampling location is lower (39\%) than the college-wide percentage (45\%), the percentage of generation 1.5 students college-wide might be even higher.

The generation 1.5 group includes students who arrived in the United States at or after kindergarten age ( $72 \%$ of generation $1.5 \mathrm{ers}$ and $17 \%$ of the total sample). If these students entered schools in the United States with solid academic foundations in both English and their native languages, they likely have caught up academically with their native English speaker peers during their K-12 years (Collier, 1989; Thompson, 2015). Some generation 1.5 students in the present study arrived in the United States at or after age 12 (36.4\% of generation 1.5 ers and $8.6 \%$ of the total sample). In addition to prior formal L1 education and in English, these students needed continued academic development in L1 upon arrival while they were working on achieving academic levels of English language proficiency (Collier, 1989).

The optimal school environment for immigrant language minority students is one that provides academic support in the native language to ensure continued academic growth while English language acquisition is in its beginning stages (Thomas \& Collier, 2002). From the data collected for this study, it is difficult to tell with certainty the type of programs these students attended, but certain inferences could be made. First, only $65.4 \%$ of the generation 1.5 participants remembered receiving ESOL services at any time during their K-12 years. It is not clear whether the rest of the participants attended bilingual programs, were homeschooled, missed by placement procedures, or simply do not remember receiving ESOL services. From participants' answers to another question one can assume, however, that most of them did not attend bilingual programs. The question asked participants to indicate the length of time spent in formal education in 
each of their languages. Participants reported that on average, they received more formal education in English $(\overline{\mathrm{x}}=10.95$ years, $\mathrm{n}=103)$ than in the native language $(\overline{\mathrm{x}}=7.08$ years, $\mathrm{n}=99$ ). This suggests that formal education in L1 may have ceased at the time of arrival since the mean age of arrival was 8.6 years. Had the participants had access to dual-language programs, the mean time spent in formal education in L1 would have been reported at least as much or even more than the mean time spent in formal education in English. As Carter (2016) pointed out, despite having a large bilingual population, Miami Dade county has only a few bilingual programs and the majority of schoolchildren receive an English-only education.

Another survey item illustrates the case for continued development and community support for native languages. Respondents were evidently confused by survey item \#9, "How many years have you spent in a country/region where the following languages are spoken?" It was expected that given the geographical location of this study, the number of years spent in a country or a region where L1 was spoken would approximate the age of the respondents as nearly $86 \%$ of the participants were native speakers of Spanish or Haitian Creole, languages widely spoken in Miami-Dade county. On the contrary, participants reported spending only 10.39 years in countries/regions where the native language is spoken, while the average age of the participants was 20.45 . Clearly, many participants did not consider South Florida a place where their native languages are spoken. At the same time, they expressed positive attitudes toward their native cultures and languages. As contrary as these findings may seem, linguists often find that language perceptions often do not match language attitudes. With the idea of English monolingualism engrained in their subconscious, participants may not think of 
their home languages as mainstream, commonly spoken languages (Carter, personal communication, November 15, 2016).

Generation 1.5 students' responses to the BLP-M expose positive attitudes toward English and their L1 as well as the U.S. culture and native cultures. As the data displayed in Table 5 indicate, participants identified strongly with both English and L1 $(76.5 \%$ and $82 \%$, respectively). They identified with both the American culture and their native culture (57\% and 69\%, respectively). This finding may have important practical implications, which will be discussed later in this chapter.

\section{Research Question 2: Predictors of English Reading Comprehension}

The study's first hypothesis, that generation 1.5 students' native language literacy, English language knowledge, and pre-ENC 1101 coursework were significant predictors of English reading comprehension, was only partially supported by the data. Two of the three independent variables (English language knowledge and pre-college coursework) had significant correlations with the dependent variable English reading comprehension, but the correlation between L1 literacy and English reading comprehension was not statistically significant. While the regression model was significant and nearly $50 \%$ of the variance in English reading comprehension scores was explained, only one of the independent variables (English language knowledge) was a significant predictor.

English reading comprehension was measured by standardized instrument, Level AR of the Gates-MacGinitie reading test, often administered to non-native speakers of English (Kamhi-Stein, 1998; Roessingh, Kover, \& Watt, 2005). Test form T, used in this study, has Kuder-Richardson Formula 20 reliability coefficient 93 (Maria \& Hughes, 2008). Participants had sufficient time to complete the test; thus, while the authenticity 
and construct validity of multiple choice questions may be questioned, for the purposes of this study, the reading scores were considered valid and reliable.

Because the correlation between native language literacy and English reading comprehension was not statistically significant $(r=-.02, p=.89)$ and native language literacy was not a significant predictor of the variance in reading scores, the results of this study did not support the interdependence hypothesis and the common underlying proficiency theory. Furthermore, this study did fully not support Bernhardt's (2011) reading model, which asserts that native language literacy can explain up to $20 \%$ of the variance in second language reading scores.

These results should be interpreted with caution for several reasons. First, I used a broad definition of L1 literacy by including reading, writing, speaking, and listening ability in an attempt to expand the definition of L1 literacy used in prior studies where a measure of L1 reading ability was used to gauge L1 literacy (Bernhardt \& Kamil, 1995; Brisbois, 1995; Park, 2013; Pichette, Segalowitz, \& Connors, 2003; Yamashita, 2002; Yamashita \& Shiotzu, 2015). Yet, my definition of L1 literacy did not incorporate all elements suggested by Bernhardt's (2011) compensatory model, which also leaves the definition open for future variables to be included in the L1 literacy category. In Bernhardt's words, L1 literacy involves “how a reader's first language realizes L1 phonemics, how texts are structured, purposes for reading, beliefs about reading, knowledge of how words and sentences are structured, and so forth" (p. 35).

Furthermore, the measures I used to gauge L1 literacy were self-reported and may have been overestimated. Although Gertken, Amengual, and Birdsong (2014) argued that bilinguals could assess their language abilities correctly and the L1 proficiency items of 
the BLP-M showed high reliability $(\alpha=.95)$, Chiang and Schmida (1999) pointed out that generation 1.5 students often see themselves as bilingual even though they may not be academically literate in their native language. Indeed, on the 6-point Likert scale, the mean of the self-reported academic L1 literacy scores was 4.89 with low variability. The scores ranged from 0.5 to 6.0 with the median at 5.25. The frequency distributions of the variables used in this study can be found in Appendix D. An examination of the data points on the histogram reveals that the distribution is skewed left with fewer observations of lower values.

Not surprisingly, the correlation between English language knowledge and reading comprehension was significant $(r=.67, \mathrm{p}<.001)$ and English language knowledge accounted for a significant unique variance, approximately 50\%, in generation 1.5 students' English reading comprehension. In this regard, this study provided support for Bernhardt's (2011) compensatory reading model, which asserts that L2 language knowledge can explain $30 \%$ of the variance in L2 reading scores, but the contribution of English language knowledge to English reading comprehension was much larger than the contribution proposed by the model. There are at least two possible reasons to explain this finding. First, this study defined English language knowledge more narrowly than the model's definition of L2 knowledge, whose components were "grammatical form, vocabulary knowledge, the impact of cognates, the distance between first language and second language, the value system attached to literacy, and so forth" (Bernhardt, 2011, p. 35). This study defined English language knowledge only in terms of grammatical form and vocabulary knowledge. Second, it is possible that knowledge of the English language indeed compensated for the lack of variance explained by L1 literacy. 
Bernhard's model allows for compensation of the lack of a variable by other variables to assist the reader in the reading process, and the variables belonging to L1 literacy and L2 knowledge account for $50 \%$ of the variance in reading scores. Therefore, in the absence of a significant correlation between L1 literacy and English reading comprehension, English knowledge could have compensated for an additional $20 \%$ of the variance. This would be consistent with the findings of prior research indicating that the role of L1 literacy in L2 reading decreases as L2 knowledge increases (Park, 2013; Upton \& LeeThompson, 2001).

The negative correlation between pre-ENC 1101 coursework and reading comprehension was statistically significant $(r=-.46, p<.001)$. Although pre-ENC 1101 coursework did not contribute to the variance in reading scores, the direction of the correlation seems to provide support to the idea that traditional college remedial programs are not suited well for generation 1.5 students. However, in the absence of information about participants' academic preparedness before enrolling in remedial coursework, such conclusion cannot be drawn. It should also be pointed out that there was also a low variability in the independent variable pre-ENC 1101 coursework. Nearly $80 \%$ of participants did not take any developmental education courses, and only two participants completed EAP coursework. The values ranged from 0 to 16 with the mean value of 0.9 and the median value of 0 . An examination of the data points on the histogram in Appendix D reveals that the distribution is skewed right with fewer observations of higher values. 


\section{Research Question 3: Predictors of Performance in College Composition}

The study's second research hypothesis, that generation 1.5 students' native language literacy, English language knowledge, and pre-ENC 1101 coursework were significant predictors of performance in ENC 1101, was not supported by the data because only one of the three independent variables (English language knowledge) showed a small positive correlation to ENC 1101 performance. Furthermore, none of the independent variables contributed to a significant amount of variance in ENC 1101 performance in the regression model.

Low variability of the values of some variables may have influenced these results. The two independent variables native language literacy and pre-ENC1101 coursework, as discussed above, had low variability. In addition, values of the dependent variable, ENC 1101 performance ranged from 0 to 5 with the mean value of 3.94 and median value of 4. An examination of the data points on the histogram in Appendix D reveals that the distribution is skewed left with fewer observations of lower values.

Another issue with using course grades as a measure of performance is that course grades are composites of a number of components that are not always direct measures of writing ability. Completion of homework assignments, extra credit work, service learning projects, or even attendance and participation are examples of such components. The results should be interpreted with the understanding that data for this study were collected in 28 different sections taught by 12 different instructors. 


\section{Implications for Research and Practice}

The results of this study have several implications for research and practice. A discussion of these implications follows.

\section{Implications for Research}

The purpose of this study was to address gaps in our understanding of the literacy backgrounds of generation 1.5 students at Miami Dade College. In the first collection of academic writing dedicated specifically to issues that involved generation 1.5 students, Harklau, Losey, and Siegal (1999) pointed out that the numbers of these students were unknown because tertiary institutions collected no data on this population. Roberge (2009), in a second collection of scholarship on generation 1.5 students edited by Roberge, Siegal, and Harklau (2009), referred to "a dramatic increase in the number of students from immigrant families" (p. 3), but specific numbers were not available and are still not widely available today. Thus, this study contributed to the literature that aims to provide a better understanding of the numbers, the literacy foundations, and the instructional needs of this group.

This study's first research question should be further explored by administering the Bilingual Language Profile (BLP-M) or a similar literacy background survey at multiple locations to a larger sample or by including such demographic questionnaire in the application packet. Such data would be indispensable toward gaining a better understanding of this demographic and tailoring programming to their needs.

Future research could focus on further refining the BLP-M or developing a similar language background questionnaire. The BLP-M showed high reliability on language proficiency and language attitudes items. These items were central to this study, 
However, language use and language history items seemed to have been confusing and reduced the reliability of the instrument as a whole.

The present study's broad definition of generation 1.5 encompasses various developmental stages at which students arrive in the United States. Future studies could introduce age of arrival as a covariate in similar studies or investigate age of arrival as a predictor. Despite Jiang's (2016) finding that years spent in the United States did not influence placement levels of generation 1.5 students in his study, such studies could contribute to the body of research in determining the length of time needed to acquire second language cognitive academic language proficiency.

The generation 1.5 group is also diverse as far as literacy experiences prior to and after arrival in the United States. Future research could focus on the relationship between various K-12 programming options and college performance. Studies could compare, for instance, the performance of generation 1.5 students who had only a few years of formal L1 education because L1 education ceased upon arrival in the U.S. with the performance of those students who had several years of L1 education because they were enrolled in a bilingual program upon arrival in the US.

The results of this study failed to provide evidence of Cummins's theories, the interdependence hypothesis and the existence of a common underlying proficiency, as self-reported levels of native language literacy did not correlate with English reading comprehension and performance in ENC 1101. Nevertheless, the role of L1 literacy foundations in the English reading comprehension and academic performance of generation 1.5 students should be further investigated. While there is sufficient evidence in the literature to support the important role L1 literacy plays in L2 development, 
research has not focused enough on generation 1.5 students in this regard. Years of formal education in the L1 could be used as an indicator of L1 academic literacy; however, it would be desirable to utilize performance-based measures of academic L1 literacy in future studies to determine the predictive power of L1 literacy in the variance in generation 1.5 students' reading and writing performance. In the present study, selfreported measures of L1 literacy were utilized in order to include a variety of native languages and to provide an alternative to prior studies that by using a L1 reading test as a measure of L1 literacy defined L1 literacy too narrowly. While the L1 literacy items showed high reliability on the survey, participants may have overestimated their academic L1 literacy skills. Furthermore, it is possible that some participants had not had academic experiences such as reading a textbook or listening to a lecture in their native languages; therefore, how they rated their abilities in those scenarios may have been entirely hypothetical.

Another important area of investigation is the applicability and usefulness of the compensatory model of second language reading (Bernhardt, 2011) with non-native speakers of English in the United States in general and with generation 1.5 students in specific. Future research can be conducted to further define each category of variables included in the model, explain the compensatory process, and investigate the role of L1 literacy at various stages of L2 development. This research is crucial. Without adequate reading comprehension skills, college students will struggle in every course that requires extensive reading and research. The generation 1.5 group in this study had a mean reading comprehension score of 29.12 (60.67\%) on the 48-question Gates-MacGinitie 
Reading Test (GMRT). The difficulty of GMRT's Level AR, used in this study, is between $7^{\text {th }}$ and $9^{\text {th }}$ grade-level.

This study found statistically significant negative correlations between the number of pre-ENC 1101 courses taken and English reading comprehension scores as well as between the number of pre-ENC 1101 courses taken and ENC 1101 performance. However, the number of pre-ENC 1101 courses were not a significant predictor of the variance of either of the dependent variables. In the absence of information about the academic preparedness of the participants before they enrolled in remedial coursework, these results cannot be used to draw conclusions regarding the effectiveness of these programs, but the results provided a starting point for future studies. Future studies could further investigate the relationship between the various college remedial programs taken and academic performance among generation 1.5 students.

Future studies that investigate writing performance should utilize writing samples, writing portfolios, or other assessment tools that are more direct measures of writing performance than course grades. Research could compare the performance of generation 1.5 students with that of first generation immigrant students as well as native English speakers on objective measures of reading and writing. Studies that compared and contrasted generation 1.5 writing with L1 writing and L2 writing found contradictory evidence. Some found that generation 1.5 writing was more similar to L2 writing than to L1 writing, while others concluded that generation 1.5 writing has more in common with L1 writing than with L2 writing (Doolan, 2014). Researchers should use writing samples from generation 1.5 students from various literacy backgrounds to determine the specific areas of difficulty for those students. Studies that are conducted to draw such 
comparisons are in important first step in tailoring instruction to the specific needs of each group and designing intervention strategies that may be beneficial to all students.

\section{Implications for Practice}

The results of this study offer several implications to placement procedures, course design, and instruction for Miami Dade College and other institutions with similarly diverse student populations.

Placement procedures. The findings suggest that more than $20 \%$ of creditseeking students at Miami Dade College could be described as generation 1.5, who could benefit from instruction that addresses the specific academic needs of this group. The findings indicated that $70 \%$ of generation 1.5 students in this study did not take preENC1101 coursework. While some of them may have indeed been well prepared for the academic rigors of college-level composition, others simply could have been exempt from placement testing by the virtue of having graduated from a Florida public high school. These students could benefit from a placement procedure that incorporates a questionnaire to gauge the native language and literacy backgrounds of students.

Extensive advisement is standard practice at Miami Dade College for first-time-incollege, direct-entry students. Senior advisors have heart-to-heart conversations with incoming freshmen, especially if students are exempt from placement testing but existing test scores and remedial coursework completed at the high school-level suggest that they could benefit from more foundational work before entering college-level coursework. A literacy background questionnaire could provide students with a tool to examine their own beliefs and college readiness and advisors with additional crucial information to guide the discussion. 
While the findings of this study cannot support or deny the claim that current course placement options are ineffective for generation 1.5 students, more varied placement options would increase the sophistication in placement decisions. For instance, offering students the option to self-select a placement testing tool, a standard practice in many Californian community colleges (Patthey, Thomas-Spiegel, \& Dillon, 2009), would give generation 1.5 students to opportunity to select a tool more appropriate for testing nonnative English speakers. Relabeling both the placement instrument and the pre-ENC1101 course offering to avoid the ESL stigma, calling instead their target audience multilingual or bilingual writers, could result in reaching more generation 1.5 writers with more appropriate support.

Furthermore, because pre-ENC 1101 coursework is not counted toward the completion of any degree program, many students decide, understandably, against paying the tuition for such coursework and attempt required courses even if such decision is against their advisors' recommendations. Incentivizing enrollment in pre-ENC1101 coursework by offering elective credits would perhaps help convince those students who are currently exempt from placement testing requirements to take a placement test of their choice and enroll in the appropriate foundational coursework.

Course design and instruction. Data regarding attitudes toward language and culture have important implications for practice. Generation 1.5 students reported generally positive attitudes toward both English and their native languages. On a sixpoint Likert scale, most participants marked 5 or 6 for identification with both English (75 participants, $76.5 \%$ ) and L1 (81 participants, $82 \%$ ), respectively. They identified with both the American culture and their native culture: 56 participants (57\%) rated their 
identification with the American culture 5 or 6 on a 6-point scale, and 67 participants (69\%) rated their identification with the native culture 5 or 6 on a 6-point scale. These language identification data may be useful when designing course content as generation 1.5 students may have an interest in college composition courses that infuse literary works from students' heritage cultures, provide supplemental instruction to address fossilized language forms and even draw on contrastive analysis at times to increase students' cross-linguistic awareness (Harklau et al., 1999; Holten, 2009; Reynolds et al., 2009).

San Francisco State University pioneered a number of revolutionary ideas to counter traditional practices that were unsuited for the increasing generation 1.5 student population. Roberge (2009) provided the following bulleted summary of these reforms:

- Developing writing courses that draw upon multilingual/multicultural students' funds of knowledge and experiences growing up in California. (Multilingual students have the option of selecting these courses rather than more traditional ESL courses or generic "mainstream" courses.)

- Instituting self-guided placement processes. (Because we cannot assume multilingual students will have particular self-perceptions or identities, we allow students to have a voice in their own program placements.)

- Eliminating punitive remediation policies and creating intellectually enriching, credit-bearing freshman-level writing courses for students who would formerly have been sent to non-credit classes. 
- Reconceptualizing our College ESL program as a program open to all multilingual students and renaming the program for "Composition for Multilingual Students" to eliminate the stigmatizing "ESL" label.

- Developing workshops on editing and revising that support multilingual students in their regular Composition classes rather than tracking students into more traditional ESL writing courses or grammar courses.

- Instituting more professional development opportunities for both graduate students and faculty who want to learn to work with a wide variety of multilingual students. (The notion of generation 1.5 functions as a useful heuristic as teachers develop a more complex picture of the linguistic and cultural diversity of our student body.)

- Broadening teacher training in both the TESOL and Composition graduate programs. (New teachers coming out of both programs may have generation 1.5 students in their classes; p.7).

Each of these solutions is worth a discussion at Miami Dade College, where $45 \%$ of the student body has a native language other than English and where generation 1.5 students could make up one-fifth of the credit-seeking student population. Miami Dade College and institutions with similarly diverse student populations may consider multifaceted solutions. Offering courses and programs designed specifically for multilingual writers involve complex approval and implementation processes.

Other strategies, such as offering supplemental workshops, may be called into existence immediately and could be immensely beneficial in assisting generation 1.5 students enrolled in composition courses. The results of this study support supplemental 
instruction in English vocabulary, structure, and written expression as English language knowledge was the single most important predictor of the variance in generation 1.5 students' reading comprehension and the only variable that correlated with ENC 1101 performance. Staff in the writing center and ESL lab should collaborate on designing such supplementary workshops for multilingual writers enrolled in college composition courses. Literature on generation 1.5 writing patterns (de Kleine, Lawton, \& Woo, 2016; di Gennaro, 2013; Doolan, 2014; Doolan \& Miller, 2012; Schleppegrell, 2009) should consulted in determining workshop topics. In the writing center, tutors should be trained to assist generation 1.5 students (Frodensen \& Starna, 1999; Thonus, 2003). Finally, more consideration should be afforded to the native language, and its utilization in the classroom, particularly in the EAP classroom, should be explored.

\section{Limitations}

This study had several limitations. First, reliability and validity of the GatesMcGinitie Reading Test and the paper-based TOEFL instruments were estimated for populations that may have different characteristics from the generation 1.5 student population at Miami Dade College. Furthermore, the authors of the Bilingual Language Profile had not yet published validity and reliability data, and the instrument was modified to fit the characteristics of the target population and the purposes of the study. Second, it may be argued that the self-reported abilities to read, write, and understand and produce oral language in the native language are not precise measures of L1 literacy. Self-reported L1 proficiency data from the BLP-M suggested that participants may have overestimated their L1 ability. Like self-reported L1 literacy, the independent variable pre-ENC 1101 coursework also showed low variability, which may have also influenced 
the results. Similarly, course grades may not accurately measure English Composition 1 performance for reasons such as lack of standardization of assignments across courses, lack of standardization of grading criteria among faculty members, latent subjectivity, etc. Finally, the study did not measure all possible variables that could make up English language knowledge and L1 literacy as Bernhardt's compensatory model of second language reading (2011) provided an infinite, and therefore impractical, list of potential measurable variables that could fall into each category.

\section{Summary}

This chapter offered a brief summary of the study followed by a discussion of the findings and their implications to research and practice.

The purpose of this study was to establish baseline data about the generation 1.5 student population at Miami Dade College and to investigate native language literacy, English language knowledge, and prior college remedial (Developmental Education or EAP) coursework as predictors of English reading comprehension and performance in college-level composition courses among generation 1.5 students. The results of the study indicated that $23.6 \%$ of the students who completed the modified version of the Bilingual Language Profile questionnaire belonged to the generation 1.5 group. Most generation 1.5 students in the sample considered Spanish or Haitian Creole to be their native language. The study's first hypothesis, that generation 1.5 students' native language literacy, English language knowledge, and pre-ENC 1101 coursework were significant predictors of English reading comprehension was partially supported by the data. The study's second research hypothesis that generation 1.5 students' native language literacy, English language knowledge, and pre-ENC 1101 coursework were significant predictors 
of performance in ENC 1101 was not supported by the data. Low variability of the values the independent variables native language literacy and pre-ENC1101 coursework as well as the dependent variable ENC 1101 grades may have influenced these results.

A number of implications and recommendations for future research are discussed.

While the findings of this study did not fully support the theories that framed the study, research should continue to focus on the growing number of generation 1.5 students producing academic texts in higher education institutions. 


\section{REFERENCES}

Alderson, J. C. (1984). Reading in a foreign language: A reading problem or a language problem? In J.C. Alderson \& A.H. Urquhart (Eds), Reading in a foreign language (pp. 1-27). New York, NY: Longman.

Anton, M., \& DiCamilla, F. (1998). Socio-cognitive functions of L1 collaborative interaction in the L2 classroom. Canadian Modern Language Review, 54(3), 314-342.

Atwill, K., Blanchard, J., Gorin, J. S., \& Burstein, K. (2007). Receptive vocabulary and cross-language transfer of phonemic awareness in kindergarten children. The Journal of Educational Research, 100(6), 336-345.

August, D. \& Shanahan, T. (2006) (Eds.) Executive Summary. Developing Literacy in Second-Language Learners: Report of the National Literacy Panel on LanguageMinority Children and Youth. London, UK: Lawrence Erlbaum Associates, Publishers. Retrieved from http://www.cal.org/projects/archive/nlpreports/Executive_Summary.pdf

Augustyn, P. (2013). Translation and bilingual practice for German vocabulary teaching and learning. Die Unterrichtspraxis/Teaching German, 46(1), 27-43.

Barsony, I. (2015, November). Language profiles of EAP students at Miami Dade College. Paper presented at MDTESOL and Bilingual Education Association Fall Symposium, Miami, FL.

Bell, F. L., \& LeBlanc, L. B. (2000). The language of glosses in L2 reading on computer: learners' preferences. Hispania, 83(2), 274-285.

Belz, J. A. (2002). Second language play as a representation of the multicompetent self in foreign language study. Journal of Language, Identity, and Education, 1(1), 1339.

Bernhardt, E. B. (2011). Understanding advanced second-language reading. New York, NY: Routledge.

Bernhardt, E. B., \& Kamil, M. L. (1995). Interpreting relationships between L1 and L2 reading: Consolidating the linguistic threshold and the linguistic interdependence hypotheses. Applied Linguistics, 16(1), 15-34.

Birdsong, D., Gertken, L.M., \& Amengual, M. (2012). Bilingual language profile: An easy-to-use instrument to assess bilingualism. COERLL, University of Texas at Austin. Retrieved from https://sites.la.utexas.edu/bilingual/ 
Blanton, L.L. (1999). Classroom instruction and language minority students: On teaching to "smarter" readers and writers. In L. Harklau, M. Siegal, \& K. M. Losey (Eds.), Generation 1.5 meets English composition (pp. 119-142). Mahweh, NJ: Lawrence Erlbaum Associates.

Blumenthal, A. (2002). English as a second language at the community college: An exploration of context and concerns. New Directions for Community Colleges, $117,45-53$.

Bosher, S., \& Rowekamp, J. (1998). The refugee/immigrant in higher education: The role of educational background. College ESL, 8(1), 23-42.

Brisbois, J. (1995). Connections between first- and second language reading. Journal of Reading Behavior, 24, 565-584.

Burt, M., Peyton, J. K., \& Adams, R. (2003). Reading and adult English language learners: A review of the research. Washington, DC: Center for Applied Linguistics.

Carter, P.M. (2016, October). Miami: Bilingual in practice, but not in theory. Keynote address at MDTESOL and Bilingual Education Association Fall Symposium, Miami, FL.

Carson, J.E., Carrell, P.L., Silberstein, S., Kroll, B., \& Kuehn, P.A. (1990). Readingwriting relationships in first and second language. TESOL Quarterly, 24(2), pp. 245-266.

Carrell, P. (1991). Second language reading: Reading ability or language proficiency? Applied Linguistics, 12, 159-179.

Celik, M. (2003). Teaching vocabulary through code-mixing. ELT Journal, 57(4), 361369.

Chang, H. (2013). Instructional initiatives for English as a Second Language (ESL) students in introductory courses. Rochester: Social Science Research Network. doi: http://dx.doi.org/10.2139/ssrn.2212809

Chuang, H., Joshi, R. M., \& Dixon, L. Q. (2012). Cross-language transfer of reading ability: Evidence from taiwanese ninth-grade adolescents. Journal of Literacy Research, 44(1), 97-119. doi:http://dx.doi.org/10.1177/1086296X11431157

Clarke, M. A. (1980). The short circuit hypothesis of ESL reading — or when language competence interferes with reading performance. The Modern Language Journal, 64(2), 203-209.

Collier, V. P. (1989). How long? A synthesis of research on academic achievement in a second language. TESOL Quarterly, 23(3), 509-31. 
Cummins, J. (1979). Linguistic interdependence and the educational development of bilingual children. Review of Educational Research, 49(2), 222-251.

Cummins, J. (2000). Language, power, and pedagogy: Bilingual children in the crossfire. [Kindle version]. In C. Baker \& N. Hornberger (Series Eds.), Bilingual Education and Bilingualism, 23. Tonawanda, NY: Multilingual Matters Ltd.

Cummins, J. (2001). Bilingual children's mother tongue: why is it important for education? Sprogforum, 19, 15-20.

Cummins, J. (2005). Teaching for cross-linguistic transfer in dual language education: Possibilities and pitfalls. Paper presented at TESOL Symposium on Dual Language Education, Istambul, Turkey. Retrieved from http://www.tesol.org/docs/default-source/new-resource-library/symposium-ondual-language-education-3.pdf?sfvrsn $=0$

de Kleine, C., \& Lawton, R. (2015). Meeting the needs of linguistically diverse students at the college level (White paper). Retrieved from College Reading \& Learning Association website: http://www.crla.net/index.php/publications/crla-whitepapers

de Kleine, C., Lawton, R., \& Woo, M. (2016, April). Myths and misconceptions about generation 1.5 students. Panel presentation at Community College Day, TESOL Convention, Baltimore, MD.

di Gennaro, K. (2013). How different are they? A comparison of generation 1.5 and international L2 learners' writing ability. Assessing Writing, 18, 154-172.

Doolan, S. M. (2014). Comparing language use in the writing of developmental generation 1.5, L1, and L2 tertiary students. Written Communication, 31(2), 215247. DOI: $10.1177 / 0741088314526352$

Doolan, S. M., \& Miller, D. (2012). Generation 1.5 written error patterns: A comparative study. Journal of Second Language Writing, 21(1), 1-22.

Dwyer, E., \& Barsony, I. (2014, March). Deprofessionalizing TESOL: Questions of access, credential, colonialism, and elitism. Paper presented at TESOL International Convention, Portland, OR

Educational Testing Service (2014). Official guide to the TOEFL ITP test. U.S.A: Educational Testing Service

Educational Testing Service (2016).TOEFL ITP. Retrieved from http://www.ets.org/toefl_itp/about/

Faul, F., Erdfelder, E., Buchner, A., \& Lang, A.-G. (2009). Statistical power analyses using G*Power 3.1: Tests for correlation and regression analyses. Behavior Research Methods, 41, 1149-1160. 
Florida Department of Education. (2016). The Fact Book. Report for the Florida College System. Retrieved from https://www.floridacollegesystem.com/data.aspx

Florida Department of Education. (n.d.). Postsecondary Education Readiness Test (P.E.R.T.). Retrieved from http://www.fldoe.org/cc/pert.asp

Frodensen, J. \& Starna, N. (1999). Distinguishing incipient and functional bilingual writers: Assessment and instructional insights gained through second-language writer profiles. In L. Harklau, M. Siegal, \& K. M. Losey (Eds.), Generation 1.5 meets English composition (pp. 61-77). Mahweh, N.J.: Lawrence Erlbaum Associates.

Genesee, F., Lindholm-Leary, K., Saunders, B., \& Christian, D. (2006). Educating English Language Learners. Cambridge, UK: Cambridge University Press.

Gertken, L. M., Amengual, M., \& Birdsong, D. (2014). Assessing language dominance with the bilingual language profile. Measuring L2 Proficiency: Perspectives from SLA, Second Language Acquisition, 78, 208-225.

Godev, C. B., Martínez-Gibson, E. A., \& Toris, C. M. (2002). Foreign language reading comprehension test: L1 versus L2 in open-ended questions. Foreign Language Annals, 35(2), 202-221.

Goldschmidt, M. M, \& Miller, C. Z. (2005). Beyond the academic needs of generation 1.5. Research \& Teaching in Developmental Education, 21(2), 10-19.

Gottardo, A., Siegel, L. S., Wade-Woolley, L., \& Yan, B. (2001). Factors related to English reading performance in children with Chinese as a first language: More evidence of cross-language transfer of phonological processing. Journal of Educational Psychology, 93(3), 530-542.

Grabe, W. (1991). Current developments in second language reading research. TESOL Quarterly, 25(3), 375-405.

Grace, C. A. (1998). Retention of word meanings inferred from context and sentencelevel translations: implications for the design of beginning-level CALL software. The Modern Language Journal, 82(4), 533-544.

Grace, C. A. (2000). Gender differences: vocabulary retention and access to translations for beginning language learners in CALL. The Modern Language Journal, 84(2), 214-224.

Grant, R. A. \& Wong, S. D. (2003). Barriers to literacy for language minority learners: An argument for change in the literacy education profession. Journal of Adolescent \& Adult Literacy, (46)5, 386-394. 
Harklau, L., \& Siegal, M. (2009). Immigrant youth and higher education. In M. Roberge, M. Siegal, \& L. Harklau (Eds.), Generation 1.5 in English composition: Teaching academic writing to US-educated learners of ESL (pp. 25-34). New York, NY: Routledge.

Harklau, L., Siegal, M., Losey, K. M. (1999). Linguistically diverse students and college writing: What is equitable and appropriate? In L. Harklau, M. Siegal, \& K. M. Losey (Eds.), Generation 1.5 meets English composition (pp. 1-16). Mahweh, N.J.: Lawrence Erlbaum Associates.

Hebblethwaite, C. (2011, August 23). Should Creole replace French in Haiti's schools? BBC News. Retrieved from http://www.bbc.co.uk

Hinkle, D.E., Wiersma, W., \& Jurs, S.G. (2003). Applied statistics for the behavioral sciences. Belmont, CA: Wadsworth.

Holten, C. (2009). Creating an inter-departmental course for generation 1.5 ESL writers. In M. Roberge, M. Siegal, \& L. Harklau (Eds.), Generation 1.5 in English composition: Teaching academic writing to US-educated learners of ESL (pp. 170-185). New York, NY: Routledge.

Jiang, B., \& Kuehn, P. (2001). Transfer in the academic language development of postsecondary ESL students. Bilingual Research Journal, 25(4), 653-672.

Jiang, W. (2016, April). Myths and misconceptions about generation 1.5 students. Panel presentation at Community College Day, TESOL Convention, Baltimore, MD.

Jiang, X. (2011). The role of first language literacy and second language proficiency in second language reading comprehension. Reading Matrix: An International Online Journal, 11(2), 177-190.

Keating, G. D., VanPatten, B., \& Jegerski, J. (2011). Who was walking on the beach?. Studies in Second Language Acquisition, 33(02), 193-221.

Kern, R. (1994). The role of mental translation in second language reading. Studies in Second Language Acquisition, 16, 441-461.

Kirk, N. W., Fiala, L., Scott-Brown, K., \& Kempe, V. (2013). Do older Gaelic-English bilinguals show an advantage in inhibitory control? In Proceedings of the 35th annual conference of the Cognitive Science Society.

Krizman, J., Marian, V., Shook, A., Skoe, E., \& Kraus, N. (2012). Subcortical encoding of sound is enhanced in bilinguals and relates to executive function advantages. Proceedings of the National Academy of Sciences, 109(20), 7877-7881. 
Lasagabaster, D. (2001). The effect of knowledge about the L1 on foreign language skills and grammar. International Journal of Bilingual Education and Bilingualism, 4(5), 310-331.

Lee, J., \& Schallert, D. L. (1997). The relative contribution of L2 language proficiency and $\mathrm{L} 1$ reading ability to $\mathrm{L} 2$ reading performance: A test of the threshold hypothesis in an EFL context. TESOL Quarterly, 31(4), 713-739.

Libben, M. R., \& Titone, D. A. (2009). Bilingual lexical access in context: evidence from eye movements during reading. Journal of Experimental Psychology: Learning, Memory, and Cognition, 35(2), 381.

Maria, K. \& Hughes, K. E. (2008). Gates-MacGinitie reading tests. Forms S and T 20052006 renorming. Print and online equating. (Technical Report Supplement). Rolling Meadows, IL: Riverside Publishing.

McNeil, K., Newman, I., \& Fraas, J.W. (2012). Designing general linear models to test research hypotheses. Lanham, MD: University Press of America.

Miami Dade College. (n.d.). A brief history of the Gordon Rule at Miami Dade College (Part 3 of 3). Retrieved from https://www.mdc.edu/asa/student/gordon_rule_history3.asp

Miami Dade College. (2014a). Catalog 2014-2016. Retrieved from https://www.mdc.edu/main/images/MDC\%202014-2016\%20Catalog\%20_tcm689060.pdf

Miami Dade College. (2104b). Faculty credentials. Retrieved from http://www.mdc.edu/accreditation/faculty-credentials/associates.aspx\#E

Miami Dade College. (2014c). Student Achievement Initiatives. Outcomes. Retrieved from http://www.mdc.edu/sai/about-us/outcomes.aspx

Miami Dade College. (2016a). Fact book. Retrieved from https://www.mdc.edu/ir/datapages/factbook.aspx

Miami Dade College. (2016b). Placement criteria for academic year 2016-2017. Retrieved from http://www.mdc.edu/ir/Placement_Criteria_Documents/PCD_2016-2017.pdf

Muchisky, D. \& Tagren, N. (1999). Immigrant student performance in an academic intensive English program. In L. Harklau, M. Siegal, \& K. M. Losey (Eds.), Generation 1.5 meets English composition (pp. 211-234). Mahweh, N.J.: Lawrence Erlbaum Associates. 
Myers, L.S., Gamst, G., \& Guarino, A.J. (2013). Applied multivariate research: Design and interpretation. ( $2^{\text {nd }}$ edition). Thousand Oaks, C.A.: SAGE Publications.

National Center for Education Statistics (2014). Table 312.10. Enrollment of the 120 largest degree-granting college and university campuses, by selected characteristics and institution: Fall 2014. Retrieved from http://nces.ed.gov/programs/digest/d15/tables/dt15_312.10.asp

Newman, I., Newman, C., Brown, R., \& McNeely, S. (2006). Conceptual statistics for beginners. ( $\left.3^{\text {rd }} \mathrm{ed}\right)$. Lanham, MD: University Press of America.

Nguyen, A., Shin, F., \& Krashen, S. (2001). Development of the first language is not a barrier to second-language acquisition: Evidence from Vietnamese immigrants to the United States. International Journal of Bilingual Education and Bilingualism, $4(3), 159-164$.

Ortmeier-Hooper, C. (2008). English may be my second language, but I'm not ESL. College Communication and Composition, 59(3), 389-419.

Padrón, E. J. (2014). The Miami Dade College story: From segregated programs to college-wide inclusiveness and equity. Great Leadership, 7(1), 6-7.

Pappamihiel, N. E., Nishimata, T., \& Mihai, F. (2008). Timed writing and adult Englishlanguage learners: an investigation of first language use in invention strategies. Journal of Adolescent \& Adult Literacy, 51(5), 386-394.

Park, G. (2013). Relations among L1 reading, L2 knowledge, and L2 reading: Revisiting the threshold hypothesis. English Language Teaching, 6(12), pp. 38-47.

DOI:10.5539/elt.v6n12p38

Patthey, G., Thomas-Spiegel, J., \& Dillon, P. (2009). Educational pathways of generation 1.5 students in community college writing courses. In M. Roberge, M. Siegal, \& L. Harklau (Eds.). (2009). Generation 1.5 in English composition: Teaching Academic writing to US-educated learners of ESL (pp. 135-150). New York, NY: Routledge.

Peña, J. (2010). Engagement experiences of Hispanic generation 1.5 English language learners at a Massachusetts community college (Doctoral dissertation). Retrieved from ProQuest (858857283.)

Peng, C-Y. J., Long, H., \& Abaci, S. (2012). Power analysis software for educational researchers. The Journal of Experimental Education, 80(2), 113-136.

Pichette, F., Segalowitz, N., \& Connors, K. (2003). Impact of maintaining L1 reading skills on L2 reading skill development in adults: Evidence from speakers of Serbo-Croatian learning French. The Modern Language Journal, 87(3), 391-403. 
Proctor, C. P., August, D., Carlo, M. S., \& Snow, C. (2006). The intriguing role of Spanish language vocabulary knowledge in predicting English reading comprehension. Journal of Educational Psychology, 98(1), 159-169.

Qi, D. S. (1998). An inquiry into language-switching in second language composing processes. Canadian Modern Language Review, 54(3), 413-435.

Reese, L., Garnier, H., Gallimore, R., \& Goldenberg, C. (2000). Longitudinal analysis of the antecedents of emergent Spanish literacy and middle-school English reading achievement of Spanish-speaking students1. American Educational Research Journal, 37(3), 633-662. doi: http://dx.doi.org/10.3102/00028312037003633

Roberge, M. (2009). A teacher's perspective on generation 1.5. In M. Roberge, M. Siegal, \& L. Harklau (Eds.). (2009). Generation 1.5 in English composition: Teaching Academic writing to US-educated learners of ESL (pp. 3-23). New York, NY: Routledge.

Rodriguez, G. (2014, August 25). MDC TV Creole language show aims to impact and inspire Haitian students. The Reporter. Retrieved from http://www.mdc.edu/main/thereporter/archive/vol0501/news/mdc_tv_creole_language_show_aims_to_impa.aspx

Rodriguez, S. (2010). CPT results for students enrolled in level 5 \& 6 EAP courses. Retrieved from Miami Dade College, Institutional Research website: http://www.mdc.edu/ir/iremployees/2010-001_CPT-Level5\&6.pdf

Rodriguez, S. (2011). Placement test results for students enrolled in level 5 \& 6 EAP courses. Retrieved from Miami Dade College, Institutional Research website: https://www.mdc.edu/ir/iremployees/2011-001_Placement-Level5\&6.pdf

Roessingh, H., Kover, P., \& Watt, D. (2005). Developing cognitive academic language proficiency: The journey. TESL Canada Journal/Revue TESL Du Canada, 23(1), $1-27$.

Ronan, B. (2012). Community colleges and the work of democracy. Connections. Retrieved from https://www.kettering.org/catalog/product/connections-2012

Rumbaut, R. G. (1994). The crucible within: Ethnic identity, self-esteem, and segmented assimilation among children of immigrants. The International Migration Review, 28(4), 748-794.

Sagarra, N. \& Alba, M. (2006). The key is in the keyword: L2 vocabulary learning methods with beginning learners of Spanish. The Modern Language Journal, 90(2), 228-243. 
Schoonen, R., Van Gelderen, A., De Glopper, K., Hulstijn, J., Simis, A., Snellings, P., \& Stevenson, M. (2003). First language and second language writing: The role of linguistic knowledge, speed of processing, and metacognitive knowledge. Language Learning, 53(1), 165-202.

Schroeder, S. R., \& Marian, V. (2012). A bilingual advantage for episodic memory in older adults. Journal of Cognitive Psychology, 24(5), 591-601.

Schwartz, G.G. (2004). Coming to terms: Generation 1.5 students in mainstream composition. The Reading Matrix, 4(3), 40-57.

Schwartz, G.G. (2010). Subtexting mainstream generation 1.5 identities: Acculturation theories at work. In M. Cox, J. Jordan, C. Ortmeier-Hooper, \& G.G. Schwartz (Eds.). Reinventing identities in second language writing (pp. 29-50). Urbana, IL: National Council of Teachers of English.

Senate Bill 1720 (2013). An Act Relating to Education. Retrieved from http://www.flsenate.gov/Session/Bill/2013/1720

Slavin, R. \& Cheung, A. (2005). A synthesis of research on language of reading instruction for English language learners. Review of Educational Research, 75(2), 247-284.

Schleppegrell, M. J. (2009). Grammar for generation 1.5: A focus on meaning. In M. Roberge, M. Siegal, \& L. Harklau (Eds.). (2009). Generation 1.5 in English composition: Teaching Academic writing to US-educated learners of ESL (pp. 221-234). New York, NY: Routledge.

Sparks, R.L., Patton, J., Ganschow, L., Humbach, N., \& Javorsky, J. (2006). Native language predictors of foreign language proficiency and foreign language aptitude. Annals of Dyslexia, 56(1), 129-160.

Stepick, A. (1998). Pride against prejudice: Haitians in the United States. Needham Heights, MA: Allyn \& Bacon.

Storch, N., \& Wigglesworth, G. (2003). Is there a role for the use of the L1 in an L2 setting? TESOL Quarterly, 37(4), 760-770.

Strebel Halpern, C. (2009). An investigation of linguistic, cognitive, and affective factors that impact English language learners' performance on a state standardized reading achievement test (Doctoral dissertation). Retrieved from ProQuest (3401101.)

Thomas, W. P., \& Collier, V. (2002). A national study of school effectiveness for language minority students' long-term academic achievement. Santa Cruz, CA:

Center for Research on Education, Diversity \& Excellence, University of California. 
Thompson, K. D. (2015). English learners' time to reclassification: An analysis.

Educational Policy, 1-34. DOI: 10.1177/0895904815598394.

Thonus, T. (2003). Serving Generation 1.5 learners in the university writing center. TESOL Journal, 12(1), 17-24.

Upton, T., \& Lee-Thompson, L. (2001). The role of the first language in second language reading. SSLA, 23, 469-495.

Van Gelderen, A., Schoonen, R., Stoel, R. D., de Glopper, K., \& Hulstijn, J. (2007). Development of adolescent reading comprehension in language 1 and language 2: A longitudinal analysis of constituent components. Journal of Educational Psychology, 99(3), 477-491.

Wang, L. (2003). Switching to first language among writers with differing secondlanguage proficiency. Journal of Second Language Writing, 12, 347-375.

Woodall, B. R. (2002). Language switching: Using the first language while writing in a second language. Journal of Second Language Writing, 11, 7-28.

Yamashita, J. (2002). Influence of L1 reading on L2 reading: different perspectives from the process and product of reading. Studies in Language and Culture, 23(2), 271283.

Yamashita, J. \& Shiotsu, T. (2015). Comprehension and knowledge components that predict L2 reading: A latent trait approach. Applied Linguistics, 1-26.

Zhang, D. (2012). Vocabulary and grammar knowledge in second language reading comprehension: A structural equation modeling study. The Modern Language Journal, 96(4), 558-575. 
APPENDICES 


\section{APPENDIX A \\ Modifications to the Bilingual English Profile}

(Explanation and additional information appear in parentheses.) The Modified Bilingual Language Profile can be found in Appendix B.

\begin{tabular}{|c|c|c|}
\hline $\begin{array}{c}\text { Survey } \\
\text { Sections } \\
\end{array}$ & $\begin{array}{c}\text { Bilingual Language Profile } \\
\text { (BLP) }\end{array}$ & $\begin{array}{c}\text { Modified Bilingual Language } \\
\text { Profile (BLP-M) } \\
\end{array}$ \\
\hline Instructions & $\begin{array}{l}\text { We would like to ask you to help } \\
\text { us by answering the following } \\
\text { questions concerning your } \\
\text { language history, use, attitudes, } \\
\text { and proficiency. This survey was } \\
\text { created with support from the } \\
\text { Center for Open Educational } \\
\text { Resources and Language Learning } \\
\text { at the University of Texas at } \\
\text { Austin to better understand the } \\
\text { profiles of bilingual speakers in } \\
\text { diverse settings with diverse } \\
\text { backgrounds. The survey consists } \\
\text { of } 19 \text { questions and will take less } \\
\text { than } 10 \text { minutes to complete. This } \\
\text { is not a test, so there are no right } \\
\text { or wrong answers. Please answer } \\
\text { every question and give your } \\
\text { answers sincerely. Thank you } \\
\text { very much for your help. }\end{array}$ & $\begin{array}{l}\text { This form was developed by } \\
\text { researchers at the University of } \\
\text { Texas at Austin to assess bilingual } \\
\text { language dominance. For the } \\
\text { purposes of the current study, it } \\
\text { has been modified to gain a better } \\
\text { understanding of Miami Dade } \\
\text { College students' language } \\
\text { backgrounds and perceived } \\
\text { academic language proficiency. } \\
\text { The survey contains } 23 \text { questions } \\
\text { and takes about } 15 \text { minutes to } \\
\text { complete. This is not a test. There } \\
\text { are no right or wrong } \\
\text { answers.Please answer every } \\
\text { question sincerely. Your personal } \\
\text { information will be protected. } \\
\text { Thank you for your help. }\end{array}$ \\
\hline $\begin{array}{l}\text { Biographical } \\
\text { Information }\end{array}$ & $\begin{array}{l}\text { (The BLP is L1-specific, e.g. } \\
\text { English-Spanish. No Haitian- } \\
\text { Creole version) }\end{array}$ & $\begin{array}{l}\text { MDC Student ID\#, Date, Age, } \\
\text { Sex, Place of Residence (Items } \\
\text { added to identify gen } 1.5: \text { ) Were } \\
\text { you born in the U. S.? How old } \\
\text { were you when you came to live in } \\
\text { the U.S.? Did you graduate from a } \\
\text { U.S. high school? Were you in an } \\
\text { ESOL program in 12th grade? } \\
\text { Were you in an ESOL program at } \\
\text { any time before } 12^{\text {th }} \text { grade? What } \\
\text { is your native language? What } \\
\text { other languages do you speak? } \\
\text { (The BLP-M is general and can be } \\
\text { used with any L1.) }\end{array}$ \\
\hline $\begin{array}{l}\text { Language } \\
\text { Proficiency }\end{array}$ & $\begin{array}{l}\text { (Language Proficiency is Section } \\
\text { IV of the BLP. Questions from the } \\
\text { English-Spanish form are used } \\
\text { below.) }\end{array}$ & $\begin{array}{l}\text { (This section is promoted to } \\
\text { Section II due to the importance of } \\
\text { perceived language proficiency to } \\
\text { the current study in order to }\end{array}$ \\
\hline
\end{tabular}




\begin{tabular}{|c|c|c|}
\hline $\begin{array}{l}\text { Survey } \\
\text { Sections }\end{array}$ & $\begin{array}{c}\text { Bilingual Language Profile } \\
\text { (BLP) }\end{array}$ & $\begin{array}{c}\text { Modified Bilingual Language } \\
\text { Profile (BLP-M) }\end{array}$ \\
\hline & $\begin{array}{l}\text { 12. a. How well do you speak } \\
\text { English? } \\
\text { b. How well do you speak } \\
\text { Spanish? } \\
\text { 13. a. How well do you } \\
\text { understand English? } \\
\text { b. How well do you understand } \\
\text { Spanish? } \\
\text { 14. a. How well do you read } \\
\text { English? } \\
\text { b. How well do you read Spanish? } \\
\text { 15. a. How well do you write } \\
\text { English? } \\
\text { b. How well do you write } \\
\text { Spanish? }\end{array}$ & 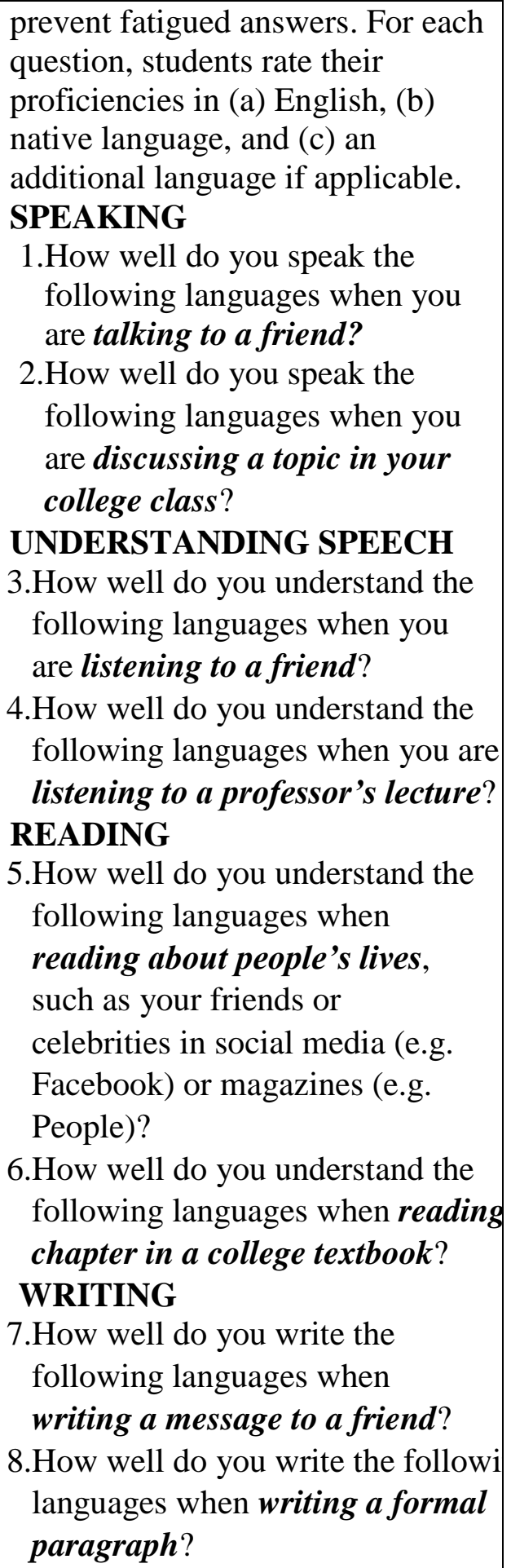 \\
\hline
\end{tabular}




\begin{tabular}{|c|c|c|}
\hline $\begin{array}{l}\text { Survey } \\
\text { Sections }\end{array}$ & $\begin{array}{c}\text { Bilingual Language Profile } \\
\text { (BLP) }\end{array}$ & $\begin{array}{c}\text { Modified Bilingual Language } \\
\text { Profile (BLP-M) }\end{array}$ \\
\hline $\begin{array}{l}\text { Language } \\
\text { history }\end{array}$ & $\begin{array}{l}\text { (Language history is Section II of } \\
\text { the BLP.) }\end{array}$ & $\begin{array}{l}\text { (Language history is Section III of } \\
\text { the BLP-M. Questions in this } \\
\text { section were not changed.) }\end{array}$ \\
\hline $\begin{array}{l}\text { Language } \\
\text { use }\end{array}$ & $\begin{array}{l}\text { (Language use is Section III of the } \\
\text { BLP.) } \\
\text { 7.In an average week, what } \\
\text { percentage of the time do you } \\
\text { use the following languages } \\
\text { with friends? } \\
\text { 8.In an average week, what } \\
\text { percentage of the time do you } \\
\text { use the following languages } \\
\text { with family? } \\
\text { 9.In an average week, what } \\
\text { percentage of the time do you } \\
\text { use the following languages at } \\
\text { school/work? } \\
\text { 10. When you talk to yourself, } \\
\text { how often do you talk to } \\
\text { yourself in the following } \\
\text { languages? } \\
\text { 11. When you count, how often } \\
\text { do you count in the following } \\
\text { languages? }\end{array}$ & $\begin{array}{l}\text { (Language use is Section IV of the } \\
\text { BLP-M.) } \\
\text { 15. In an average week, which } \\
\text { language do you use most } \\
\text { often with friends? } \\
\text { 16. In an average week, which } \\
\text { language do you use most } \\
\text { often with family? } \\
\text { 17. In an average week, which } \\
\text { language do you use most often } \\
\text { work? } \\
\text { 18. In which language do you } \\
\text { think most often? } \\
\text { 19. In which language do you } \\
\text { count most often? }\end{array}$ \\
\hline $\begin{array}{l}\text { Language } \\
\text { attitudes }\end{array}$ & $\begin{array}{l}\text { (Language attitudes is Section V } \\
\text { of the BLP.) }\end{array}$ & $\begin{array}{l}\text { (Language attitudes is Section V } \\
\text { of the BLP-M. Questions in this } \\
\text { section were not changed.) }\end{array}$ \\
\hline
\end{tabular}




\section{APPENDIX B}

\section{The Modified Bilingual Language Profile}

\section{Bilingual Language Profile-Modified (BLP-M)}

This form was developed by researchers at the University of Texas at Austin to assess bilingual language dominance. For the purposes of the current study, it has been modified to gain a better understanding of Miami Dade College students' language backgrounds and perceived academic language proficiency.

The sunvey contains 23 questions and takes about 15 minutes to complete. This is not a test.

There are no right or wrong answers.

Non-native speakers of English: Please complete all sections.

Native English speakers: Ahays skip (b) in Sections II and III. Stop after completing Section IV on page 5.

Please answer each question sincerely. Your personal information will be protected.

Thank you for your help.

\section{Biographical Information}

MDC Student ID\#: Today's Date:

Age:

$\square$ Male $\square$ Female

Where do you live? (city) (county) (state)

A. Were you born in the United States?

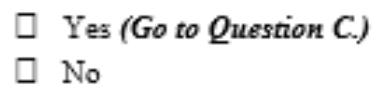

B. How old were you when you came to live in the U.S.?

C. Did you graduate from a U.S. high gchool?

口 Yes

1. No (Go to Question F.)

D. Were you in an ESOL program in $12^{\text {th }}$ grade?

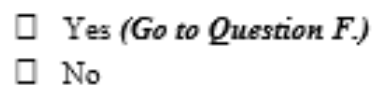

E. Were you in an ESOL program at any time before $12^{\text {th }}$ grade?

1) Yes
$\square$ No

F. What is your native language?

G. What other languages do you speak? 


\section{Language Proficiency}

Please rate your knowledge in each of your languages by placing checkmarks in the appropriate boxes. NATIVE ENGLISH SPEAKERS: Please respond to (a). Skip (b). Respond to (c) if applicable.

\section{SPEAKING}

1. How well do you speak the following languages when you are talking to a friend?

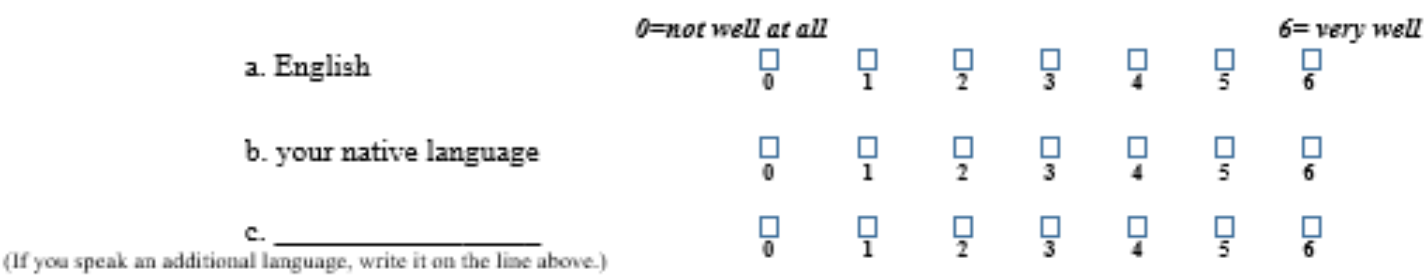

2. How well do you speak the following languages when you are discussing a topic in your college class?

\begin{tabular}{|c|c|c|c|c|c|c|c|}
\hline a. Engligh & $\begin{array}{c}0=\text { not well at all } \\
\square \\
0\end{array}$ & $\stackrel{\square}{1}$ & $\frac{\square}{2}$ & $\frac{\square}{3}$ & $\square$ & $\frac{\square}{5}$ & $\begin{array}{c}6=\text { very well } \\
\frac{\square}{6}\end{array}$ \\
\hline b. your native language & $\square_{0}$ & $\stackrel{\square}{1}$ & $\frac{\square}{2}$ & $\frac{\square}{3}$ & $\square$ & $\frac{\square}{5}$ & $\stackrel{\square}{6}$ \\
\hline c. & $\square_{0}$ & $\frac{\square}{1}$ & $\frac{\square}{2}$ & $\frac{\square}{3}$ & $\square$ & $\frac{\square}{5}$ & $\square_{6}$ \\
\hline
\end{tabular}

\section{UNDERSTANDING SPEECH}

3. How well do you understand the following languages when you are listening to a friend?

\begin{tabular}{|c|c|c|c|c|c|c|c|}
\hline a. English & $\begin{array}{c}0=\text { not well at all } \\
\square \\
0\end{array}$ & $\stackrel{\square}{1}$ & $\frac{\square}{2}$ & $\frac{\square}{3}$ & $\square$ & $\frac{\square}{5}$ & $\begin{array}{c}6=\text { very well } \\
\square \\
6\end{array}$ \\
\hline b. your native language & $\square_{0}$ & $\stackrel{\square}{1}$ & $\frac{\square}{2}$ & $\frac{\square}{3}$ & $\square$ & $\frac{\square}{5}$ & $\frac{\square}{6}$ \\
\hline c. & $\square_{0}$ & $\stackrel{\square}{1}$ & $\frac{\square}{2}$ & $\frac{\square}{3}$ & $\square$ & $\frac{\square}{5}$ & $\frac{\square}{6}$ \\
\hline
\end{tabular}

4. How well do you understand the following languages when you are listening to a professor's lecture?
a. English
$0=$ not well at all
b. your native language
c.
(additional language)

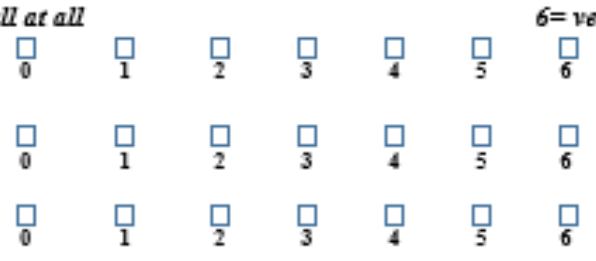

Survey Page 2 of 6 


\section{READING}

5. How well do you understand the following languages when reading about people's lives, such as your friends or celebrities in social media (e.g. Facebook) or magazines (e.g. People)?
a. English
b. your native language
c.
(additional language)

$0=$ not well at all

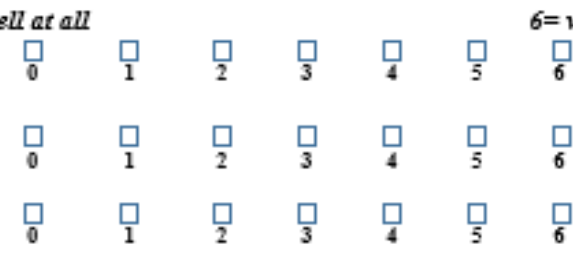

6. How well do you understand the following languages when reading a chapter in a college textbook?

\begin{tabular}{|c|c|c|c|c|c|c|c|}
\hline a. English & $\begin{array}{c}0=\text { not well at all } \\
\square \\
0\end{array}$ & $\frac{\square}{1}$ & $\frac{\square}{2}$ & $\frac{\square}{3}$ & $\frac{\square}{4}$ & $\frac{\square}{5}$ & $\begin{array}{c}6=v e r y \text { well } \\
\frac{\square}{6}\end{array}$ \\
\hline b. your native language & $\square_{0}$ & $\stackrel{\square}{1}$ & $\frac{\square}{2}$ & $\frac{\square}{3}$ & 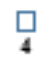 & $\frac{\square}{5}$ & $\frac{\square}{6}$ \\
\hline c. & $\square_{0}^{\circ}$ & $\frac{1}{1}$ & $\frac{\square}{2}$ & $\frac{\square}{3}$ & $\square_{4}$ & $\frac{\square}{5}$ & $\frac{\square}{6}$ \\
\hline
\end{tabular}

\section{WRITING}

7. How well do you write the following languages when writing a message to a friend?

\begin{tabular}{|c|c|c|c|c|c|c|c|}
\hline a. English & $\begin{array}{c}0=\text { not well at all } \\
\square \\
0\end{array}$ & $\stackrel{\square}{1}$ & $\frac{\square}{2}$ & $\frac{\square}{3}$ & $\square_{4}$ & $\frac{\square}{5}$ & $\begin{array}{c}6=\text { very well } \\
\square \\
6\end{array}$ \\
\hline b. your native language & $\square_{0}$ & $\stackrel{\square}{1}$ & $\frac{\square}{2}$ & $\frac{\square}{3}$ & $\square_{4}$ & $\frac{\square}{5}$ & $\underset{6}{\square}$ \\
\hline c. & $\square_{0}$ & $\stackrel{\square}{1}$ & $\frac{\square}{2}$ & $\frac{\square}{3}$ & $\square$ & $\frac{\square}{5}$ & $\frac{\square}{6}$ \\
\hline
\end{tabular}

8. How well do you write the following languages when sriting a formal paragraph?

\begin{tabular}{|c|c|c|c|c|c|c|c|}
\hline a. English & $\begin{array}{c}0=\text { not well at all } \\
\square \\
0\end{array}$ & $\stackrel{\square}{1}$ & $\frac{\square}{2}$ & $\frac{1}{3}$ & $\frac{\square}{4}$ & $\frac{\square}{5}$ & $\begin{array}{c}6=\text { very well } \\
\square \\
6\end{array}$ \\
\hline b. your native language & $\square_{0}$ & $\underset{1}{\square}$ & $\frac{\square}{2}$ & $\frac{\square}{3}$ & $\square_{4}^{\square}$ & $\frac{\square}{5}$ & $\frac{\square}{6}$ \\
\hline c. & $\square_{0}$ & $\stackrel{\square}{1}$ & $\frac{\square}{2}$ & $\frac{\square}{3}$ & $\underset{4}{\square}$ & $\frac{\square}{5}$ & $\frac{\square}{6}$ \\
\hline
\end{tabular}




\section{Language History}

Please answer the questions by placing checkmarks in the appropriate boxes. NATIVE ENGLISH SPEAKERS: Please respond to (a). Skip (b). Respond to (c) if applicable.

\section{At what age did you start learning the following languages?}

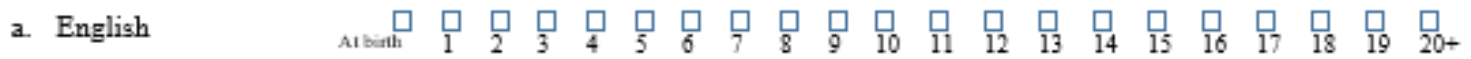

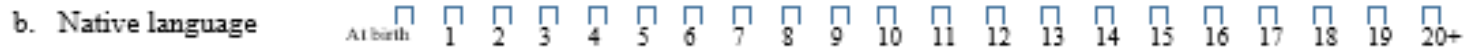

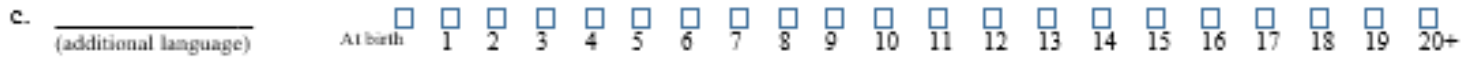

10. At what age did you start to feel comfortable using the following languages?

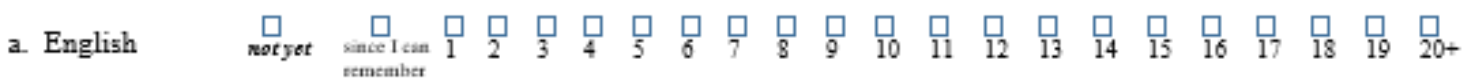

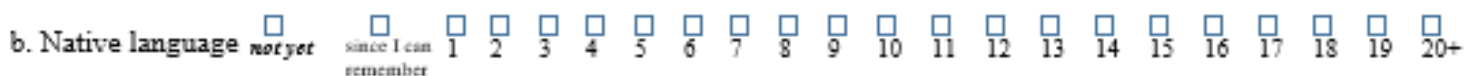
c.

11. How many years of classes (grammar, history, math, etc.) have you had in the following languages? (From elementary school through college)

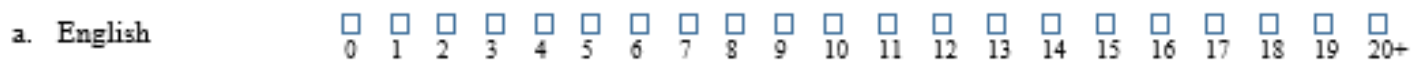

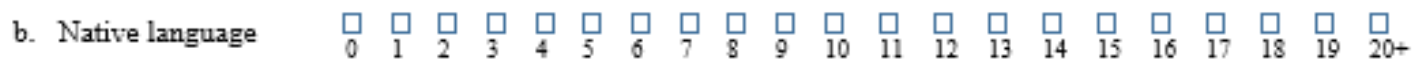

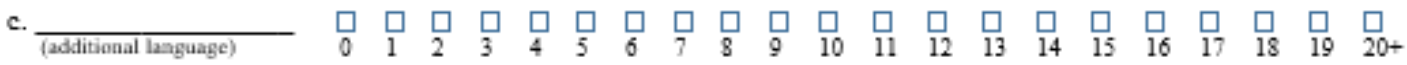

12. How many years have you spent in a country/region where the following languages are spoken?

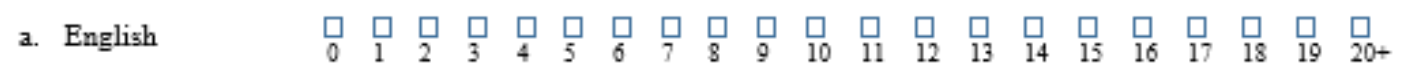

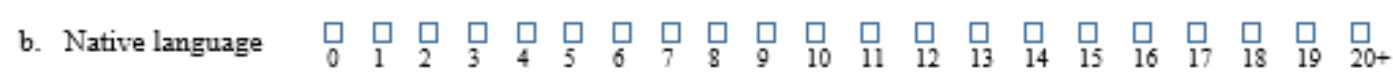

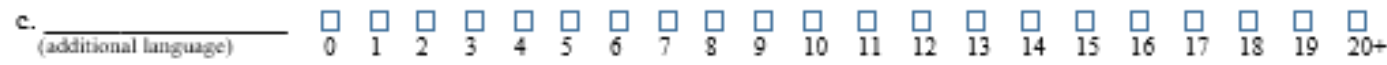


13. How many years have you spent in a family where the following languages are spoken?
a. English
$\begin{array}{llllllllllllllllllllll}\square & \square & \square & \square & \square & \square & \square & \square & \square & \square & \square & \square & \square & \square & \square & \square & \square & \square & \square & \square & \square \\ 0 & 1 & 2 & 3 & 4 & 5 & 6 & 7 & 8 & 9 & 10 & 11 & 12 & 13 & 14 & 15 & 16 & 17 & 18 & 19 & 20+\end{array}$
b. Native language
$\begin{array}{llllllll}\square & \square & \square & \square & \square & \square & \square \\ 0 & 1 & 2 & 3 & 4 & 5 & 6\end{array}$
\begin{tabular}{lllll}
\hline & $\square$ & $\square$ & 9
\end{tabular}
$\begin{array}{llllllllll}\square & \square & \square & \square & \square & \square & \square & \square & \square & \square \\ 11 & 12 & \frac{13}{13} & \square & 15 & 16 & 17 & 18 & 19 & 20+\end{array}$
c.
(additional language)
$\begin{array}{lllllllllllllllllllll}\square & \square & \square & \square & \square & \square & \square & \square & \square & \square & \square & \square & \square & \square & \square & \square & \square & \square & \square & \square & \square \\ 0 & 1 & 2 & 3 & 4 & 5 & 6 & 7 & 8 & 9 & 10 & 11 & 12 & 13 & 14 & 15 & 16 & 17 & 18 & 19 & 20+\end{array}$

14. How many years have you spent in a work environment where the following languages are spoken?
a. English

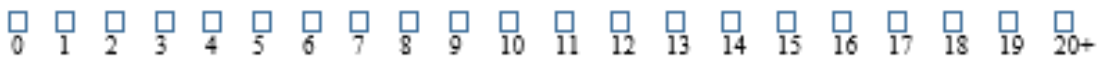

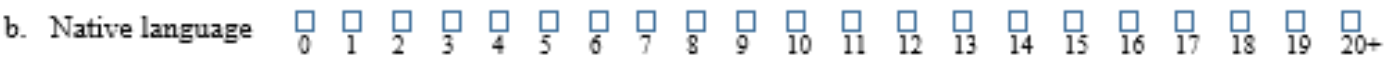

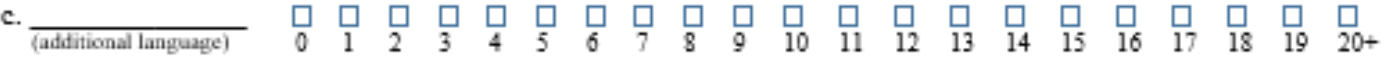

\section{Language Use}

Please answer the questions by placing checkmarks in the appropriate boxes.

15. In an average week, which language do you use most often with friends?

(1) English

๑) Other language: (Please write in the language you use.)

16. In an average week, which language do you use most often with family?

- English

๑) Other language: (Please write in the language you use.)

17. In an average week, which language do you use most often at work?

$\square$ English

(1) Other language:

I I do not have a job at the moment. (Please write in the language you use.)

18. In which language do you think most often?

(1) English

(]) Other language: (Please write in the language you use.)

19. In which language do you count most often?

( English

$\square$ Other language: (Please write in the language you use.) 


\section{Please respond to the section below ONLY if your native language is NOT English.}

If you are a native English speaker, thank you for responding to the previous questions. Please procesd to the grammar section.

\section{Language Attitudes}

Please respond to each statement by placing checkmarks in the appropriate boxes.

20. a. I feel like myself when I speak English.

$$
\begin{aligned}
& \begin{array}{ccccccc}
\mathbf{0 =} \text { disagree } & & & & & & \mathbf{6}=\mathbf{a g r e e} \\
\square & \square & \square & \square & \square & \square & \square \\
0 & 1 & 2 & \mathbf{3} & \mathbf{4} & \mathbf{5} & \mathbf{6} \\
\square & \square & \square & \square & \square & \square & \square \\
0 & 1 & \mathbf{2} & \mathbf{3} & \mathbf{4} & \mathbf{5} & \mathbf{6}
\end{array} \\
& 0=\text { disagree } \quad 6=\text { agree } \\
& \text { 21. a. I identify with the American culture. } \quad \begin{array}{llllllll}
\square & \square & \square & \square & \square & \square & \square
\end{array} \\
& \text { eventually use) English like a native speaker. } \\
& \begin{array}{ccccccc}
0 \text { = disagree } & & & & & & 6=\text { agree } \\
\square & \square & \square & \square & \square & \square & \square \\
0 & 1 & 2 & 3 & 4 & 5 & 6
\end{array} \\
& \begin{array}{lllllll}
\square & \square & \square & \square & \square & \square & \square
\end{array} \\
& \begin{array}{llllllll}
\text { 23. b. I want others to think I am a native } & \square & \square & \square & \square & \square & \square & \square \\
\text { speaker of my native language. } & \mathbf{0} & \mathbf{1} & \mathbf{2} & \mathbf{3} & \mathbf{4} & \mathbf{5} & \mathbf{6}
\end{array}
\end{aligned}
$$

20. b. I feel like myself when I speak my native language.$$
\begin{array}{lllllllll}
\text { 21. b. I identify with my native culture. } & \square & \square & \square & \square & \square & \square & \square \\
& 0 & \mathbf{1} & \mathbf{2} & \mathbf{3} & \mathbf{4} & \mathbf{5} & \mathbf{6}
\end{array}
$$$$
\text { 22. a. It is important to me to use (or }
$$$$
\text { 22. b. It is important to me to use (or }
$$$$
\text { eventually use) my native language like a }
$$$$
\text { native speaker. }
$$

23. a. I want others to think I am a native speaker of English.

Thank you for your response. Please proceed to the grammar section.

This survey was modified from

Birdsong, D., Gertken, L.M., \& Amengual, M. (2012). Bilingual Language Profile: An Easy-to-Use Instrument to Assess Bilingualism. COERLL, University of Texas at Austin. 


\title{
APPENDIX C
}

\section{The Modified Structure and Written Expression Test}

\author{
TEST OF ENGLISH LANGUAGE KNOWLEDGE
}

\section{Test of English Language Knowledge}

(Adapted from TOEFL ITP)

This section is designed to measure your ability to recognize language that is appropriate for standard written English. There are two types of questions in this section with special directions for each type.

\section{Structure}

Directions: Questions 1-8 are incomplete sentences. Beneath each incomplete sentence you will see four words or phrases, marked (A), (B), (C), and (D). Choose the one word or phrase that best completes the sentence. Then, on your answer sheet, find the number of the question and fill in the space that corresponds to the letter of the answer you have chosen.

\section{EXAMPLE:}

During the early period of ocean navigation, sophisticated instruments and techniques. any need for

(A) so that havdly

(B) when there was hardly

(C) hardly was

(D) there was hardly

The sentence should read: "During the early period of ocean navigation, there was havdly any" need for sophisticated instruments and techniques. "Therefore, you should choose (D).

\section{NOW BEGIN TO WORK ON THE QUESTIONS.}

1. Although thunder and lightning are produced at the same time, light waves travel faster , so we see the lightning before we hear the thunder.
(A) than sound waves do
(B) than sound waves are
(C) do sound waves
(D) sound waves

2. The philosopher and educator John Dewey rejected
(A) to use authoritarian teaching methods
(B) that authoritarian teaching methods
(C) for authoritarian teaching methods
(D) authoritarian teaching methods 


\section{TEST OF ENGLISH LANGUAGE KNOWLEDGE}

3. In its pure state antimony has no important uses, but with other substances, it is an extremely useful metal.

(A) when combined physically or chemically

(B) combined when physically or chemically

(C) the physical and chemical combination

(D) it is combined physically and chemically

4. The dawn redwood appears some 100 million years ago in northern forests, around the world.
(A) was flourished
(B) having to flourish
(C) to have flourished
(D) have flourished

5. Richard Wright enjoyed success and influence among Black American writers of his era.
(A) were unparalleled
(B) are unparalleled
(C) unparalleled
(D) the unparalleled

6. of large mammals once dominated the North American prairies: the American bison and the pronghorn antelope.
(A) There are two species
(B) With two species
(C) Two species are
(D) Two species

7. Franklin D. Roosevelt was the great force of radio and the opportunity it provided for taking government policies directly to the people.
(A) as the first president he understood fully
(B) the first President that, to fully understand
(C) the first president fully understood
(D) the first president to understand fully

8. During the late fifteenth century, of the native societies of America had professions in the field of arts and crafts.
(A) only a few
(B) a few but
(C) few, but only
(D) a few only 
TEST OF ENGLISH LANGUAGE KNOWLEDGE

\section{Written Expression}

Directions: In questions 9-20, each sentence has four underlined words or phrases. The four underlined parts are marked (A), (B), (C), and (D). Choose the one underlined word or phrase that must be changed for the sentence to be correct. Mark the letter of your choice on your answer sheet. Please do not write on this test.

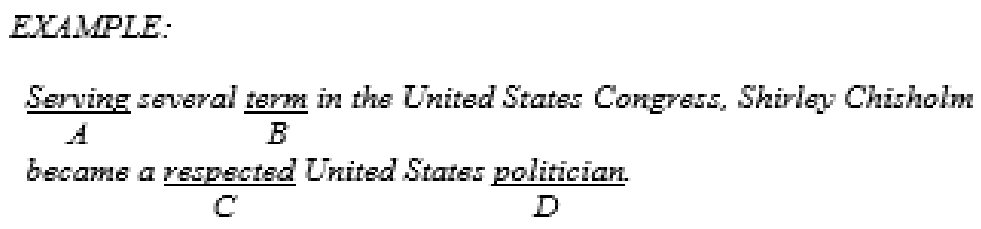

The sentence should read: "Senving several terms in the United States Congress, Shirley Chisholm became a respected United States politician." Therefore, you should choose B.

\section{NOW BEGIN TO WORK ON THE QUESTIONS.}

9. Jane Addams, social worker, author, and spokeswoman for the peace and women's suffrage A movements, she received the Nobel Peace Prize in 1931 for her humanitarian achievements.

B D

10. The public ceremonies of the North American Plains Indians are lesser elaborate A B than those of the Navajo in the Southwest.

C

11. When she retires in September 1989, tennis champion Christine Evert was the most A B famous woman athlete in the United States.

D

12. When the temperature drops below 68 degrees Fahrenheit, the body conserves warm by A B restricting blood flowing to the skin.

D 
TEST OF ENGLISH LANGUAGE KNOWLEDGE

$\$$

13. Musical instruments are divided into various types, depending on whether the vibration

$$
\text { A }
$$

that produces their sound is made by striking, strumming, scraping, or is blown.

C

14. Zoos in New Orleans, San Diego, Detroit, and the Bronx have become biological parks A where animals roams freely and people watch from across a moat.

B C

D

15. Each chemical element is characterized to the number of protons that an atom of A. B that element contains, called its atomic number. 16. Although diamond is colorless and transparent $\frac{\text { when }}{\text { A }}$ pure, it may appear in various $\frac{\text { color, }}{\mathrm{C}}$, ranging from pastels to opaque black, if it is contaminated with other material.

17. A seismograph records oscillation of the ground caused by seismic waves, vibrations that A. travel from its point of origin through Earth or along its surface.

B C D

18. Located in Canada, the Columbia Icefield covers area of 120 square miles and is 3,300

feet thick in some places.

A B

19. Although traditional flutes are among the world's oldest musical instruments, but the flute A used in orchestras today is one of the most technically sophisticated. $\mathrm{C}$ D

20. Estuaries are highly sensitive and ecologically important habitats, providing breeding A and feeding grounds for much life-forms.

B C D 


\section{Appendix D}

\section{Frequency Distributions of Variables}

Table D-1

Frequencies of Reading Comprehension Scores

\begin{tabular}{cccc}
\hline Score & Frequency & Percent & \\
\hline $0-6$ & 0 & 0.00 & $\%$ \\
$7-12$ & 1 & 1.05 & $\%$ \\
$13-18$ & 8 & 8.42 & $\%$ \\
$19-24$ & 20 & 21.05 & $\%$ \\
$25-30$ & 25 & 26.32 & $\%$ \\
$31-36$ & 23 & 24.21 & $\%$ \\
$37-42$ & 13 & 13.68 & $\%$ \\
$42-48$ & 5 & 5.26 & $\%$ \\
$49-54$ & 0 & 0.00 & $\%$ \\
\hline Total & 95 & 100.00 & $\%$ \\
\hline
\end{tabular}

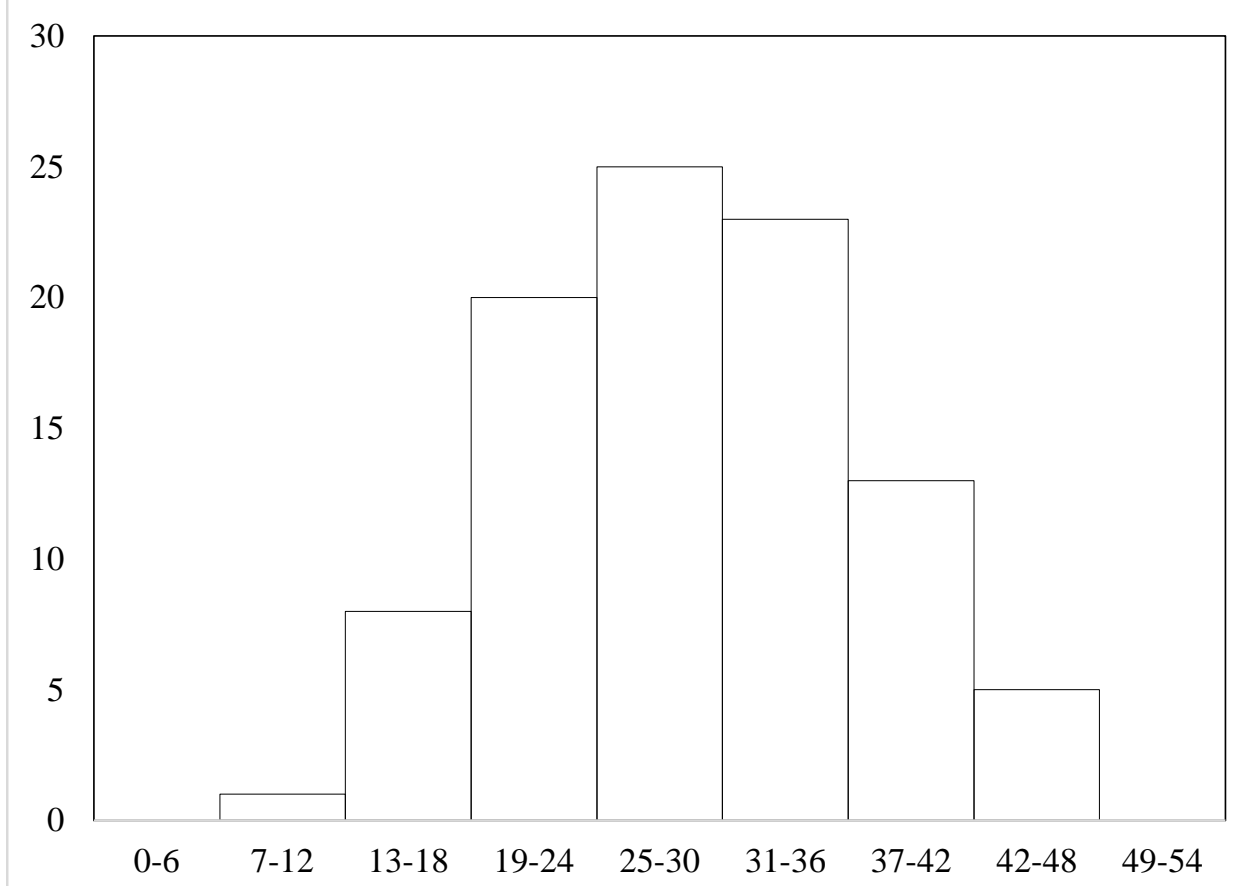

Figure D-1. Frequencies of Reading Comprehension Scores 
Table D-2

Frequencies of ENC 1101 Grades

\begin{tabular}{ccrc}
\hline Grade & Frequency & Percent & \\
\hline F, W, or IW & 8 & 9.20 & $\%$ \\
D & 5 & 5.70 & $\%$ \\
C & 13 & 14.90 & $\%$ \\
B & 19 & 21.80 & $\%$ \\
A & 42 & 48.30 & $\%$ \\
\hline Total & 87 & 100.00 & $\%$ \\
\hline
\end{tabular}

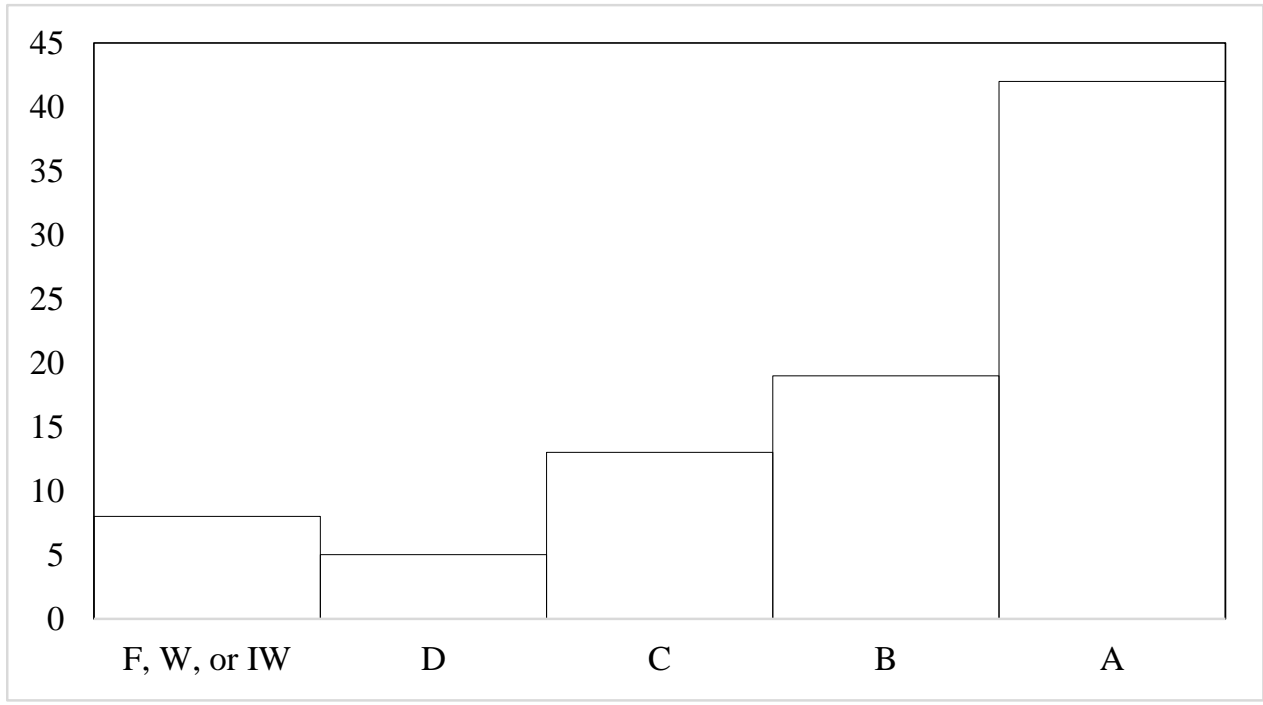

Figure D-2. Frequencies of ENC 1101 Grades 
Table D-3

Frequencies of Self-Reported L1 Literacies

\begin{tabular}{ccrc}
\hline Avg. Rating & Frequency & Percent & \\
\hline $0-1$ & 2 & 2.06 & $\%$ \\
$1.1-2$ & 4 & 4.12 & $\%$ \\
$2.1-3$ & 2 & 2.06 & $\%$ \\
$3.1-4$ & 13 & 13.40 & $\%$ \\
$4.1-5$ & 19 & 19.59 & $\%$ \\
$5.1-6$ & 57 & 58.76 & $\%$ \\
\hline Total & 97 & 100.00 & $\%$ \\
\hline
\end{tabular}

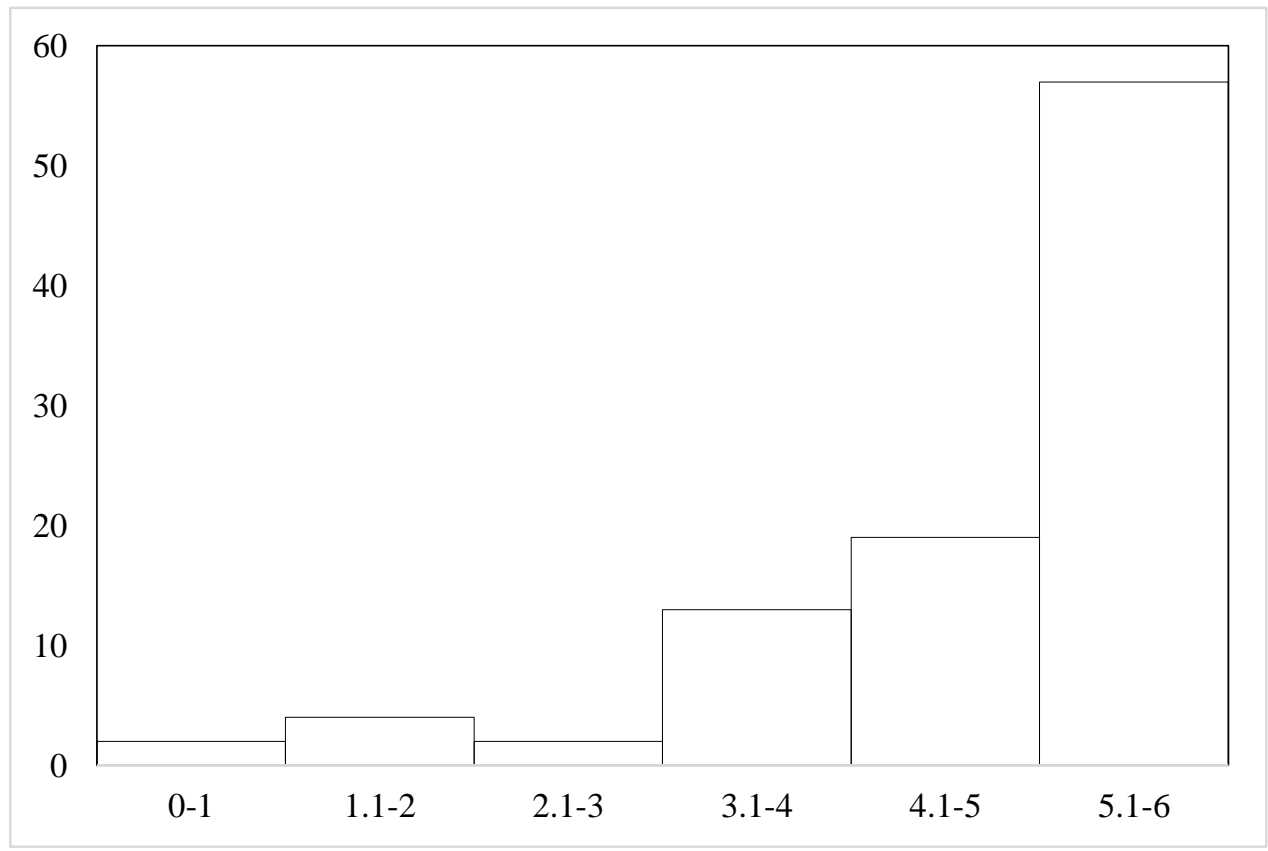

Figure D-3. Frequencies of Self-Reported L1 Literacies 
Table D-4

Frequencies of English Language Knowledge Scores

\begin{tabular}{cccc}
\hline Score & Frequency & Percent & \\
\hline $0-8$ & 0 & 0.00 & $\%$ \\
$9-16$ & 0 & 0.00 & $\%$ \\
$17-24$ & 4 & 4.26 & $\%$ \\
$25-32$ & 9 & 9.57 & $\%$ \\
$33-40$ & 30 & 31.91 & $\%$ \\
$41-48$ & 26 & 27.66 & $\%$ \\
$49-56$ & 19 & 20.21 & $\%$ \\
$57-64$ & 6 & 6.38 & $\%$ \\
\hline Total & 95 & 100.00 & $\%$ \\
\hline
\end{tabular}

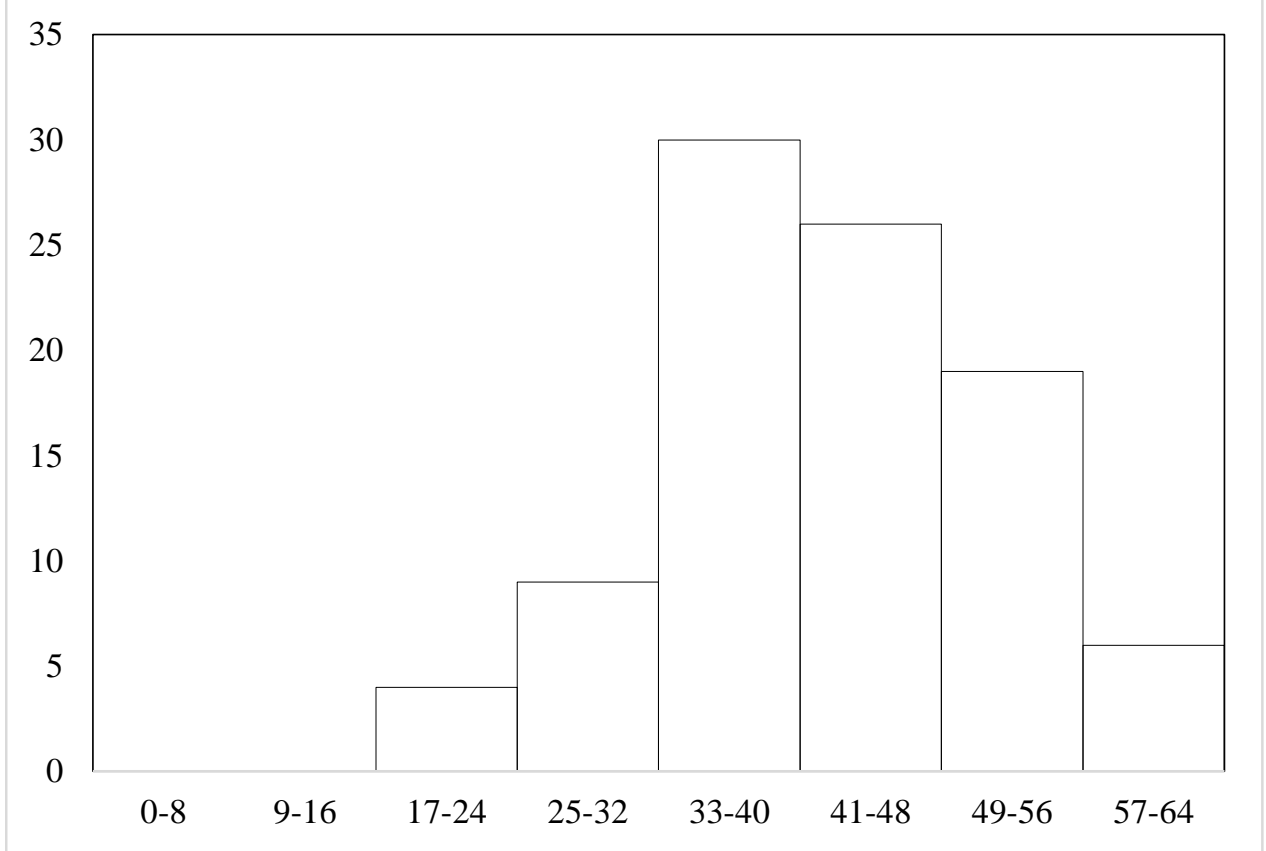

Figure D-4. Frequencies of English Language Knowledge Scores 
Table D-5

Frequencies of Pre-ENC 1101 Coursework

\begin{tabular}{ccrc}
\hline Number of Courses & Frequency & Percent & \\
\hline $0-2$ & 96 & 89.72 & $\%$ \\
$3-4$ & 9 & 9.28 & $\%$ \\
$5-6$ & 1 & 1.03 & $\%$ \\
$7-8$ & 0 & 0.00 & $\%$ \\
$9-10$ & 0 & 0.00 & $\%$ \\
$11-12$ & 0 & 0.00 & $\%$ \\
$13-14$ & 0 & 0.00 & $\%$ \\
$15-16$ & 1 & 1.03 & $\%$ \\
\hline Total & 107 & 100.00 & $\%$ \\
\hline
\end{tabular}

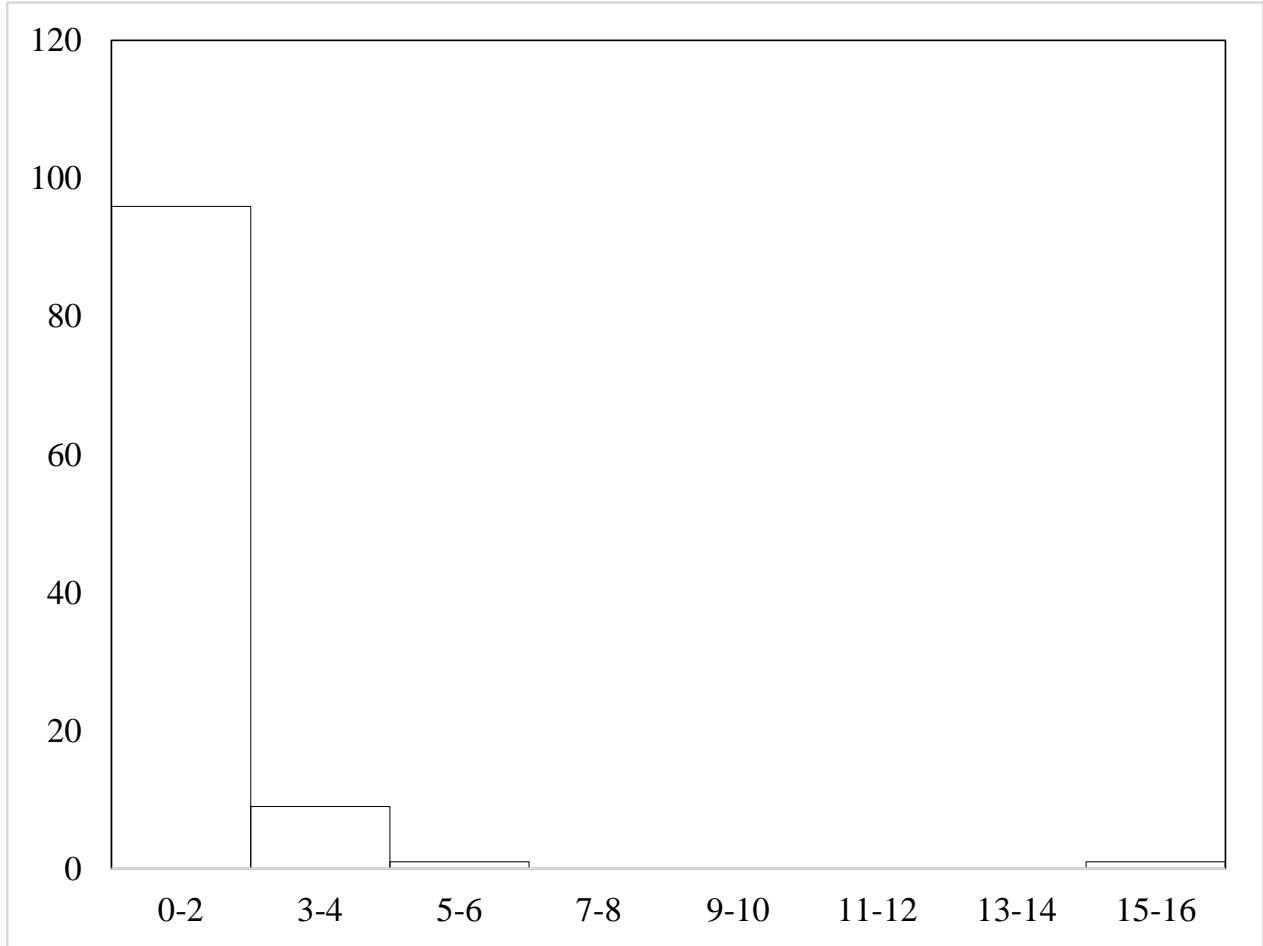

Figure D-5. Frequencies of Pre-ENC 1101 Coursework 
VITA

\section{ILDIKO BARSONY}

Born Kiskunfélegyháza, Hungary

B.S.Teaching EFL and History

University of Szeged, Hungary

$2005-2007 \quad$ ESOL Teacher

Miami-Dade County Public Schools

2006

M.S.TESOL

Florida International University

2007 - $2015 \quad$ Associate Instructor, Developmental Education

Miami Dade College

2007 - Present Adjunct Faculty, EAP and Developmental Education

Miami Dade College

2014 Ed.S. Curriculum and Instruction

Specialization in Reading Education

Florida International University

2015 - Present Academic Support Writing Coach

Miami Dade College

2016

Doctoral Candidate, Curriculum and Instruction

Florida International University

\section{PUBLICATIONS AND PRESENTATIONS}

Barsony, I., Taghi Zoghi, K., \& Johnson, M. (2011, November). Using technology in reading and writing labs. Poster session presented at Miami Dade College Technology Symposium, Miami, FL.

Barsony, I. (2013). Perceptions of French and Creole among first-generation adult Haitian English language learners. In M. S. Plakhotnik \& S. M. Nielsen (Eds.), Proceedings of the 12th Annual South Florida Education Research Conference (pp. 2-10). Miami: Florida International University. Retrieved from http://education.fiu.edu/research_conference/ 
Barsony, I., \& Peña, J. (2013, October). Jump-starting college: P.E.R.T. bootcamps for high school grads. Paper presented at MDTESOL and Bilingual Education Association Fall Symposium, Miami, FL.

Barsony, I. (2014, September). Improving course placement \& learning outcomes for FTIC-DE students: Summer boot camps. Paper presented at EDUCAUSE Conference, Orlando, FL.

Dwyer, E., \& Barsony, I. (2014, March). Deprofessionalizing TESOL: Questions of access, credential, colonialism, and elitism. Paper presented at TESOL International Convention, Portland, OR.

Barsony, I. (2015, November). Language profiles of EAP students at Miami Dade College. Paper presented at MDTESOL and Bilingual Education Association Fall Symposium, Miami, FL.

Barsony, I. (2016, October). Generation 1.5 students: Who are they and what do they need. Paper presented at MDTESOL and Bilingual Education Association Fall Symposium, Miami, FL. 